UNIVERSIDADE DE BRASÍLIA

FACULDADE DE TECNOLOGIA

DEPARTAMENTO DE ENGENHARIA CIVIL E AMBIENTAL

SISTEMA DE MEDIÇÃO DE DESEMPENHO OPERACIONAL DOS TRANSPORTADORES RODOVIÁRIOS: UMA ABORDAGEM ATRAVÉS DO BALANCED SCORECARD

HUGO GUEDES TOLEDO FLORENCIO

ORIENTADOR: SÉRGIO RONALDO GRANEMANN

DISSERTAÇÃO DE MESTRADO EM TRANSPORTES

BRASÍLIA / DF: JUNHO/2016

UNIVERSIDADE DE BRASÍLIA 
FACULDADE DE TECNOLOGIA

DEPARTAMENTO DE ENGENHARIA CIVIL E AMBIENTAL

\title{
SISTEMA DE MEDIÇÃO DE DESEMPENHO OPERACIONAL DOS TRANSPORTADORES RODOVIÁRIOS: UMA ABORDAGEM ATRAVÉS DO BALANCED SCORECARD
}

\author{
HUGO GUEDES TOLEDO FLORENCIO
}

DISSERTAÇÃO SUBMETIDA AO DEPARTAMENTO DE ENGENHARIA CIVIL E AMBIENTAL DA FACULDADE DE TECNOLOGIA DA UNIVERSIDADE DE BRASÍLIA COMO PARTE DOS REQUISITOS NECESSÁRIOS PARA OBTENÇÃO DO GRAU DE MESTRE EM TRANSPORTES.

APROVADA POR:

PROF. Dr. SÉRGIO RONALDO GRANEMANN - PPGT/UNB (ORIENTADOR)

PROF. Dra. ADELAIDA PALLAVICINI FONSECA - PPGT/UNB) (EXAMINADOR I)

PROF. Dra. GIOVANNA MEGUMI ISHIDA TEDESCO - IFB (EXAMINADOR EXTERNO)

DATA: BRASÍLIA/DF, 09 DE JUNHO DE 2016 


\section{FICHA CATALOGRÁFICA}

\section{FLORENCIO, HUGO GUEDES TOLEDO}

Sistema de Medição de Desempenho Operacional dos Transportadores Rodoviários:

Uma Abordagem através do Balanced Scorecard [Distrito Federal] 2016.

xv, 129p., 210 x 297 mm (ENC/FT/UnB, Mestre, Transportes, 2016).

Dissertação de Mestrado - Universidade de Brasília. Faculdade de Tecnologia

Departamento de Engenharia Civil e Ambiental.

1. Sistema de medição de desempenho

2. Balanced Scorecard

3. Transportadores rodoviários

4. MCDA-C

I. ENC/FT/UnB

II. Título (Série)

\section{REFERÊNCIA BIBLIOGRÁFICA}

FLORENCIO, H.G.T. (2016). Sistema de Medição de Desempenho Operacional dos Transportadores Rodoviários: Uma Abordagem através do Balanced Scorecard. Dissertação de Mestrado em Transportes, Publicação T.DM-011/2016, Departamento de Engenharia Civil e Ambiental, Universidade de Brasília, Brasília, DF, 129p.

\section{CESSÃO DE DIREITOS}

AUTOR: Hugo Guedes Toledo Florencio.

TÍTULO: Sistema de Medição de Desempenho Operacional dos Transportadores

Rodoviárias: Uma Abordagem através do Balanced Scorecard.

GRAU: Mestre ANO: 2016

É concedida à Universidade de Brasília permissão para reproduzir cópias desta dissertação de mestrado e para emprestar ou vender tais cópias somente para propósitos acadêmicos e científicos. $\mathrm{O}$ autor reserva outros direitos de publicação e nenhuma parte dessa dissertação de mestrado pode ser reproduzida sem autorização por escrito do autor.

Hugo Guedes Toledo Florencio

SQN 309, Bloco F, Apt. 402 - Asa Norte

70.755-060 Brasília - DF - Brasil. 


\section{DEDICATÓRIA}

Dedico esta obra a minha família por ter me ensinado a importância do conhecimento e à minha esposa, Luiza, pelo companheirismo nos estudos, ao longo desta etapa. 


\section{AGRADECIMENTOS}

\section{À Deus.}

Ao meu orientador Prof. Dr. Sergio Ronaldo Granemann.

Aos professores do Programa de Pós-Graduação em Transportes da Universidade de Brasília: Adelaida Pallavicini Fonseca, Alan Ricardo da Silva, Ana Claudia Farranha Santana, Augusto Cesar de Mendonça Brasil, Carlos Henrique Marques da Rocha, Fabiana Serra de Arruda, José Augusto Abreu Sá Fortes, José Matsuo Shimoishi, Maria Alice Prudêncio Jacques, Michelle Andrade, Pastor Willy Gonzales Taco, Paulo Cesar Marques da Silva, pelos ensinamentos passados durante o curso.

À Associação Nacional do Transportes de Cargas e Logística, em nome Dra. Sônia Rotondo, pelo auxílio na aplicação do questionário de pesquisa.

Aos colegas de PPGT, em especial aos colegas Paulo e Susan. Aos amigos da ANTT, pelo apoio e incentivo que proporcionaram uma fonte menor de dificuldades para a transposição dessa etapa em minha vida. Por fim, agradeço a todos que me auxiliaram nesta jornada. 


\section{RESUMO}

O transporte rodoviário é o principal modo de transporte de carga utilizado no Brasil, sendo responsável por movimentar mais de $61 \%$ de toda carga transportada no país. Este mercado é caracterizado por uma elevada competitividade e complexidade operacional, em que os clientes exigem um elevado nível de serviço a preços baixos. Neste sentido, para que os transportadores rodoviários possam atender às exigências dos clientes e se destacar no mercado, torna-se fundamental gerir os processos, informações e mensurar o desempenho operacional. Assim, este trabalho teve como objetivo o desenvolvimento de um sistema de medição de desempenho baseado na metodologia do Balanced Scorecard, para os transportadores rodoviários, assim como a construção de índices de desempenho para cada uma das perspectivas do Balanced Scorecard. Para alcançar o objetivo, o trabalho foi desenvolvido basicamente em duas etapas: na primeira etapa, foi construído o sistema de medição de desempenho, a partir da identificação de indicadores de desempenho para transporte, da adaptação da metodologia do Balanced Scorecard para os transportadores rodoviários e da utilização da Metodologia Multicritério de Apoio à Decisão - Construtivista (MCDA-C) para definição dos pesos dos indicadores. Como resultado desta etapa foi desenvolvida uma ferramenta computacional para realizar a medição de desempenho; a segunda etapa consistiu na verificação da aplicabilidade do modelo proposto em uma empresa de transporte rodoviário de cargas. Os resultados mostraram-se consistentes e indicaram que o modelo proposto é adequado para mensurar o desempenho dos transportadores rodoviários. 


\begin{abstract}
The road freight is the main mode of transport used in Brazil, which is responsible for moving over $61 \%$ of Brazilian's freights. This market is characterized by high competitiveness and operational complexity, in which customers require a high level of service at low prices. Therefore, in order to achieve costumer requirements and stand out on the market, it is essential to manage the processes, information and measure operational performance. This work aimed to develop a performance measurement system based on the Balanced Scorecard for road transport companies, as well as the construction of performance indicators for each of the perspectives of the Balanced Scorecard. To achieve the objectives, the work was basically developed in two stages: In the first stage, after identification of transport performance indicators, the adaptation of Balanced Scorecard for road transport companies and the definitions of the indicator's weight using Multicriteria Decision Aid Constructivist (MCDAC), it was built the performance measurement system. As a result of this stage, it was presented a computational tool to support the performance measurement; the second step was to check the applicability of the model in a road transport company. The results were consistent and indicated that the methodology can be used to measure the performance of road transport companies.
\end{abstract}




\section{Sumário}

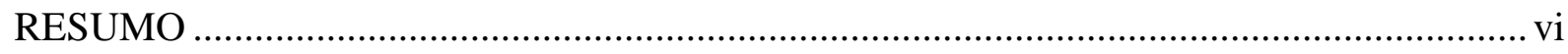

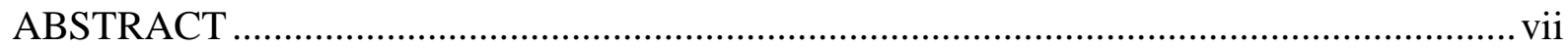

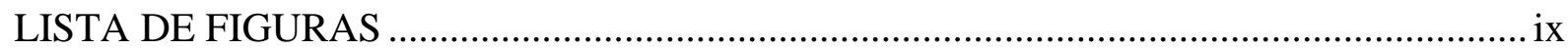

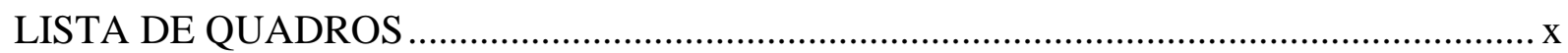

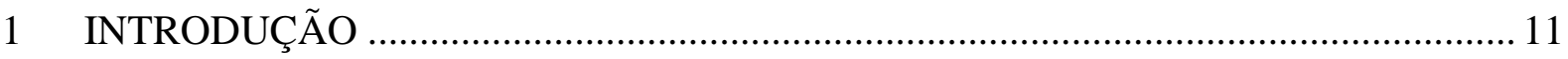

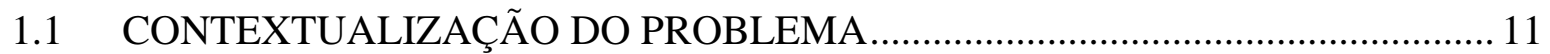

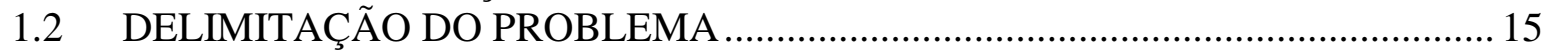

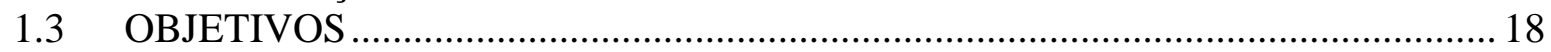

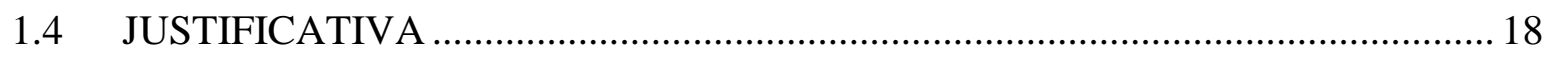

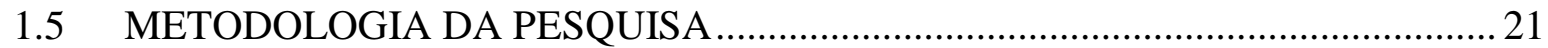

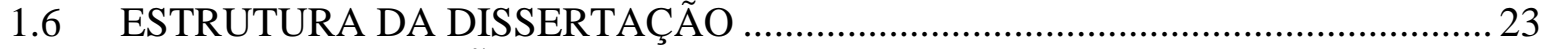

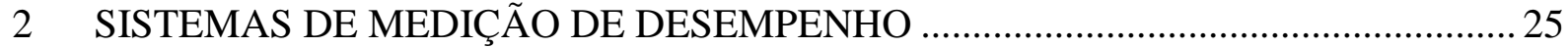

2.1 IMPORTÂNCIA DOS SISTEMAS DE MEDIÇÃO DE DESEMPENHO ...............25

2.2 CONCEITUAÇÃO DE SISTEMAS DE MEDIÇÃO DE DESEMPENHO ..............27

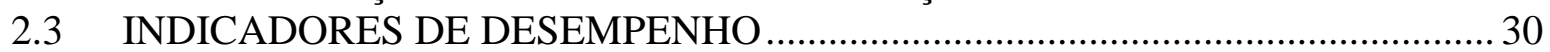

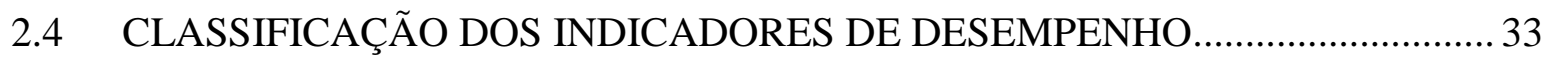

2.5 MEDIÇÃO DE DESEMPENHO DO SERVIÇO DE TRANSPORTE ...................... 35

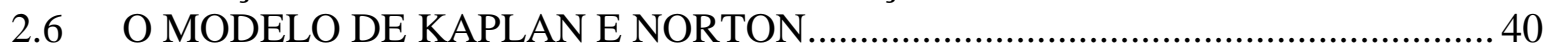

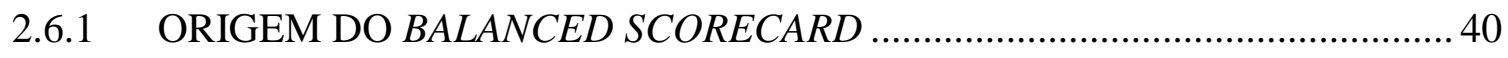

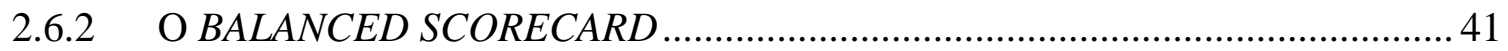

2.6.3 PERSPECTIVAS DO BALANCED SCORECARD ......................................... 44

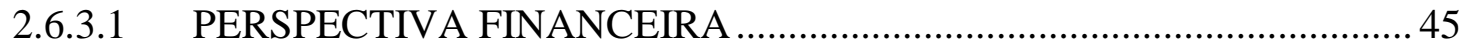

2.6.3.2 PERSPECTIVA DOS CLIENTES ….......................................................... 49

2.6.3.3 PERSPECTIVA DOS PROCESSOS INTERNOS ................................. 52

2.6.3.4 PERSPECTIVA DO APRENDIZADO E CRESCIMENTO ...................... 56

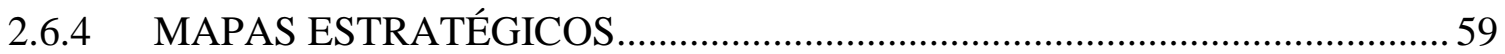

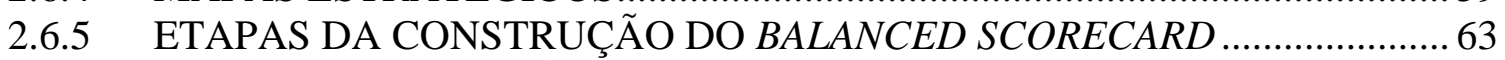

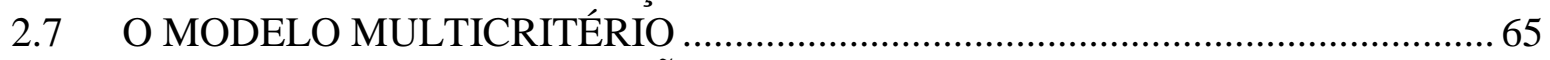

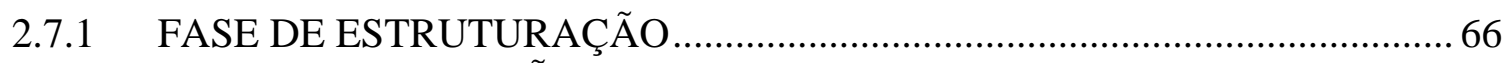

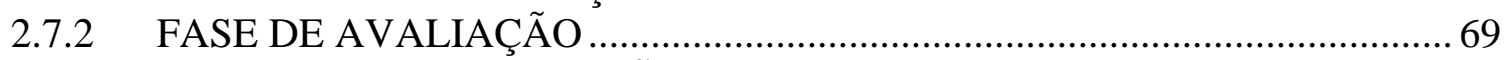

2.7.3 FASE DE RECOMENDAÇÕES ...................................................................... 72

3 CONSTRUÇÃO DO SISTEMA DE MEDIÇÃO DE DESEMPENHO BASEADO NO

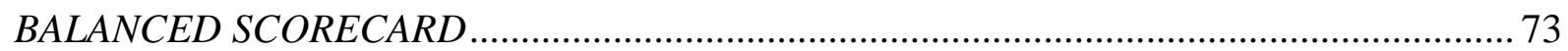

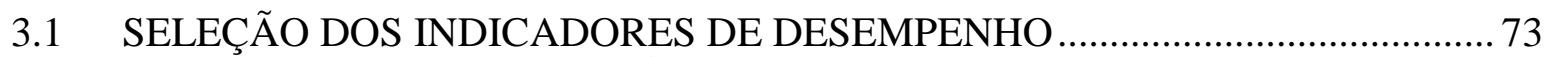

3.2 DESENVOLVIMENTO DOS ÍNDICES DE DESEMPENHO ................................... 82

3.2.1 ESTRUTURAÇÃO DO PROBLEMA …........................................................ 83

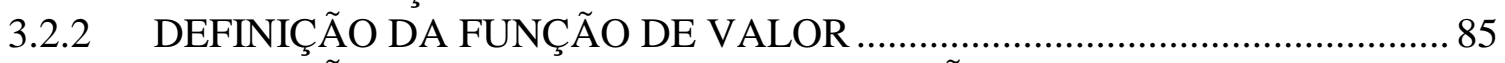

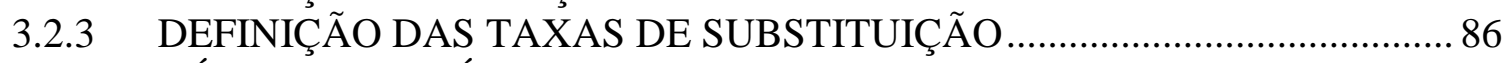

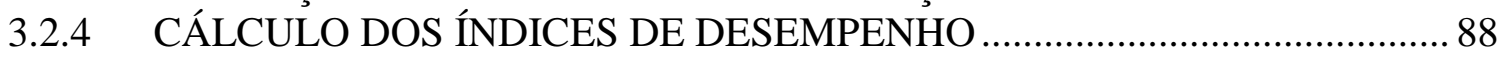

3.3 O MODELO PROPOSTO DO BALANCED SCORECARD ….......................... 90

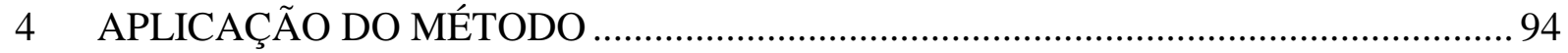

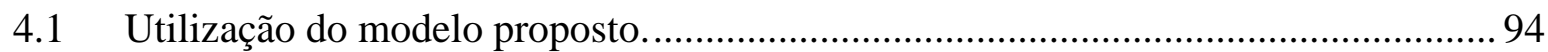

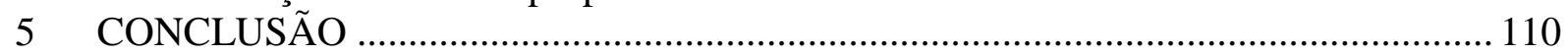

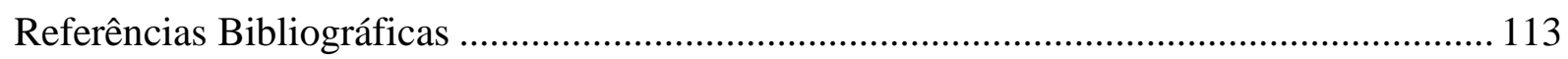




\section{LISTA DE FIGURAS}

Figura 1.1 - Evolução da matriz de transporte brasileira entre 1950 e 1963 ............................ 12

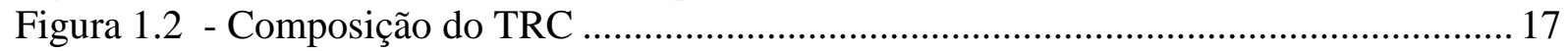

Figura 1.3 - Matriz de Transporte de Carga Brasileira ....................................................... 18

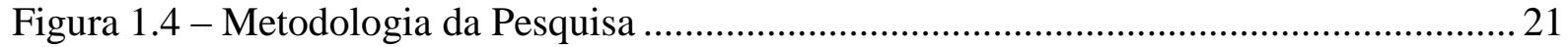

Figura 2.1 - Estrutura para design de Sistemas de Medição de Desempenho.......................... 29

Figura 2.2 - Perspectivas do Balanced Scorecard ...................................................................... 42

Figura 2.3 - O Balanced Scorecard e os processos gerenciais críticos .................................. 43

Figura 2.4 - Perspectivas do Balanced Scorecard ............................................................ 45

Figura 2.5 - Medidas Essenciais da perspectiva do Cliente ............................................. 51

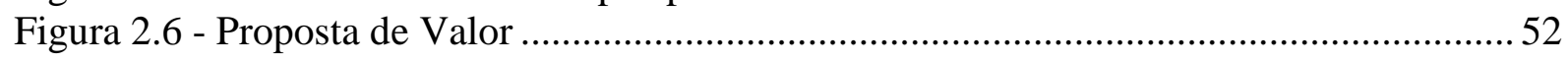

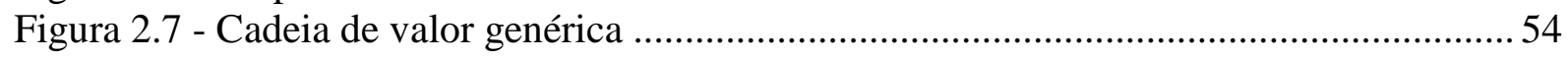

Figura 2.8 - O mapa estratégico representa como a empresa cria valor.................................. 61

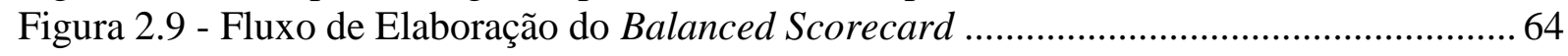

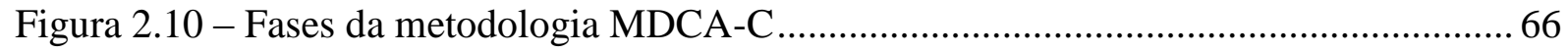

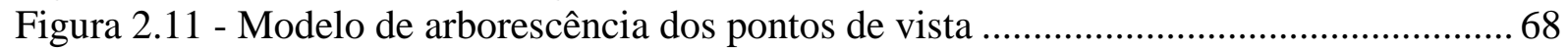

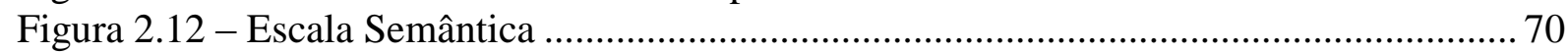

Figura 3.1 - Mapa estratégico para transportadores rodoviários ........................................... 76

Figura 3.2 - Balanced Scorecard para transportadores rodoviários ..................................... 81

Figura 3.3 - Árvore dos pontos de vistas fundamentais ................................................. 84

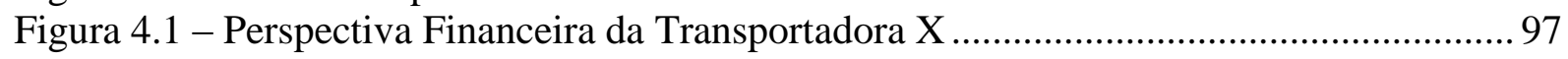

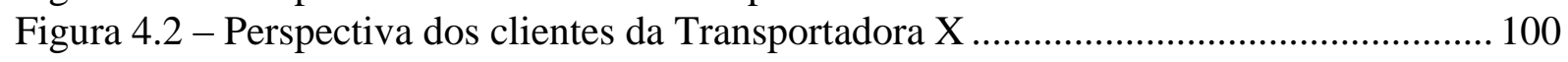

Figura 4.3 - Perspectiva dos processos internos da Transportadora X ................................. 106

Figura 4.4 - Perspectiva do aprendizado e crescimento da Transportadora X ..................... 107

Figura 4.5 - Balanced Scorecard da Transportadora X ....................................................... 109 


\section{LISTA DE QUADROS}

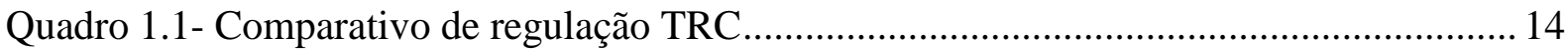

Quadro 2.1- Definição de indicador de desempenho ............................................................. 33

Quadro 2.2- Indicadores de Desempenho para o setor de transportes .................................... 38

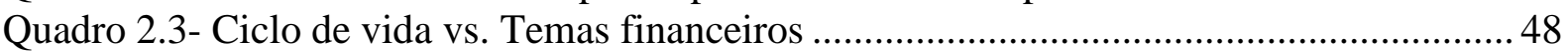

Quadro 2.4- Indicadores potenciais da perspectiva dos processos internos...........................56

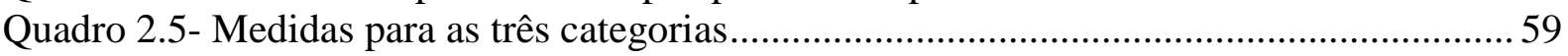

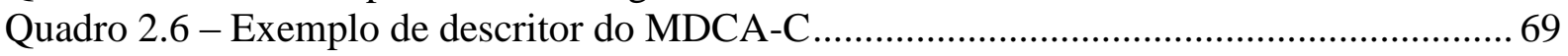

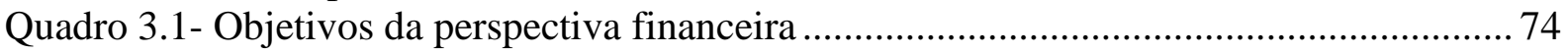

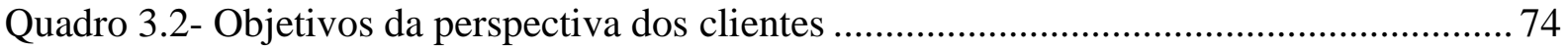

Quadro 3.3- Objetivos da perspectiva dos processos internos ............................................. 75

Quadro 3.4- Objetivos da perspectiva do aprendizado e crescimento .................................. 75

Quadro 3.5- Relação dos objetivos estratégicos com os indicadores de desempenho ............. 78

Quadro 3.6 - Descrição dos indicadores de desempenho do Balanced Scorecard ................... 79

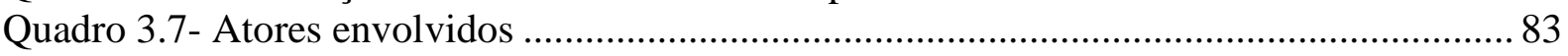

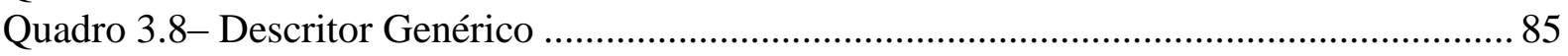

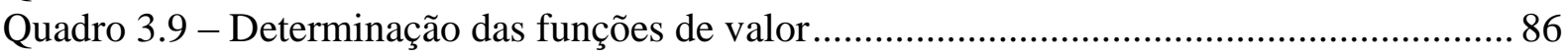

Quadro 3.10 - Ponderação dos indicadores de desempenho ............................................... 88

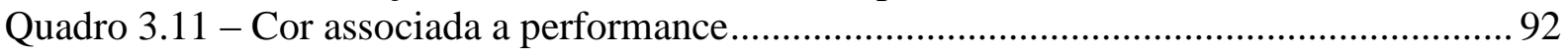

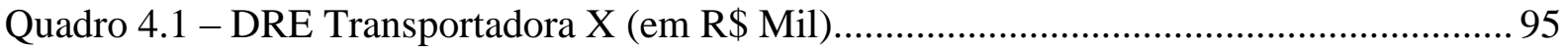

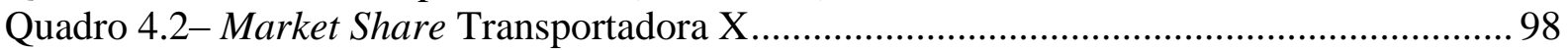

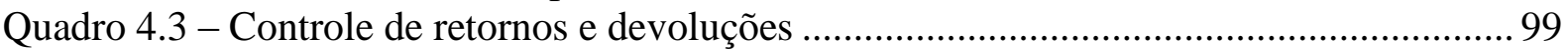

Quadro 4.4- Controle do tempo para resolução de problemas .............................................. 99

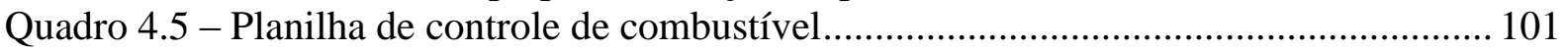

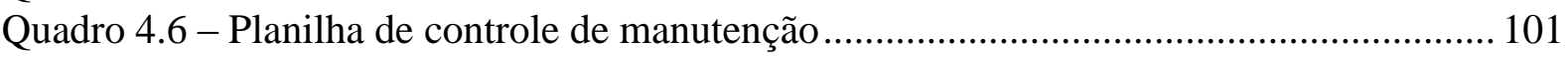

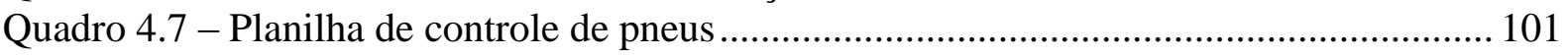

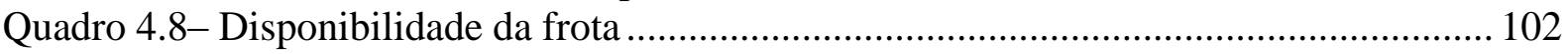

Quadro 4.9- Planilha de controle de viagens da frota......................................................... 102

Quadro 4.10- Forma de cálculo dos indicadores da perspectiva dos processos internos ....... 105 


\section{INTRODUÇÃO}

Neste capítulo será apresentada a contextualização do objeto de estudo, bem como a delimitação do problema, a justificativa e os objetivos. E, para a compreensão do desenvolvimento da pesquisa, serão descritos os aspectos metodológicos e a estrutura da dissertação.

\subsection{CONTEXTUALIZAÇÃO DO PROBLEMA}

Desde os primórdios da humanidade os seres humanos foram obrigados a transportar, muitas vezes em suas próprias costas, alimentos, roupas etc. Com o passar do tempo e o com o desenvolvimento tecnológico, os meios de transporte foram se moldando a realidade da época, passando desde a tração animal até a era da motorização (BERTAGLIA, 2002).

Sandroni (2005) apresenta o transporte como um meio ou serviço pelo qual se deslocam pessoas ou mercadorias. É através dele que a força de trabalho e insumos chegam aos seus destinos, possibilitando produzir e distribuir serviços, bens, tecnologia e consequentemente desenvolvimento para os países (SHIFTAN et al., 2003; AKMANLIGIL E PALVIA, 2004). São utilizados cinco modos de transporte de cargas, sendo eles: ferroviário, aquaviário, dutoviário, aéreo e rodoviário. Este último é o mais utilizado no Brasil (KEEDI, 2012).

O transporte rodoviário de cargas é aquele que se realiza em estradas de rodagem com a utilização de veículos como caminhões e carretas, podendo ser realizado em território nacional ou internacional (ARAUJO, 2011).

Segundo Kouri e Spina (2007), o desenvolvimento do Transporte Rodoviário de Carga (TRC) possui algumas semelhanças com a história do Brasil. O TRC iniciou no Brasil com a construção da Rodovia Rio - São Paulo, em 1932, entretanto somente passou a ter expressividade na matriz de transporte brasileira a partir da década de 50. Conforme relatado em Geipot (2001), no período entre 1950 e 1960, três grandes fatores geraram profundas alterações na economia e foram responsáveis pelo definitivo desenvolvimento do sistema rodoviário nacional: 
a) a criação em 1954 da Petrobras, com suas fábricas de asfalto instaladas estrategicamente, contribuindo para o desenvolvimento da pavimentação no país;

b) a implantação da indústria automobilística, que contribuiu para o avanço do processo de industrialização; e

c) a construção de Brasília, cuja localização gerou a necessidade de implantação de grandes eixos rodoviários, integrando-a a todas as regiões do país.

Conforme apresentado na Figura 1.1, em um período de 13 anos, entre 1950 e 1963, a participação do transporte rodoviário no transporte de carga subiu de $38 \%$ para mais de $64 \%$, enquanto a ferrovia decresceu de $29,2 \%$ para $16,8 \%$, e o transporte marítimo de $32,4 \%$ para $18,3 \%$.

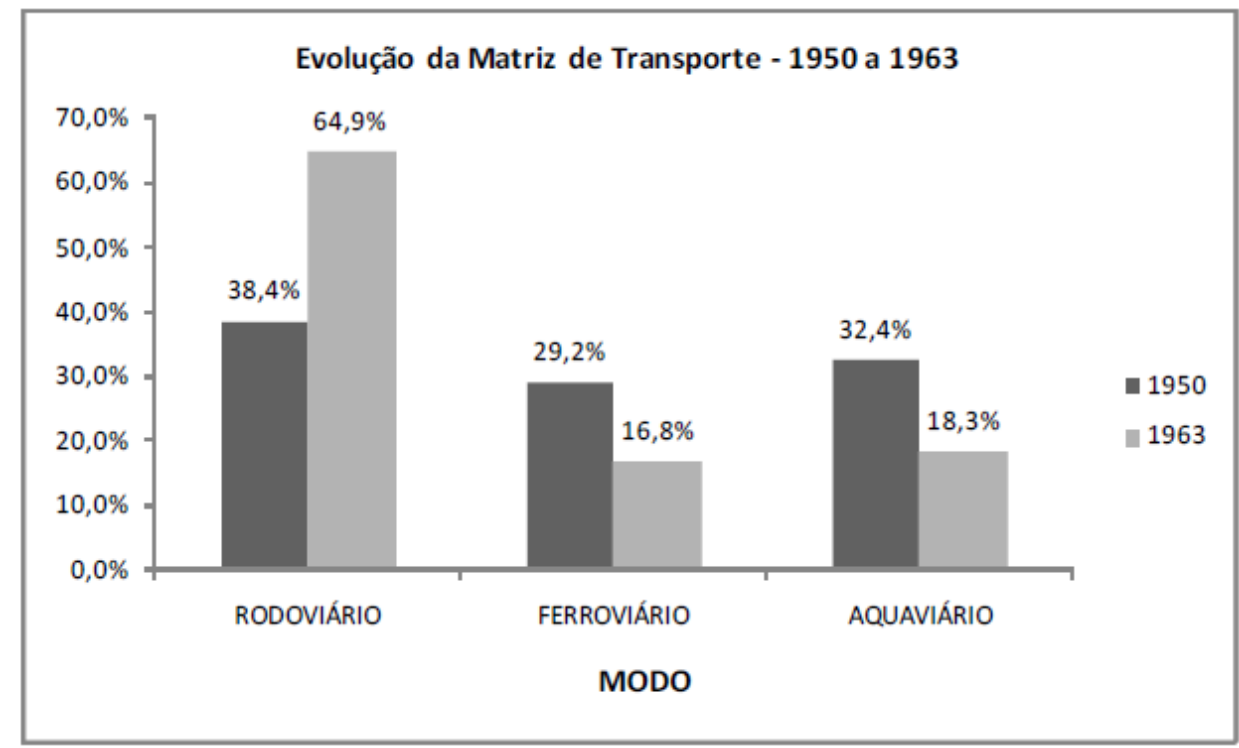

Figura 1.1 - Evolução da matriz de transporte brasileira entre 1950 e 1963

Fonte: Adaptado de GEIPOT (2001)

A partir de então, foi adotada a política de privilegiar as rodovias e o TRC passou a exercer um papel estratégico na matriz de transporte brasileira, e, portanto, na economia do país. Entre os anos de 1970 e 2000, o setor de transportes cresceu cerca de 400\%, enquanto o crescimento do PIB foi de $250 \%$ (TEDESCO, 2012).

Ao mesmo tempo, para ter capacidade de escoar todo o volume de carga produzido, a frota de transporte de carga brasileira cresceu, neste período, cerca de $200 \%$, com a entrada de novos transportadores no mercado, de acordo com dados de INEAVAR (2011). 
Este rápido crescimento do setor transformou o mercado de transporte rodoviário de cargas, antes marcado pela existência de poucas empresas, aumentando o nível concorrencial e exigindo das transportadoras maior ritmo na geração de diferenciais competitivos para se destacar no mercado (PASSERI, 2001).

Estudos apresentados pela CNT/COPPEAD (2002) e mais recentemente pela ANTT (2012), WANKE (2012), Machado (2015) e Vianna (2015) apontam que o setor de transporte rodoviário de carga configura-se como um mercado de elevada competitividade, havendo, inclusive, excesso de oferta de serviço, o qual muitas vezes provoca concorrência predatória no mercado de fretes, com a cobrança de fretes abaixo do custo total incorrido, ou seja, com empresas operando com margens negativas. Dados da ANTT (2012) indicam que o transporte rodoviário de cargas no país possui uma tarifa média $46 \%$ menor que a praticada nos Estados Unidos.

Dentre os fatores que contribuíram para a grande quantidade de transportadores operando pode-se destacar a ausência de barreiras à entrada no mercado, devido à baixa regulação, associado aos incentivos de financiamento para aquisição de caminhões, por meio dos programas do Banco Nacional do Desenvolvimento Econômico e Social (BNDES), como o Programa Pró-caminhoneiro (CNT/COPPEAD, 2002), (ARAÚJO et. al., 2014), (MACHADO, 2015) e (VIANNA, 2015).

Arruda Junior (2014) comparou as exigências regulatórias de diversos países, mostrando que o Brasil em relação aos Estados Unidos e a Espanha apresenta um baixo nível de regulação, conforme Quadro 1.1. De fato, para se tornar um transportador autônomo basta o interessado ter carteira de habilitação e um veículo registrado na ANTT. Dessa forma as linhas de crédito impulsionaram a aquisição de caminhões, provocando uma oferta excedente de transporte (VIANNA, 2015). 
Quadro 1.1- Comparativo de regulação TRC

\begin{tabular}{|c|c|c|c|c|}
\hline \multicolumn{2}{|c|}{ ITENS REGULATÓRIOS } & EUA & ESPANHA & BRASIL \\
\hline \multicolumn{2}{|c|}{ Registro Nacional } & $\checkmark$ & $\checkmark \mid$ & $\checkmark$ \\
\hline \multicolumn{2}{|c|}{ Requisitos Adicionais à Habilitação } & $\checkmark$ & $\checkmark$ & \\
\hline \multicolumn{2}{|c|}{ Responsável Técnico } & O & $\checkmark$ & O \\
\hline \multicolumn{2}{|c|}{ Frota Mínima para Registro } & O & $\checkmark$ & \\
\hline \multicolumn{2}{|c|}{ Área Minima de Terminais } & O & $\checkmark$ & O \\
\hline \multirow{2}{*}{ Vistoria Veicular } & Annual & $\checkmark$ & - & $\checkmark^{*}$ \\
\hline & $>1$ ano & - & $\checkmark$ & - \\
\hline \multicolumn{2}{|c|}{ Autorização de Transporte Contigenciada } & O & $\checkmark$ & 0 \\
\hline \multicolumn{2}{|c|}{ Limitação de Idade Máxima da Frota } & O & O & 8 \\
\hline \multicolumn{2}{|c|}{ Limitação do Tempo de Direção } & $\checkmark$ & $\checkmark$ & $\checkmark^{*}$ \\
\hline \multicolumn{2}{|c|}{ Peso Máximo por Eixo } & $\checkmark$ & $\checkmark$ & $\checkmark^{*}$ \\
\hline \multicolumn{2}{|c|}{ Publicação de Tarifas de Frete } & $\checkmark$ & O & \\
\hline \multicolumn{2}{|c|}{ Monitoramento das faixas de Frete } & $\checkmark$ & $\checkmark$ & 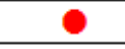 \\
\hline
\end{tabular}

Fonte: Adaptado de Arruda Junior (2014).

Atualmente, o setor de Transporte Rodoviário de Cargas sob remuneração de terceiros é composto por aproximadamente 179 mil empresas, 888 mil transportadores autônomos e 420 cooperativas, os quais operam, em conjunto, uma frota aproximada de 2.300 .000 veículos (ANTT, 2015). Ainda de acordo com ANTT (2015), mais de $45 \%$ da frota rodoviária pertence aos transportadores autônomos, ratificando, assim, a pulverização excessiva do mercado.

Assim, em um cenário altamente competitivo, as empresas precisam dispor de meios para oferecer um serviço de excelente qualidade para seus clientes, praticar preços competitivos e obter resultados financeiros que lhes sustentem no mercado, possibilitem o investimento em melhoria contínua e proporcionem lucro (PINHEIRO, 2013).

Diante desta realidade de elevada complexidade operacional, em que os clientes exigem um elevado nível de serviço a preços baixos, torna-se fundamental gerir os processos, informações e mensurar o desempenho operacional. Neste sentido, Novaes (2001) afirma que medir eficiência e monitorar permanentemente o desempenho das empresas de transporte passam a ser atividades de grande importância no mercado consumidor, não havendo espaço para o gerenciamento das empresas de forma empírica.

Conforme ensina Peter Drucker (1992): "Se você não pode medir, você não pode gerenciar". Assim, para a melhoria do desempenho é necessária a realização de diagnósticos e avaliações, 
quantitativas e qualitativas, da situação atual, caso contrário não haverá como gerenciar melhorias e definir a situação futura.

Nesta perspectiva, os sistemas de medição de desempenho (SMD), que são um conjunto de atividades sistêmicas para se coletar e analisar dados com o intuito de medir e avaliar a eficiência e a eficácia dos processos por meio da aplicação de indicadores de desempenho, podem se constituir em uma ferramenta essencial para gerenciar o desempenho da organização.

Diversos modelos de sistemas de medição de desempenho foram desenvolvidos a partir da década de 1990, período denominado de Revolução da Medição (NEELY, 1998). Dentre estes, pode-se destacar o Performance Pyramid, o Balanced Scorecard, o Integrated Performance Measurement Systems e o Performance Prism.

O Balanced Scorecard (BSC) desenvolvido por Kaplan e Norton (1992), é sem dúvida, o modelo de medição de desempenho mais disseminado, praticado e estudado entre todos os modelos produzidos nas últimas décadas (GOESSLER, 2009). Nascimento et al. (2008) afirmam que a metodologia do BSC é a de maior destaque, isto porque procura integrar os indicadores de desempenho à estratégia da empresa.

O BSC é um sistema de medição de desempenho focado no desempenho organizacional sob quatro perspectivas: financeira, do cliente, dos processos internos e de aprendizado e crescimento. Isto é, o BSC contempla as medidas financeiras tradicionais com medidas não financeiras, buscando integrá-las numa relação de causa e efeito. De acordo com Kaplan e Norton (1997), o BSC é mais de que um sistema de medição, ele tem sido usado como um sistema de gestão estratégica.

\subsection{DELIMITAÇÃO DO PROBLEMA}

Conforme descrito anteriormente, existem diversas formas de classificar os transportadores rodoviários de cargas. Para Tedesco (2012) o TRC, no que diz respeito às características do serviço e do transportador que o executa, pode ser subdivido em: 
a. Transporte Rodoviário de Carga Própria (TCP); e

b. Transporte Rodoviário Remunerado de Cargas (TRRC).

O Transporte Rodoviário de Carga Própria (TCP) é o serviço realizado por transportadores que movimentam suas próprias cargas, ou seja, não realizam serviço remunerado e não possuem o transporte como sua atividade-fim. No TCP a nota fiscal é emitida no nome da empresa, do indivíduo arrendatário ou proprietário do veículo utilizado no deslocamento da carga (TEDESCO, 2012).

Segundo Tedesco (2012), não se pode afirmar que o TCP esteja enquadrado no mercado de transporte rodoviário de cargas, uma vez que não são estabelecidos contratos para a prestação do serviço. Contudo, este tipo de categoria deve ser considerado como uma atividade que influencia e impacta o mercado de transporte rodoviário de cargas, pois diminui a demanda pelo transporte por terceiros.

O escopo deste projeto não abordará o Transporte Rodoviário de Carga Própria (TCP), visto que normalmente esta atividade é realizada por setores da própria empresa embarcadora e se constitui numa atividade secundária ao processo fim da organização.

Sobre a caracterização do transportador rodoviário de carga, a Lei n ${ }^{0} 11.442$ (BRASIL, 2007), que dispõe sobre o transporte rodoviário de carga por conta de terceiros mediante remuneração, define o Transporte Rodoviário de Carga realizado por terceiros, como atividade econômica de natureza comercial, exercida por pessoa física ou jurídica em regime de livre concorrência, dependente de prévia inscrição do transportador no Registro Nacional de Transportadores Rodoviários de Cargas (RNTRC) realizado pela Agência Nacional de Transportes Terrestres (ANTT). Os transportadores são classificados sob as seguintes categorias, pela Lei $\mathrm{n}^{0} 11.142 / 2007$ :

a) Transportador Autônomo de Carga (TAC) - pessoa física que tenha no transporte rodoviário de cargas a sua atividade profissional, proprietário, co-proprietário ou arrendatário de, pelo menos, 1 (um) veículo automotor de carga, registrado em seu nome no órgão de trânsito, como veículo de aluguel. 
b) Empresa de Transporte Rodoviário de Cargas (ETC) - pessoa jurídica constituída por qualquer forma prevista em lei, que tenha no transporte rodoviário de cargas a sua atividade principal, e mediante comprovação ser proprietária ou arrendatária de, pelo menos, 1 (um) veículo automotor de carga, registrado no País.

c) Cooperativas de Transporte de Carga (CTC) - empresas de Transporte Rodoviário de Carga constituída como Cooperativas de Transporte de Cargas, sendo necessário comprovar a propriedade ou o arrendamento dos veículos automotores de cargas de seus associados.

A Figura 1.2 apresenta a participação de cada tipo de transportador no mercado de TRC, de acordo com a ANTT (2015):

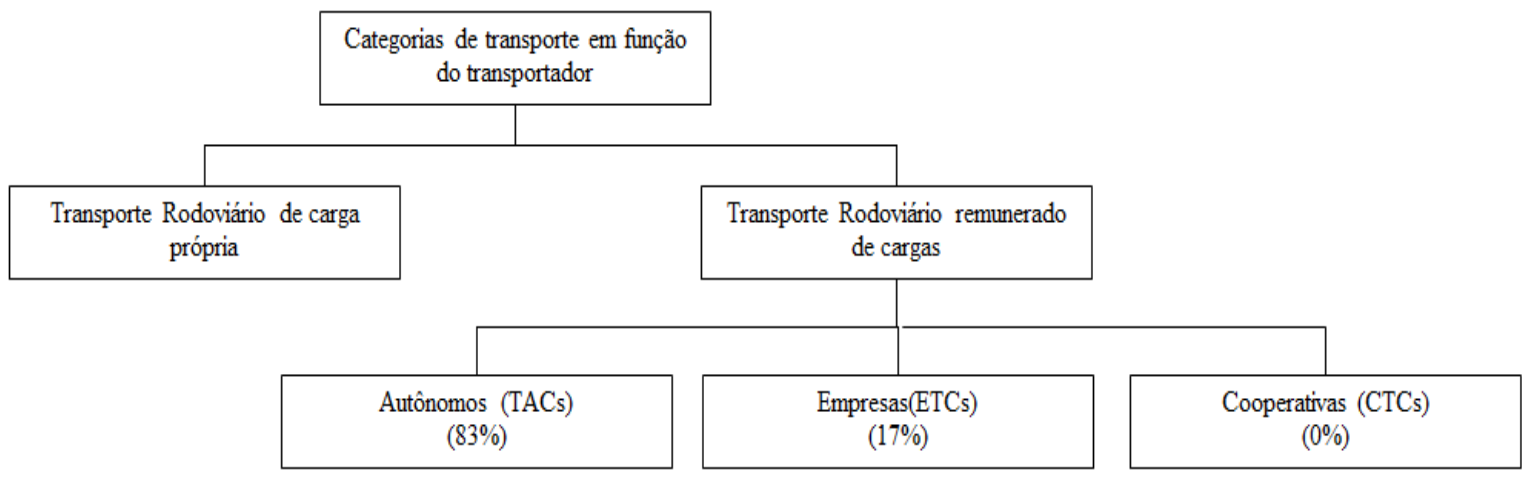

Figura 1.2 - Composição do TRC

Para o desenvolvimento do presente trabalho, decidiu-se restringir a análise de indicadores de desempenho às empresas transportadoras de cargas.

Dessa forma, o foco do presente trabalho é propor um sistema de medição de desempenho para as empresas que realizam o Transporte Rodoviário Remunerado de Cargas (TRRC), ou melhor, que tenham o transporte de carga rodoviária como sua atividade principal. Ademais, este projeto procura responder à seguinte questão:

O Método do Balanced Scorecard é aplicável para a análise da qualidade do serviço prestado pelas Empresas de Transporte Rodoviário de Cargas? 


\subsection{OBJETIVOS}

O objetivo principal deste trabalho é desenvolver um sistema de medição de desempenho, baseado na metodologia do Balanced Scorecard, para empresas de transporte rodoviário de cargas (ETRC).

Os objetivos específicos são:

a. Avaliar a aplicabilidade das técnicas propostas pelo Balanced Scorecard, no ambiente de uma empresa de transporte de cargas.

b. Selecionar indicadores de desempenho para avaliar os serviços das ETRC.

c. Criar índices para cada uma das perspectivas do Balanced Scorecard e um índice geral que avalie o nível de serviço das ETRC.

\subsection{JUSTIFICATIVA}

O transporte rodoviário de carga é o principal modo de transporte utilizado no Brasil. O setor é responsável por movimentar mais de $61 \%$ de toda carga transportada no país, conforme Figura 1.3 (CNT, 2015), isto é, transporta cerca de 485 milhões de tonelada por quilômetro útil por ano, desempenhando, portanto, um papel fundamental para o desenvolvimento econômico e social do país (GOMES, 2006).

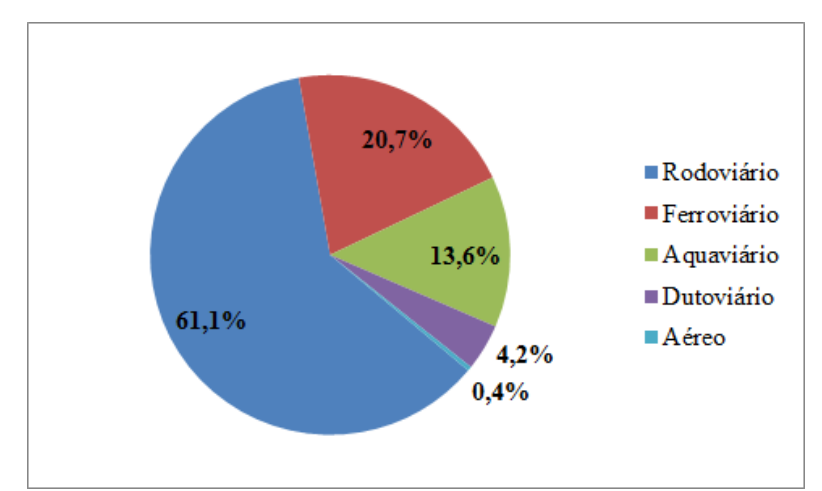

Figura 1.3 - Matriz de Transporte de Carga Brasileira

Fonte: Adaptado de CNT (2015)

De acordo com estudo da COOPEAD/CNT (2002), o setor vem vivenciando há vários anos graves problemas que afetam o desempenho das empresas e a qualidade dos serviços oferecidos. O setor vem sofrendo uma degradação contínua e lenta. A inexistência de 
barreiras de entrada no setor provocou um excesso de oferta e consequente redução de preços de frete, gerando uma competição acirrada e desleal (BARBOSA, 2013).

Tais fatos, associados à baixa formação escolar dos profissionais do setor, à administração empírica, à informalidade nos negócios, geram uma redução do nível de serviço oferecido aos usuários (BELÉM JR, 2007), frustrando muitas vezes as expectativas dos clientes. Em termos macroeconômicos, a ineficiência de gestão de processos das empresas do setor implica elevação dos custos financeiros e sociais do país, contribuindo significativamente com o Custo Brasil (BELÉM JR, 2007), prejudicando o desenvolvimento do país e a competitividade do produto nacional.

Neste sentido, para que os transportadores rodoviários possam atender às exigências dos clientes e se destacar no mercado é fundamental terem informações acerca da situação atual, isto é, do nível de serviço prestado, para que possam desenvolver ações de melhoria contínua.

Uma metodologia que permita aos transportadores rodoviários diagnosticar seu desempenho atual e sirva como sistema de apoio à decisão para a melhoria de seus processos internos e atendimento das expectativas dos clientes, poderá contribuir para melhoria do nível de serviço e melhores resultados para a empresa.

Os sistemas de medição de desempenho vêm sendo amplamente estudados no meio acadêmico. Ao pesquisar nas bases de dados Periódico CAPES, PROQUEST e SCIELO, as palavras chaves "medição de desempenho" e "transporte de cargas" obtêm-se diversos resultados. Analisando os artigos, dissertações e teses publicadas, observa-se, porém, que a maioria aborda como tema principal a logística, e não exclusivamente o desempenho da atividade de transporte. Isto é, a maior parte dos trabalhos avalia a medição de desempenho da cadeia de suprimentos, de forma global, como é o caso dos estudos realizados por Heaver e Henriksson (1994), Brewer e Speh (2000), Piotrowicz (2008) e Lai et al. (2002), Rocha (2009) e Saboia (2006).

Encontram-se, também, estudos como o de Silva et al. (2011) e Frederico (2015), que abordam a aplicação do Balanced Scorecard para empresas de transporte ferroviário. Enquanto outros, como o de Galo et al. (2013), utilizam medição de desempenho para auxiliar as empresas na seleção de fornecedores de transporte, McKinnon (2009) apresenta um 
conjunto de indicadores de desempenho utilizados pelo Governo do Reino Unido para realizar benchmarking entre as empresas de transporte rodoviário de cargas.

Em relação aos estudos voltados exclusivamente para medição de desempenho de empresas do transporte rodoviário de cargas, pode-se destacar: Vaccari (2006), Vieira et al. (2015), Chuguano (2008), Bongiolo da Silva (2014) Belém Jr (2007), Souza et al. (2010) Dias (2008), Neto et al. (2011), Roberto da Silva (2013) e Pinheiro (2013).

Vaccari (2006), Vieira et al. (2015), Chuguano (2008), Bongiolo da Silva (2014) desenvolveram, em seus respectivos trabalhos, um sistema de medição de desempenho, baseado no Balanced Scorecard, porém para uma única empresa de transporte.

Já Dias (2008), Roberto da Silva (2013) e Neto et al. (2011) abordaram apenas alguns aspectos do Balanced Scorecard em seus trabalhos. O primeiro analisou a relação de causa e efeito entre os indicadores, o segundo utilizou algumas das ferramentas do Balanced Scorecard para desenvolver o planejamento estratégico e o último desenvolveu apenas alguns indicadores.

Por fim, alguns trabalhos utilizaram metodologias, diferentes do Balanced Scorecard, para avaliar o desempenho das empresas de transporte rodoviário de cargas. Belém Jr (2007) criou uma metodologia de avaliação de desempenho das ETRC, baseado na visão do usuário. Souza et al. (2010) analisaram a eficiência das empresas de transporte com base no DEA (Análise Envoltória de Dados), enquanto Pinheiro (2013) utilizou um modelo multicritério para avaliação das ETRC.

Portanto, o presente trabalho é relevante por desenvolver um sistema de medição de desempenho voltado para os transportadores rodoviários, utilizando, como ferramenta, a metodologia do Balanced Scorecard e adicionalmente propõe a criação de índices com base nos indicadores do Scorecard. O sistema a ser desenvolvido tem o intuito de apoiar a tomada de decisão dos gestores, servir como ferramenta de benchmarking e promover a melhoria do nível de serviço das ETRC. 


\subsection{METODOLOGIA DA PESQUISA}

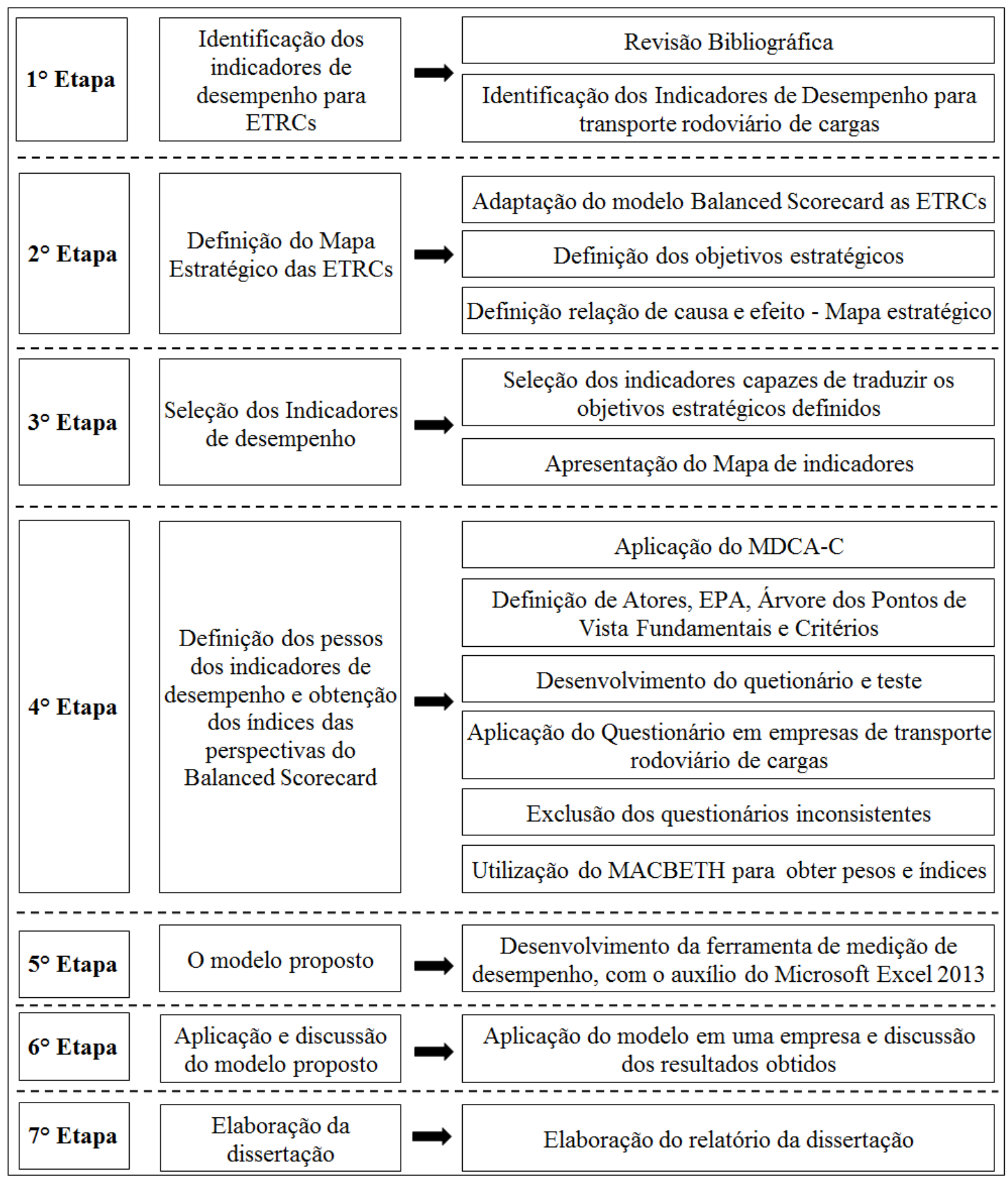

Figura 1.4 - Metodologia da Pesquisa

Inicialmente, foi realizada pesquisa bibliográfica em livros, artigos científicos e periódicos nacionais e internacionais para identificar os principais indicadores utilizados na medição de desempenho das empresas prestadoras de serviço de transporte rodoviário de cargas. 
Em seguida, adaptou-se o modelo genérico do Balanced Scorecard desenvolvido por Kaplan e Norton (1997) para definir os objetivos estratégicos dos transportadores rodoviários, isto é, as atividades críticas que devem ser mensuradas, nas quatro perspectivas do Balanced Scorecard, e suas relações de causa e efeito, representada pelo Mapa Estratégico das ETRC.

Posteriormente, foram selecionados do conjunto de indicadores de desempenho identificados na pesquisa bibliográfica, aqueles alinhados aos objetivos estratégicos determinados, ou seja, aqueles capazes de mensurar cada um dos objetivos, para compor o sistema de indicadores de desempenho.

Na sequência, foram definidos de pesos para cada um dos indicadores do sistema de medição, com o intuito de desenvolver os índices das perspectivas, assim como do índice geral da qualidade do serviço de transporte. Para realizar a ponderação dos indicadores de desempenho utilizou-se a Análise Multicritério de Apoio à Decisão - Construtivista (MCDA-C).

O MCDA-C foi selecionado porque se caracteriza pela flexibilidade de permitir forte iteração do modelo a ser construído com os tomadores de decisão e suas percepções da problemática em estudo (PEREIRA NETO, 2001). Essa metodologia defende a aprendizagem pela participação, que, através da interatividade dos atores envolvidos, estabelece um processo de discussão crítica acerca da problemática (PEREIRA NETO, 2001).

Assim, inicialmente, estruturou-se o modelo, definindo o contexto do problema, os atores envolvidos, os elementos primários de avaliação, a árvore dos pontos de vista fundamentais e os critérios de avaliação.

Com base no modelo de arborescência proposto, desenvolveu-se questionário de pesquisa (Anexo I), cujo objetivo era validar e obter os pesos dos indicadores de desempenho que compõem o Balanced Scorecard. O questionário foi previamente testado em duas transportadoras rodoviárias de cargas, em 21 e 23 de janeiro de 2016, e após a identificação de inconsistências, realizou-se as correções para obtenção de melhores resultados.

Para a coleta de dados através do questionário desenvolvido, foi definido um grupo composto por empresas pertencentes à Associação Nacional do Transportes de Cargas e Logística. A pesquisa foi realizada em 23 de fevereiro de 2016, em uma reunião com os transportadores, na 
qual inicialmente foram apresentados os objetivos do projeto e ressaltada a importância da contribuição dos mesmos. Em seguida, foi aplicado o questionário com 15 especialistas da área de transporte rodoviário de cargas, pertencentes ao grupo de empresas.

Após a exclusão dos questionários que apresentavam inconsistências, com o auxílio do software M-MACBETH, os dados coletados foram transformados em taxas de substituição, que correspondem aos pesos de cada um dos indicadores de desempenho, permitindo a construção dos índices.

Assim, com base nos indicadores de desempenho e seus respectivos pesos, foi desenvolvido o sistema de medição de desempenho com o auxílio do programa Microsoft Excel 2013. O sistema tem por objetivo ser uma ferramenta útil e de fácil entendimento para os transportadores rodoviários, além de permitir o gerenciamento das atividades críticas.

Como forma de validar e demonstrar a aplicabilidade do modelo proposto selecionou-se uma empresa de capital aberto, haja vista que boa parte dos dados da empresa, necessários para a construção do Balanced Scorecard, estão disponíveis ao público. Destaca-se que para as informações não disponíveis ao público, realizou-se uma simulação dos dados.

Assim, detalhou-se o passo a passo do procedimento de geração dos dados necessários para a obtenção de cada um dos indicadores de desempenho e foram discutidos os resultados obtidos.

Por fim, foi elaborado o relatório final da dissertação.

\subsection{ESTRUTURA DA DISSERTAÇÃO}

Considerando os objetivos deste estudo e suas etapas metodológicas, a dissertação está estruturada em cinco capítulos. O capítulo 1 apresenta a contextualização do tema, a delimitação do problema, os objetivos, a justificativa e a metodologia proposta.

O capítulo 2 aborda o referencial teórico relacionado ao problema de pesquisa, discorre sobre a importância dos sistemas de medição de desempenho e conceitua os sistemas de medição de 
desempenho. Também realiza a caracterização e classificação dos indicadores de desempenho, além de especificar os indicadores de desempenho do transporte rodoviário de cargas. Por fim, aborda a metodologia do Balanced Scorecard para a construção do sistema de indicadores de desempenho.

O capítulo 3 descreve a construção do sistema de medição de desempenho para os transportadores rodoviários.

O Capítulo 4 objetiva apresentar a aplicação do modelo em uma empresa de transporte rodoviário de cargas.

Por fim, as conclusões obtidas ao longo do desenvolvimento da dissertação, assim como sugestões propostas para futuros trabalhos sobre o tema da pesquisa serão apresentadas no Capítulo 5. 


\section{SISTEMAS DE MEDIÇÃO DE DESEMPENHO}

Neste capítulo será abordado o referencial teórico acerca dos sistemas de indicadores de desempenho de forma geral e, em específico, do Balanced Scorecard, assim como dos indicadores de desempenho voltados para o transporte rodoviário de cargas.

\subsection{IMPORTÂNCIA DOS SISTEMAS DE MEDIÇÃO DE DESEMPENHO}

Para uma organização atingir êxito de curto e longo prazos não basta apenas definir corretamente seus objetivos, é preciso acompanhar o que foi estabelecido (HOLANDA, 2007). Sendo assim, é fundamental monitorar e mensurar as atividades da organização para verificar se os objetivos estabelecidos estão sendo alcançados e se os mesmos estão gerando benefícios para a organização.

Na medida em que o sistema de medição de desempenho gera informações relevantes a respeito do desempenho organizacional, torna-se valioso para o processo decisório da empresa, permitindo a tomada de decisões mais adequadas com base no desempenho real da organização (CARVALHO, 2007).

Sink e Tuttle (1993) consideram o papel dos sistemas de medição de desempenho como mecanismos de retroalimentação de informações para a tomada de decisão. Para os autores, os sistemas de medição de desempenho são parte integrante do sistema gerencial. Nesse sentido, Kaydos (1991) considera que a medição de desempenho é um dos elementos centrais de gestão, com a percepção de que o desempenho é em parte resultado das decisões tomadas e, assim, a qualidade da decisão, em boa parte, é limitada pela informação disponível em termos de qualidade e quantidade sobre o desempenho.

Portanto, conforme Rummler e Brache (1994) enfatizaram, a ausência de um sistema de medição de desempenho afeta negativamente o desempenho global da organização, visto que o desempenho não pode ser gerenciado e, consequentemente, não se pode identificar de forma adequada os problemas e estabelecer prioridades. Para Harrigton (1993), se não puder medir, não pode controlar; se não controlar, não pode gerenciar; se não gerenciar, não se pode melhorar. Em outras palavras, Kaplan e Norton (1997) afirmam “o que não é medido, não é 
gerenciado". Mais detalhadamente, Rummler e Brache (1994) descrevem os prejuízos de uma organização sem sistema de medição de desempenho:

- sem medição, o desempenho não está sendo gerenciado;

- sem medição, não se pode identificar adequadamente os problemas, nem estabelecer um conjunto de prioridades;

- sem medição, as pessoas não podem compreender totalmente o que se espera delas;

- sem medição, as pessoas não têm certeza de que seu desempenho é adequado ou não;

- sem medição, não pode haver uma base objetiva e equitativa para recompensas ou punições;

- sem medição, não há gatilho para as ações de aperfeiçoamento do desempenho;

- sem medições, o gerenciamento é um conjunto de adivinhações desordenadas.

Percebe-se, assim, que a medição de desempenho é mais que uma ferramenta gerencial: é uma medida estratégica de sobrevivência (MIRANDA e SILVA, 2002). Os autores destacam as seguintes razões para as empresas implementarem um sistema de medição de desempenho:

- controlar as atividades operacionais da empresa;

- alimentar os sistemas de incentivo dos funcionários;

- controlar o planejamento;

- criar, implantar e conduzir estratégias competitivas;

- identificar problemas que necessitem intervenção dos gestores;

- verificar se a missão da empresa está sendo atingida.

Harrington (1993), também, enumerou uma série de benefícios de se ter medições fidedignas:

- entender o que está acontecendo;

- avaliar as necessidades de mudanças;

- avaliar o impacto das mudanças;

- assegurar que os ganhos realizados não sejam perdidos;

- corrigir situações fora do controle;

- estabelecer prioridades; 
- decidir quando aumentar as responsabilidades;

- determinar necessidade de treinamento adicional;

- planejar para atender novas expectativas do cliente;

- estabelecer cronogramas realistas.

Logo, observa-se que o objetivo principal da medição de desempenho é controlar e monitorar o desempenho da empresa, indicando se a mesma está adequadamente direcionada para atingir suas metas estratégicas (KAYDOS,1991).

\subsection{CONCEITUAÇÃO DE SISTEMAS DE MEDIÇÃO DE DESEMPENHO}

Segundo Juran (2003), o remédio mais eficaz para a imprecisão e os múltiplos dialetos é a medição - "dizer em números". Transformar dados subjetivos em informações, transformar hipóteses em fatos. A gestão atual necessita do maior número possível de ferramentas que facilitem a compreensão e o diagnóstico da situação atual.

Neely et al. (1995) definem a medição de desempenho como o processo de quantificar a eficiência e eficácia de uma ação, em que a eficiência é entendida como o grau em que os requisitos do cliente são atingidos e a eficácia é a medida em termos do consumo de recursos organizacionais utilizados para que estes requisitos sejam economicamente alcançados.

Este processo também pode ser entendido como as atividades de coleta, exame, classificação, análise, interpretação e disseminação dos dados adequados para a avaliação da eficiência e eficácia (NEELY, 1998).

Já a Fundação para o Prêmio Nacional da Qualidade (FPNQ, 1995) define medição de desempenho como uma relação matemática que mede, numericamente, atributos de um processo ou de seus resultados, com o objetivo de comparar esta medida com metas numéricas, pré-estabelecidas.

Com uma visão mais técnica, Kueng et al. (2000) afirmam que o sistema de medição de desempenho (SMD) pode ser entendido como um sistema de tecnologia de informação que 
coleta dados relevantes de desempenho a partir de várias fontes, compara dados atuais com dados históricos e metas, e comunica os resultados para os usuários.

Para Clark Jr. (1995), o sistema de medição de desempenho pode ser definido como o conjunto de pessoas, processo, métodos e ferramentas que conjuntamente geram, analisam, expõem, descrevem, avaliam e revisam dados e informações sobre as múltiplas dimensões do desempenho organizacional. Franco-Santos et al. (2004) conceituam um sistema de medição de desempenho como "um conjunto de processos que uma organização usa para gerenciar a implementação de sua estratégia, comunicar sua posição e influenciar o comportamento e as ações de seus empregados. Isso exige a identificação dos objetivos estratégicos, medidas de desempenho multidimensionais, alvos e o desenvolvimento de uma infraestrutura de suporte".

Segundo Kaplan e Norton (2004) e Müller (2003), a medição de desempenho permite o acompanhamento da implementação das ações definidas no planejamento estratégico. Sink e Tuttle (1993) salientam que a medição, se executada de modo adequado, é uma ferramenta eficaz e necessária, mas não suficiente para assegurar que a estratégia seja implementada em todos os níveis da organização.

No processo de desenvolvimento de um sistema de medição de desempenho, é fundamental considerar alguns elementos importantes para que o sistema cumpra sua função, isto é, para que sirva de apoio à gestão operacional. Conforme estabelece Kaydos (1991), um sistema de medição de desempenho deve conter os seguintes elementos:

- $\quad$ ser capaz de comunicar estratégia e clarear valores - onde o sistema de medição de desempenho deve ser capaz de traduzir a estratégia da organização de forma clara para todos os seus integrantes;

- facilitar a identificação de problemas e oportunidades - problemas e oportunidades devem ser identificados de forma a superar eventuais problemas de alinhamento entre ações e a estratégia;

- facilitar o entendimento de processos - para melhorar o desempenho estratégico de uma organização, é necessário conhecer os processos, seus resultados esperados e a relação desses resultados com metas estratégicas; 
- $\quad$ subsidiar a tomada de decisão em relação à alocação de recursos - informações sobre o desempenho da organização e a relação de tais desempenhos com os resultados dos seus processos ajudam a colocar as opções de alocação de recursos em perspectiva, permitindo o estabelecimento, por exemplo, de critérios para ações de melhoria;

- apoiar a definição de responsabilidades, tornando a delegação de tarefas efetiva e os resultados visíveis - dentro de uma perspectiva processual, com resultados compartilhados, sistemas de medição de desempenho devem ser orientadores de performance de atividades individuais, facilitando a definição de responsabilidades dos funcionários e tornando visível o esforço empreendido nas ações;

- servir de orientador para comportamentos, envolvendo as pessoas e recompensando bons desempenhos - por clarear e comunicar a estratégia, os sistemas de medição de desempenho acabam por influenciar o comportamento dos funcionários, em especial, quando as medidas de desempenho são utilizadas como parte ativa da remuneração funcional.

Adicionalmente, Neely et al. (1995) estabelecem que a construção de um Sistema de Medição de Desempenho deve considerar três dimensões: as medidas de desempenho individuais, isto é, os indicadores de desempenho específicos para cada objetivo; o conjunto de medidas de desempenho que formam o sistema de medição, ou seja, as medidas devem estar agrupadas; e a relação entre o sistema e os ambientes, interno e externo, que fornecem a estrutura de suporte para que este possa operar. A figura 2.1 ilustra os três níveis descritos pelos autores.

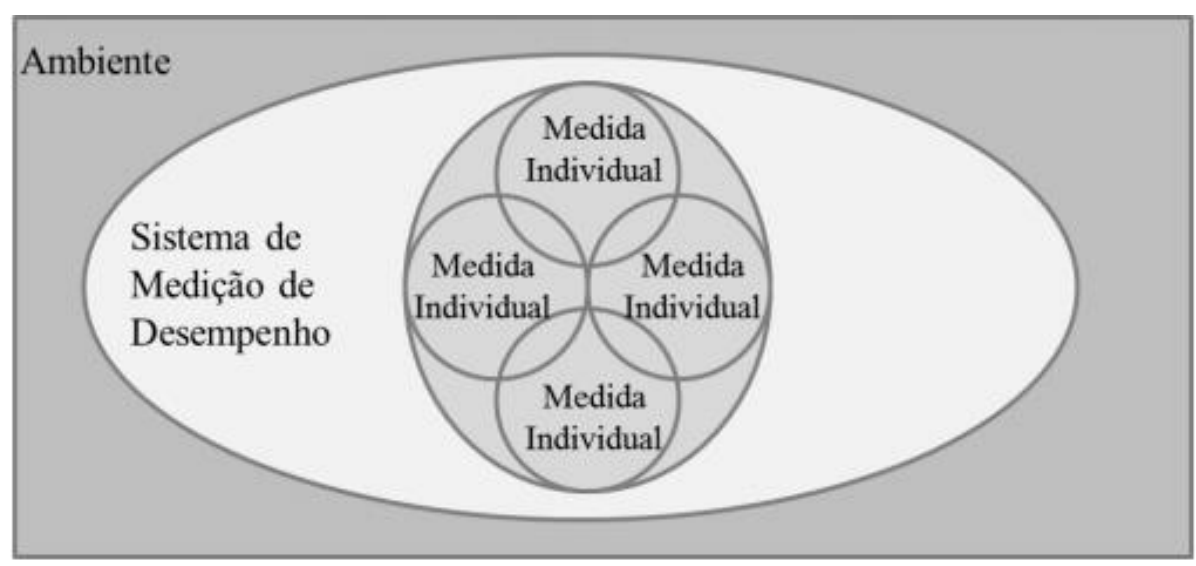

Figura 2.1 - Estrutura para design de Sistemas de Medição de Desempenho Fonte: Neely et al. (1995) 


\subsection{INDICADORES DE DESEMPENHO}

A medida de desempenho é entendida como um atributo, qualitativo ou quantitativo, usado para verificar ou avaliar algum produto por meio de comparação com um padrão, isto é, a referência (MOREIRA, 2002). A medição de desempenho é a quantificação de quão bem as atividades dentro de um processo ou seu output atingem uma meta especificada (HRONEC, 1994).

Já o indicador de desempenho deve ser entendido como uma forma objetiva de medir a situação real contra um padrão previamente estabelecido e acordado (CARVALHO, 1995). Isto é, o indicador é o resultado de uma medida que torna possível a compreensão da evolução do que se pretende avaliar. Apesar da diferença conceitual entre os termos, a maioria dos autores considera indicador e medida como sinônimos (MOREIRA, 2002).

De acordo com Takashina e Flores (2005), indicadores são formas de representação quantificáveis das características de produtos e processos. São utilizados para controlar e melhorar o desempenho e a qualidade dos produtos e processos da organização. Neste mesmo sentido, Kardec et al. (2002) definem indicadores como guias que permitem medir não somente a eficácia das ações tomadas, como também avaliar o desempenho através da comparação das ações programadas e o realizado.

Em seus estudos, Hronec (1993) considera os indicadores de desempenho como sendo os sinais vitais de uma organização, visto que é um instrumento que permite avaliar e mostrar a situação e as tendências das condições de um dado ambiente organizacional (TOCCHETTO E PEREIRA, 2004).

Portanto, os indicadores são essenciais ao planejamento e ao controle dos processos das organizações. São essenciais ao planejamento porque possibilitam o estabelecimento de metas quantificadas e o seu desdobramento na organização. E são essenciais ao controle porque os resultados apresentados através dos indicadores são fundamentais para a análise crítica do desempenho da organização, para a tomada de decisões e para o replanejamento (TAKASHINA E FLORES, 2005). 
Assim, conforme estabelece Kardec (2002), sem os indicadores é praticamente impossível avaliar o desempenho das organizações. Entretanto, também é verdade que a utilização de um número muito grande de indicadores de desempenho torna a mensuração inviável e sem sentido. É melhor, conforme Camargo (2000), selecionar o que realmente é importante, evitando medidas muito complexas, ou seja, selecionar aqueles poucos indicadores essenciais.

Para identificar estes indicadores prioritários é fundamental responder à pergunta: "Por que medir?" (MIRANDA e SILVA, 2002). Possamai e Hansen (1998) e Harrington (1993) enumeram uma série de motivos para as organizações utilizarem indicadores de desempenho:

- concentrar a atenção em fatores que contribuem para a realização das prioridades de atuação ;

- mostrar a eficiência com os recursos são empregados;

- garantir objetividade de avaliação e estabelecimento de metas;

- permitir o estabelecimento de tendências e acompanhamento histórico;

- definir papeis responsabilidades;

- identificar oportunidades para a melhoria contínua;

- fornecer dados para determinar causas críticas, servindo de instrumento de apoio a decisão;

- permitir o auto gerenciamento e o monitoramento do desenvolvimento;

Deve-se, também, adotar uma série de requisitos básicos para a construção de um indicador de desempenho (CAMARGO, 2000; TIRONI et al.,1992; NEELY et al., 1997):

- Seletividade: os indicadores devem ser relacionados a fatores críticos do processo a ser avaliado. Tais processos essenciais devem ser identificados a partir da estratégia definida pela organização;

- Representatividade: o indicador deve ser desenvolvido de forma que possa representar satisfatoriamente aquilo que se pretende mensurar.

- Simplicidade e clareza: devem ser de fácil compreensão e aplicação, principalmente para as pessoas responsáveis pela monitoração do indicador;

- Baixo custo: $O$ custo para coleta, processamento e avaliação não pode ser superior ao benefício a ser alcançado. 
- Estabilidade: devem ser coletados com base em procedimentos rotineiros e que permitam sua comparação ou análise de tendência ao longo do tempo.

- Comparação externa: alguns indicadores devem ser desenvolvidos para permitir a comparação do desempenho da empresa com outras empresas do setor ou de outros setores (Benchmarking). Sendo um instrumento importante de comparação do grau de competitividade.

- Melhoria contínua: os indicadores devem ser periodicamente avaliados e se necessário devem ser modificados ou ajustados de acordo com as mudanças no ambiente organizacional.

Ainda sobre as características dos indicadores de desempenho, Horngren et al. (2004) e Berliner e Brimson (1992) indicam que as boas medidas de desempenho deverão:

- relatar e suportar as metas organizacionais;

- ser adaptáveis às necessidades do negócio;

- equilibrar interesses de curto e longo prazo;

- ser objetivas e facilmente entendida pelos empregados;

- ser fáceis de mensurar e eficientes do ponto de vista de custos;

- ser utilizadas consistente e regularmente;

- ser visíveis e aceitas por todos os níveis da organização, a fim de receberem e encorajarem a melhoria do desempenho.

Um dos pontos mencionados por estes autores é a necessidade dos indicadores de desempenho serem definidos e comunicados de forma que seu significado e objetivo fiquem claros para todos na organização. Sem a compreensão dos objetivos e metas estabelecidos pelos indicadores, os colaboradores não serão capazes de alinhar seus esforços para atingir os objetivos propostos.

Assim, ao estabelecer um indicador de desempenho é fundamental que se especifique o objetivo, a fórmula de cálculo e as fontes de dados. Com o intuito de reduzir o mal entendido na compreensão dos indicadores, Nelly et al. (1997) sugerem um conjunto de definições e detalhamentos a serem aplicados a cada um dos indicadores quando de sua construção. Este conjunto de definições está relacionado no Quadro 2.1: 
Quadro 2.1- Definição de indicador de desempenho

\begin{tabular}{|l|l|}
\hline Detalhe & Objetivo \\
\hline Título & Explicar o que é o indicador e por que é importante \\
\hline Propósito & Mostrar o que está sendo medido e com que propósito \\
\hline Relacionada a & Ligar o indicador aos objetivos de desempenho da empresa \\
\hline Escopo & Definir que áreas da organização estão envolvidas \\
\hline Meta & Especificar nível de desempenho desejado e prazos \\
\hline Fórmula & Definir exatamente como calcular o indicador \\
\hline Unidades de medida & Definir a(s) unidades(s) usada(s) \\
\hline Frequência de medição & Definir com que frequência o indicador será calculado \\
\hline Frequência de revisão & Definir com que frequência o indicador será revisto \\
\hline Quem mede? & Especificar o responsável por coletar e relatar os dados \\
\hline Fonte dos dados & Especificar a exata fonte dos dados a serem utilizados \\
\hline Quem são os donos da medida? & Especificar os proprietários do indicador \\
\hline O que eles fazem? & Explicitar suas atribuições \\
\hline Quem age sobre os dados? & Definir quem é o responsável por agir sobre os resultados \\
\hline O que eles fazem? & $\begin{array}{l}\text { Definir de maneira geral que processo gerencial deverá ser seguido em } \\
\text { função do desempenho }\end{array}$ \\
\hline
\end{tabular}

Fonte: Adaptado de Neely et al. (1997)

\subsection{CLASSIFICAÇÃO DOS INDICADORES DE DESEMPENHO}

Segundo Camargo (2000), existe uma interdependência entre os indicadores de desempenho, sendo possível agrupá-los e classificá-los conforme o nível de agregação. A literatura apresenta diversas formas de classificação para os indicadores de desempenho. A seguir serão abordados os tipos mais gerais.

Harrington (1993) separa os indicadores de desempenho em dois grupos: os qualitativos ou de atributos e os quantitativos ou de variáveis. Segundo o autor, o indicador qualitativo indica um juízo de valor e pode contar com o auxílio de um critério sim ou não, aceita ou rejeita. Já o indicador quantitativo relata um processo empresarial a partir da coleta de valores numéricos representativos do processo considerado. De forma mais detalhada, o autor também os classifica como indicadores de eficiência, eficácia e de adaptabilidade, sendo este último a representação de como processos ou pessoas reagem às mudanças do ambiente de negócios.

Já Sink e Tuttle (1993) propõem a classificação dos indicadores segundo a finalidade que fornecem, determinando critérios para a avaliação da informação. Os indicadores podem ser para visibilidade (fornece um diagnóstico inicial), para controle dos processos e para a introdução de melhorias (estabelecimento de metas). Dessa forma, tem-se o grupo dos 
indicadores gerenciais, destinados ao acompanhamento e à implantação da estratégia e os operacionais com a finalidade de estabelecer objetivos no âmbito de cada processo.

Uma abordagem semelhante, porém mais ampla que a anterior, é a classificação dos indicadores quanto aos níveis organizacionais estratégico, tático e operacional (GUNASEKARAN et al., 2001). Os indicadores de desempenho devem permear toda a organização, visto que as decisões tomadas em um nível influenciam nos demais níveis e, consequentemente, no desempenho global.

Outra classificação bastante utilizada é a proposta por Kaplan e Norton (1997), a qual classifica os indicadores como financeiros e não financeiros. Os indicadores financeiros estão relacionados com as medidas mais tradicionais como receita, custos e lucros, referentes à contabilidade. Já as medidas não financeiras, também conhecidas como não tradicionais estão relacionadas com medidas referentes aos clientes, processos internos e aprendizado e crescimento. Estes autores também classificam os indicadores como: de resultado, aqueles que verificam se as iniciativas de curto prazo e as estratégias estão gerando o resultado desejado e os vetores de desempenho, os quais fornecem informações sobre as previsões e tendências da organização.

Miranda e Silva (2002) propõem uma classificação semelhante ao dividir os indicadores de desempenho em três grupos:

- indicadores financeiros tradicionais - são aqueles que existem na literatura há muito tempo, como: faturamento, margem de lucro, lucro líquido;

- indicadores não financeiros tradicionais - dentre o grupo dos não financeiros, são os que também existem na literatura há muito tempo, como: volume de vendas, volume de produção e market-share.

- indicadores não tradicionais - podem ser financeiros ou não financeiros e representam o conjunto de indicadores que não aparecem na literatura ou que começaram a aparecer recentemente, tais como o valor da marca ou do acionista.

Hronec (1993), por sua vez, caracteriza os medidores de processo e output. O medidor de processo controla as atividades, permitindo o monitoramento da atividade e a resolução de problemas, além de motivar as pessoas envolvidas. Já o medidor de output mostra os 
resultados de um processo e geralmente são dirigidos pela alta administração. Além disso, o autor indica que para os indicadores de processo predominam medidas não financeiras, como tempo de ciclo e tempo de resposta ao cliente, enquanto que para o medidor de output a predominância é de medidas financeiras como receita líquida e retorno sobre o investimento.

Por fim, destaca-se a classificação em indicadores internos e externos proposta por (BOWERSOX E CLOSS, 2001). Os indicadores internos concentram-se na comparação de atividades e processos com metas pré-estabelecidas ou com o desempenho anterior e estão relacionados às dimensões custo, serviço ao cliente, qualidade e produtividade. Já os indicadores externos são utilizados para a avaliação organizacional detalhada, focando na percepção do cliente e no benchmarking com outras organizações.

Observa-se, portanto, que a diferença entre as classificações dos indicadores refere-se, especificamente, aos objetivos desejados pelos usuários na geração da informação, visto que existem diferentes formas de gerar os indicadores (HOLANDA, 2007).

\subsection{MEDIÇÃO DE DESEMPENHO DO SERVIÇO DE TRANSPORTE}

Em um mercado altamente competitivo, os consumidores estão cada vez mais exigentes em termos de prazo, preços e serviços e neste contexto a logística emerge como estratégia criadora de valor, melhorando a confiabilidade na entrega, reduzindo tempos de entrega e custos (BARBOSA et al., 2007).

A atividade logística passou a ser entendida como estratégica para as empresas, tornando-se um diferencial competitivo e gerando valor para os clientes. Isto é, a logística de distribuição tornou-se uma ferramenta essencial para redução de custos e melhoria do nível de serviço das organizações (FIGUEIREDO et al.,2010).

O principal componente do sistema logístico é o transporte. Sua importância pode ser medida através de pelo menos três indicadores financeiros: custos, faturamento e lucro. $\mathrm{O}$ transporte representa, em média, 60\% dos custos logísticos, 3,5\% do faturamento, e em alguns casos, mais que o dobro do lucro (FLEURY, 2002). 
Diante da importância da atividade de transporte, Chan (2003) defende que o setor de transporte não deve ser considerado apenas uma "área meio" responsável pela transferência dos produtos, pois, para o autor, a eficiência logística pode melhorar o desempenho de uma indústria e de toda a cadeia produtiva que a cerca.

Para Bowersox e Closs (2001), à medida que a competência logística se torna um fator mais crítico na criação e na manutenção de vantagem competitiva, a precisão nessas tarefas tornase mais importante, pois a diferença entre operações rentáveis e não rentáveis torna-se cada vez menor.

Neste contexto, para que os transportadores rodoviários possam atender às necessidades das organizações é fundamental oferecer um serviço de elevada qualidade e ao mesmo tempo de custos módicos. Fawcett e Clinton (1997) identificaram que as empresas que utilizam métodos de avaliação voltados para medição de desempenho apresentam níveis de prestação de serviço superiores aos concorrentes.

Conforme Hijar et al. (2005), a mensuração da logística é uma forma de avaliar e monitorar as melhorias do processo logístico e, consequente, a redução de custos, a qual possibilita a oferta de maior valor ao cliente. Portanto a mensuração de desempenho na atividade de transporte propicia avaliar a produtividade da utilização dos recursos, o nível de serviço ofertado e a criação de vantagem competitiva para o cliente.

De acordo com Caixeta-Filho e Martins (2010) medir o desempenho dos serviços de transporte é considerar quanto é atingido dos principais objetivos do sistema de prestação de serviço no conjunto das operações realizadas". Ainda segundo os autores, a avaliação de desempenho possui duas abordagens: realizar a monitoração do desempenho visando acompanhar seu comportamento ou procurar com base em comparações, referências ou metas preestabelecidas, identificar e executar ações no sistema para melhorar seu comportamento e resultados.

Pelo fato da atividade de transporte não ser um produto em si, mas sim se configurar como um serviço e apresentar algumas particularidades que condicionam sua realização há algumas dificuldades na definição e quantificação do seu desempenho. Caixeta Filho et al. (2001) descrevem essas dificuldades: 
- o transporte é uma demanda derivada de outras atividades econômicas, ou seja, movimenta-se uma mercadoria para colocá-la à disposição em determinado local.

- não se realiza uma viagem como objetivo final;

- a intangibilidade e a grande variedade de produtos transportados dificulta a quantificação do desempenho;

- o serviço de transporte varia demasiadamente com as necessidades dos clientes;

- o transporte é um produto extremamente heterogêneo, ou seja, é a soma de benefícios explícitos (ex: o deslocamento em si) e implícitos (ex: segurança) apoiada por bens (veículos) e instalações (terminais), afetados pelos clientes;

- as empresas prestadoras de serviços de transportes almejam maximizar seu desempenho de acordo com seus objetivos. No entanto, em serviços, boa parte da qualidade final dos produtos está nos benefícios gerados aos clientes e deve ser resultado do balanço entre a expectativa e a percepção do cliente.

- existe uma grande variabilidade e uma baixa repetitividade dos resultados dos serviços de transporte prestado aos clientes, o que dificulta a análise de desempenho;

- em serviços o consumo ocorre simultaneamente à produção. Portanto, a programação das atividades necessárias à prestação do serviço deve ocorrer anteriormente, e com base na demanda prevista, ao invés da demanda atual;

- dificuldade em mensurar a expectativa e a satisfação do cliente em relação ao serviço de transporte.

Mesmo com toda dificuldade exposta, não se pode perder o foco no objetivo básico de um processo de avaliação de desempenho para os transportadores rodoviários, que é o de conhecer os processos internos, entender as necessidade dos clientes e identificar os fatoreschave responsáveis pelo desempenho da organização.

Assim, diante da influência do transporte sobre a eficiência das organizações, diversos trabalhos passaram a analisar e desenvolver indicadores para medição do desempenho da prestação do serviço de transporte. A partir dos estudos de Bowersox et al. (2006), Faria e Costa (2008), Neves et al. (2011), Ângelo (2005), Buarque et al. (2003), Freitas et al. (2012), Rodrigues et al. (2011) Alves (2001), Tavares (2014) e do Departamento de Transporte do 
Reino Unido (2003), foram identificados 76 indicadores de desempenho distintos aplicados ao setor de transporte, conforme o Quadro 2.2 a seguir:

Quadro 2.2- Indicadores de Desempenho para o setor de transportes

\begin{tabular}{|c|c|c|c|c|c|c|c|c|c|c|}
\hline Métricas Típicas de desempenho & 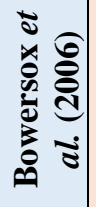 & 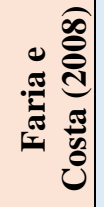 & $\begin{array}{l}\vec{z} \\
\tilde{z} \\
\bar{z} \\
\bar{z} \\
z \\
z \\
\bar{d}\end{array}$ & 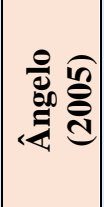 & 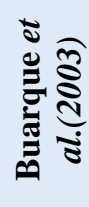 & 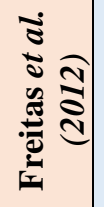 & 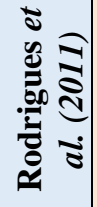 & 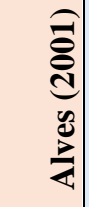 & 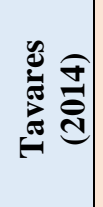 & 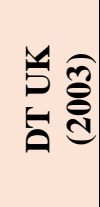 \\
\hline $\begin{array}{l}\text { \% de entregas ou coletas realizadas no } \\
\text { prazo }\end{array}$ & & & $\mathbf{X}$ & & & & $\mathbf{X}$ & & & \\
\hline Acidentes & & & & & & $\mathbf{X}$ & $\mathbf{X}$ & & $\mathbf{X}$ & \\
\hline Acidentes com fatalidades & & & & & & $\mathbf{X}$ & & & $\mathbf{X}$ & \\
\hline Acompanhamento pós-serviço & & & & & & & $\mathbf{X}$ & $\mathbf{X}$ & & \\
\hline Acuracidade de previsão & & $\mathbf{X}$ & & & $\mathbf{X}$ & & & & $\mathbf{X}$ & \\
\hline $\begin{array}{l}\text { Acuracidade na emissão do } \\
\text { conhecimento }\end{array}$ & & & $\mathbf{X}$ & & & & & $\mathbf{X}$ & & \\
\hline Avarias & & $\mathbf{X}$ & $\mathbf{X}$ & & $\mathbf{X}$ & & $\mathbf{X}$ & & & \\
\hline Taxa de Novos Clientes & & & $\mathbf{X}$ & & & & $\mathbf{X}$ & & & \\
\hline Acidentes ambientais & & & & & & & & & & $\mathbf{X}$ \\
\hline $\begin{array}{l}\text { Porcentagem de veículos com tecnologia } \\
\text { embarcada }\end{array}$ & & & & $\mathbf{X}$ & & $\mathbf{X}$ & & & & \\
\hline Gratificações por colaboradores & & $\mathbf{X}$ & & & & & & $\mathbf{X}$ & & \\
\hline Taxa de fidelização de clientes & & & $\mathbf{X}$ & & & & $\mathbf{X}$ & & & \\
\hline Carregamento de inventário & $\mathbf{X}$ & & & & & & & & & \\
\hline Colisões & & & & & & $\mathbf{X}$ & & & & \\
\hline Consumo de combustível (Co2)/km & & & & & & & & & & $\mathbf{X}$ \\
\hline Custo administrativo & $\mathbf{X}$ & & & & $\mathbf{X}$ & & & & & \\
\hline $\begin{array}{l}\text { Custo com não conformidade em } \\
\text { transportes }\end{array}$ & $\mathbf{X}$ & & $\mathbf{X}$ & $\mathbf{X}$ & & $\mathbf{X}$ & $\mathbf{X}$ & $\mathbf{X}$ & & \\
\hline Custo de combustível por km rodado & & & & & & $\mathbf{X}$ & & & $\mathbf{X}$ & \\
\hline Custo de compra & & $\mathbf{X}$ & & & & & & & & \\
\hline Custo de danos & $\mathbf{X}$ & & & & & & & $\mathbf{X}$ & & \\
\hline $\begin{array}{l}\text { Custo de devolução como uma \% das } \\
\text { receitas }\end{array}$ & & & $\mathbf{X}$ & & & & & & & \\
\hline Custo de hora extra & & & & & & $\mathbf{X}$ & & & & \\
\hline Custo de manutenção por km rodado & & & & & & $\mathbf{X}$ & & & $\mathbf{X}$ & \\
\hline Custo de mão de obra direta & $\mathbf{X}$ & & & & & & & $\mathbf{X}$ & & \\
\hline Custo de pneu por km rodado & & & & & & $\mathbf{X}$ & & & $\mathbf{X}$ & \\
\hline Custo de produtos desenvolvidos & $\mathbf{X}$ & & & & $\mathbf{X}$ & & & & & \\
\hline $\begin{array}{l}\text { Custo de transporte como uma } \\
\text { porcentagem das vendas }\end{array}$ & & & $\mathbf{X}$ & & $\mathbf{X}$ & & & $\mathbf{X}$ & & \\
\hline Custo de transporte da distribuição & & $\mathbf{X}$ & & & & & & & & \\
\hline Custo de transporte de coleta & & $\mathbf{X}$ & & & & & & & & \\
\hline Custo total & $\mathbf{X}$ & & & & $\mathbf{X}$ & & & & & \\
\hline Custo total como porcentagem de vendas & $\mathbf{X}$ & & & & $\mathbf{X}$ & & & & & \\
\hline Custo unitário & $\mathbf{X}$ & & & $\mathbf{X}$ & $\mathbf{X}$ & & & $\mathbf{X}$ & & \\
\hline Desempenho na entrega & $\mathbf{X}$ & $\mathbf{X}$ & & & $\mathbf{X}$ & $\mathbf{X}$ & $\mathbf{X}$ & $\mathbf{X}$ & $\mathbf{X}$ & $\mathbf{X}$ \\
\hline Disponibilidade da frota & $\mathbf{X}$ & & & & $\mathbf{X}$ & $\mathbf{X}$ & & $\mathbf{X}$ & $\mathbf{X}$ & \\
\hline Disponibilidade da informação & $\mathbf{X}$ & & & & & & & $\mathbf{X}$ & & \\
\hline
\end{tabular}

Continua 


\begin{tabular}{|c|c|c|c|c|c|c|c|c|c|c|}
\hline Métricas Típicas de desempenho & 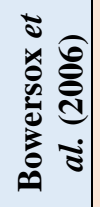 & 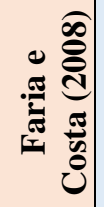 & 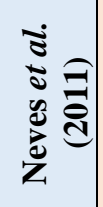 & 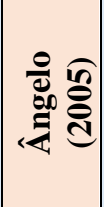 & 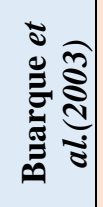 & 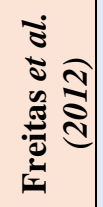 & 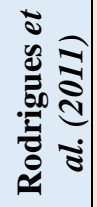 & 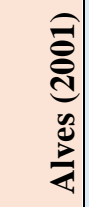 & 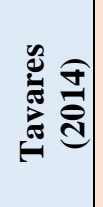 & 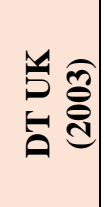 \\
\hline Eficiência na cobrança de duplicatas & & & & & $\mathbf{X}$ & & & & & \\
\hline Erro na expedição & $\mathbf{X}$ & & & & & & & & & \\
\hline Frequência de danos & $\mathbf{X}$ & & & & & & & & & \\
\hline Frete de expedição & $\mathbf{X}$ & & & & & & & & & \\
\hline Frete de recebimento & $\mathbf{X}$ & & & & & & & & & \\
\hline Horas de treinamento & & & & & $\mathbf{X}$ & & $\mathbf{X}$ & & $\mathbf{X}$ & \\
\hline Idade média dos veículos & & & & & $\mathbf{X}$ & & & & $\mathbf{X}$ & \\
\hline Índice de atendimento do pedido & $\mathbf{X}$ & & $\mathbf{X}$ & & & & & & & \\
\hline Índice de inadimplência & & & & & $\mathbf{X}$ & & & & & \\
\hline Índice de produtividade & $\mathbf{X}$ & & & & $\mathbf{X}$ & $\mathbf{X}$ & & $\mathbf{X}$ & & $\mathbf{X}$ \\
\hline Liquidez corrente & & & & & $\mathbf{X}$ & & & & & \\
\hline Lucro residual & & & & & $\mathbf{X}$ & & & & & \\
\hline Margem de contribuição & $\mathbf{X}$ & & & & $\mathbf{X}$ & & & & & \\
\hline Multas por motoristas & & & & & & & & & $\mathbf{X}$ & \\
\hline Nível global de satisfação dos clientes & $\mathbf{X}$ & & & & $\mathbf{X}$ & & & & $\mathbf{X}$ & \\
\hline Número de devoluções & $\mathbf{X}$ & & & & $\mathbf{X}$ & & & & & \\
\hline $\begin{array}{l}\text { Número de pedidos não atendidos no } \\
\text { prazo }\end{array}$ & $\mathbf{X}$ & & & & $\mathbf{X}$ & & & & & \\
\hline Número de reclamações & $\mathbf{X}$ & $\mathbf{X}$ & & & $\mathbf{X}$ & & & $\mathbf{X}$ & & \\
\hline Número de viagens vazias & & & & & & & & & & $\mathbf{X}$ \\
\hline Participação no mercado & & & & & $\mathbf{X}$ & & & & & \\
\hline Pedido perfeito & $\mathbf{X}$ & $\mathbf{X}$ & $\mathbf{X}$ & & & $\mathbf{X}$ & $\mathbf{X}$ & $\mathbf{X}$ & $\mathbf{X}$ & \\
\hline $\begin{array}{l}\text { Percentual da receita bruta aplicada em } \\
\text { treinamento }\end{array}$ & & & & & $\mathbf{X}$ & & & & & \\
\hline Precisão da entrada de novos pedidos & $\mathbf{X}$ & $\mathbf{X}$ & & & $\mathbf{X}$ & & $\mathbf{X}$ & & & \\
\hline Processamento dos pedidos no depósito & $\mathbf{X}$ & & & & & & $\mathbf{X}$ & & & \\
\hline Qualidade no local de trabalho & & & & & $\mathbf{X}$ & & & & & \\
\hline Realizado vs. Orçado & $\mathbf{X}$ & & & & & & & & & \\
\hline Retorno ou devoluções & & $\mathbf{X}$ & & & $\mathbf{X}$ & & & & & \\
\hline Retorno sobre ativos líquidos & $\mathbf{X}$ & & & & & & & & & \\
\hline Retorno sobre os investimentos & $\mathbf{X}$ & & & & $\mathbf{X}$ & & & $\mathbf{X}$ & & \\
\hline Rotatividade dos funcionários & & & & & $\mathbf{X}$ & & & & & \\
\hline Roubo de cargas & & & & & & & $\mathbf{X}$ & & & \\
\hline Satisfação dos empregados & & & & & $\mathbf{X}$ & & & & $\mathbf{X}$ & \\
\hline Taxa de absenteísmo & & & & & $\mathbf{X}$ & & & & & \\
\hline Tempo de ciclo da logística reversa & & & $\mathbf{X}$ & & & & & & & \\
\hline Tempo de ciclo do pedido & & $\mathbf{X}$ & $\mathbf{X}$ & & $\mathbf{X}$ & & & $\mathbf{X}$ & & \\
\hline Tempo de resposta às solicitações & $\mathbf{X}$ & & & & $\mathbf{X}$ & & & $\mathbf{X}$ & & \\
\hline Tempo médio de carga e descarga & & & & $\mathbf{X}$ & & & & & & \\
\hline $\begin{array}{l}\text { Ultrapassagem do tempo máximo de } \\
\text { viagem }\end{array}$ & & & & & & & & & $\mathbf{X}$ & \\
\hline $\begin{array}{l}\text { Utilização da capacidade de carga do } \\
\text { caminhão }\end{array}$ & & $\mathbf{X}$ & $\mathbf{X}$ & & $\mathbf{X}$ & & & $\mathbf{X}$ & & $\mathbf{X}$ \\
\hline Volume de bonificação & & & & & & & & & $\mathbf{X}$ & \\
\hline Volume total de embarques/Tempo & & & & & & & & & $\mathbf{X}$ & \\
\hline
\end{tabular}




\subsection{O MODELO DE KAPLAN E NORTON}

\subsubsection{ORIGEM DO BALANCED SCORECARD}

A década de 90 foi marcada por um intenso desenvolvimento do assunto, medição de desempenho, em especial nos Estados Unidos (KINGESKI, 2010). Havia tanto no ambiente acadêmico como no ambiente empresarial a percepção de que os métodos existentes de medição de desempenho das organizações, baseados apenas em indicadores contábeis e financeiros estavam se tornando obsoletos e prejudicando a capacidade das empresas de criar valor econômico para o futuro (REIS, 2001).

Tais medidas financeiras, portanto, tornaram-se inadequadas para orientar e avaliar a trajetória da empresa na era da informação (KAPLAN e NORTON, 1997). Nesse contexto, diversos estudos foram desenvolvidos com o intuito de estabelecer novos sistemas de indicadores de desempenho capazes de proporcionar diferencial competitivo para as empresas e geração de valor futuro. Esse período ficou conhecido como "A Revolução da Medição" (NEELY, 1998), ou "Manifesto do Desempenho" (ECCLES, 2000). Extenso levantamento bibliográfico realizado por Martins (1999) identificou mais de 20 modelos para a medição de desempenho desenvolvidos ao longo da década de 80 e 90.

Merece destaque o desenvolvimento do sistema de medição de desempenho Balanced Scorecard, que traduzido "ao pé da letra", significa "cartão de marcação equilibrado". O Balanced Scorecard nasceu de um grupo de estudos intitulado "Measuring Performance in the Organization of the Future", formado em 1990 e liderado por David Norton e Robert Kaplan, sendo que a primeira publicação aconteceu no periódico Harvard Business Review em 1992.

Participaram do estudo representantes de dezenas de empresas, que acreditando não ser possível mais depender de medidas de desempenho consolidadas, baseadas em dados financeiros, se reuniram a cada dois meses, com o objetivo de desenvolver um novo modelo de medição de desempenho das organizações (KAPLAN E NORTON, 1997).

Algumas organizações já vinham utilizando sistemas inovadores de mensuração de desempenho. Um deles, a Analog, estava utilizando um scorecard que continha, além de medidas financeiras tradicionais, outras medidas de desempenho relativas a prazos de entrega, 
qualidade, ciclos de produção e, ainda, eficácia no desenvolvimento de novos produtos (KAPLAN E NORTON, 1997).

Destas experiências, os participantes concluíram que os sistemas de medição de desempenho somente seriam capazes de refletir a realidade da organização, caso conseguissem traduzir as diversas perspectivas e objetivos da empresa.

Dessa forma, considerando ser a ferramenta mais promissora e completa para auxiliar a gestão da empresa, o grupo focou no desenvolvimento de um sistema de medição de desempenho multidimensional e equilibrado. O resultado das discussões levou a uma ampliação e melhoria do scorecard utilizado pela Analog, o qual se transformou no que conhecemos como Balanced Scorecard (KARDEC et al., 2002).

\subsubsection{O BALANCED SCORECARD}

Os primeiros conceitos deste novo modelo foram sintetizados num artigo publicado em 1992 na Havard Business Review (HBR) intitulado "The Balanced Scorecard - Measures That Drive Performance ". Segundo Kaplan e Norton (1992), a construção do modelo baseou-se na percepção de que uma única medida não seria capaz de proporcionar uma visão geral do negócio. Após uma série de discussões entre criar um sistema de medição baseado exclusivamente em novos indicadores financeiros ou exclusivamente em indicadores operacionais, entendeu-se que os gestores desejavam um sistema balanceado que apresentasse tanto indicadores operacionais quanto financeiros.

O Balanced Scorecard é um sistema de medição de desempenho, que avalia o desempenho organizacional a partir de quatro perspectivas distintas - financeira, do cliente, interna e de inovação e aprendizado, integrando-as numa relação de causa e efeito (KAPLAN E NORTON, 1997). O Balanced Scorecard preserva as medidas financeiras tradicionais, relacionada com o desempenho passado, e as complementam com medidas não financeiras, as quais são vetores que impulsionam o desempenho futuro.

O nome adotado procurava refletir o equilíbrio (balance) entre objetivos de curto e longo prazos, entre medidas financeiras e não financeiras, entre indicadores de tendências (leading) 
e ocorrências (lagging) e entre as perspectivas interna e externa de desempenho (KAPLAN E NORTON, 1997), conforme Figura 2.2.

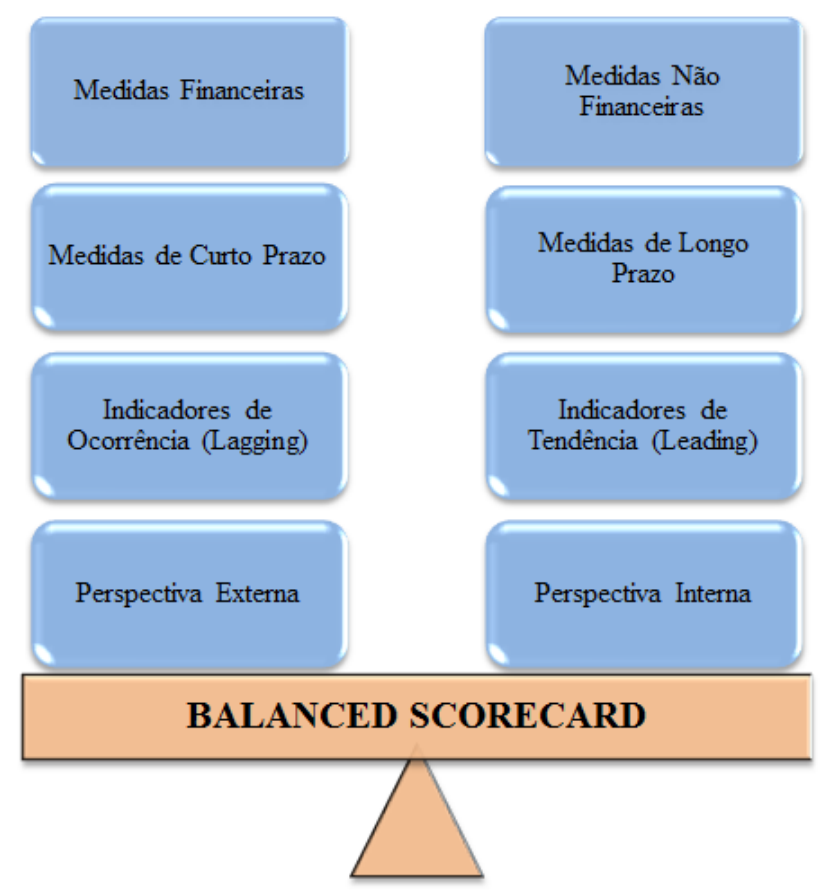

Figura 2.2 - Perspectivas do Balanced Scorecard

Segundo Kaplan e Norton (2004), o Balanced Scorecard (BSC) é um conjunto de indicadores que proporciona aos gerentes uma visão rápida de toda a empresa. Este modelo reconhece a necessidade de satisfazer os objetivos de múltiplos stakeholders, isto é, os investidores, os clientes e os colaboradores (BROWN e MCDONNELL, 1995) e por isso combina indicadores financeiros e não financeiros.

O objetivo inicial do desenvolvimento do Balanced Scorecard foi criar um sistema de indicadores com medidas complementares às tradicionais de medição do desempenho financeiro. Entretanto ao longo de sua aplicação, os gestores e pesquisadores perceberam que a ferramenta tinha um potencial maior do que apenas mensuração. Schmidt et al. (2006) indica que o Balanced Scorecard permitia aos executivos traduzir com maior facilidade os objetivos estratégicos da empresa em um conjunto coerente de medidas de desempenho, inseridas nas quatro perspectivas.

Desta forma, o Balanced Scorecard passa de uma ferramenta que relatava desempenho do passado, para um modelo de apoio capaz de comunicar a visão e os objetivos organizacionais, 
com foco centralizado na implementação da estratégia (FERREIRA, 2012). Empresas inovadoras estão utilizando o scorecard como sistema de gestão para administrar a estratégia a longo prazo. Elas adotaram a filosofia do scorecard para viabilizar processos gerenciais críticos:

1. esclarecer e traduzir a visão e a estratégia.

2. comunicar e associar objetivos e medidas estratégicas.

3. planejar e estabelecer metas e alinhar iniciativas estratégicas.

4. melhorar o feedback e o aprendizado estratégico.

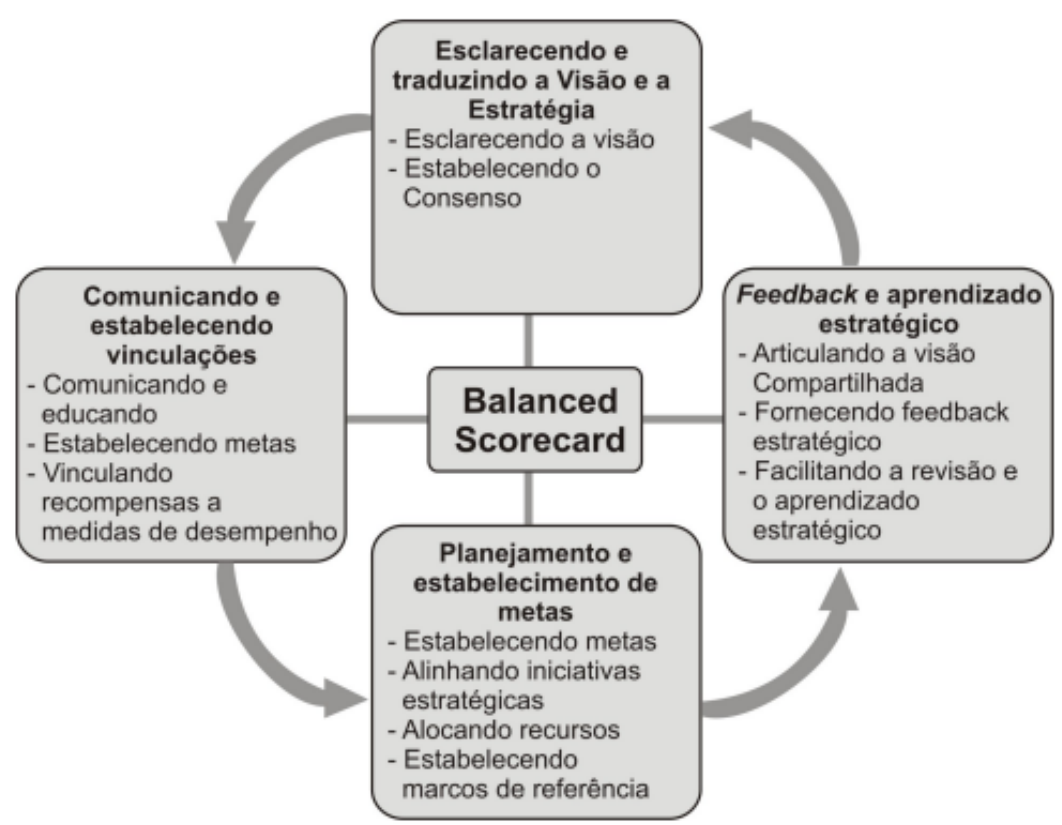

Figura 2.3 - O Balanced Scorecard e os processos gerenciais críticos Fonte: Kaplan e Norton (1997)

Lima (2008) ratifica a ideia que desde o surgimento, o Balanced Scorecard passou por diversas alterações e estabelece que a evolução da ferramenta pode ser dividida em 3 gerações: na primeira fase, período correspondente à primeira metade dos anos 1990, a ferramenta concentrou-se na mensuração do desempenho; na segunda fase, que ocorreu a partir de 1996, o modelo passa a ser considerado um sistema de gestão estratégica; e na última fase, a partir de 2000, o scorecard assume papel central nas organizações orientadas para estratégia. 


\subsubsection{PERSPECTIVAS DO BALANCED SCORECARD}

O Balanced Scorecard deve contar a história da unidade de negócios, isto é, descrever a visão e a estratégia da empresa por meio de uma sequência de relações de causa e efeito. A construção do scorecard traduz a estratégia da empresa em um modelo holístico, capaz de comunicar a todos os funcionários os objetivos estratégicos do negócio, para que estes possam contribuir com o sucesso organizacional (ARANTES, 2006).

Todas as medidas das perspectivas do Balanced Scorecard derivam da visão e estratégia estabelecida pela empresa. Portanto, a visão e a estratégia constituem os temas centrais do modelo e estão integradas numa relação de causa e efeito, essenciais para o sucesso estratégico (LIMA, 2008; HERNANDES et al., 2000).

Assim, o sistema de mensuração procura comunicar a estratégia de forma lógica, baseada nas relações (hipóteses) entre os objetivos (as medidas) nas diversas perspectivas, por meio de mapas estratégicos. Deve ser decomposto em objetivos, indicadores, metas e iniciativas em quatro dimensões de negócio que representam as principais variáveis e estruturam o Balanced Scorecard (ARANTES, 2006) (BERTON, 2003), conforme a Figura 2.4 a seguir:
1. financeira
2. clientes
3. processos internos
4. aprendizado e crescimento

Tais perspectivas procuram responder a quatro perguntas (Kaplan e Norton, 1996):

- para ter sucesso financeiro, como devemos nos mostrar aos nossos acionistas?

- para atingir nossa visão, como devemos nos mostrar para nossos clientes?

- para satisfazer nossos acionistas e clientes, em quais processos devemos ser excelentes?

- para atingir nossa visão, como manteremos nossa habilidade de mudar e melhorar? 


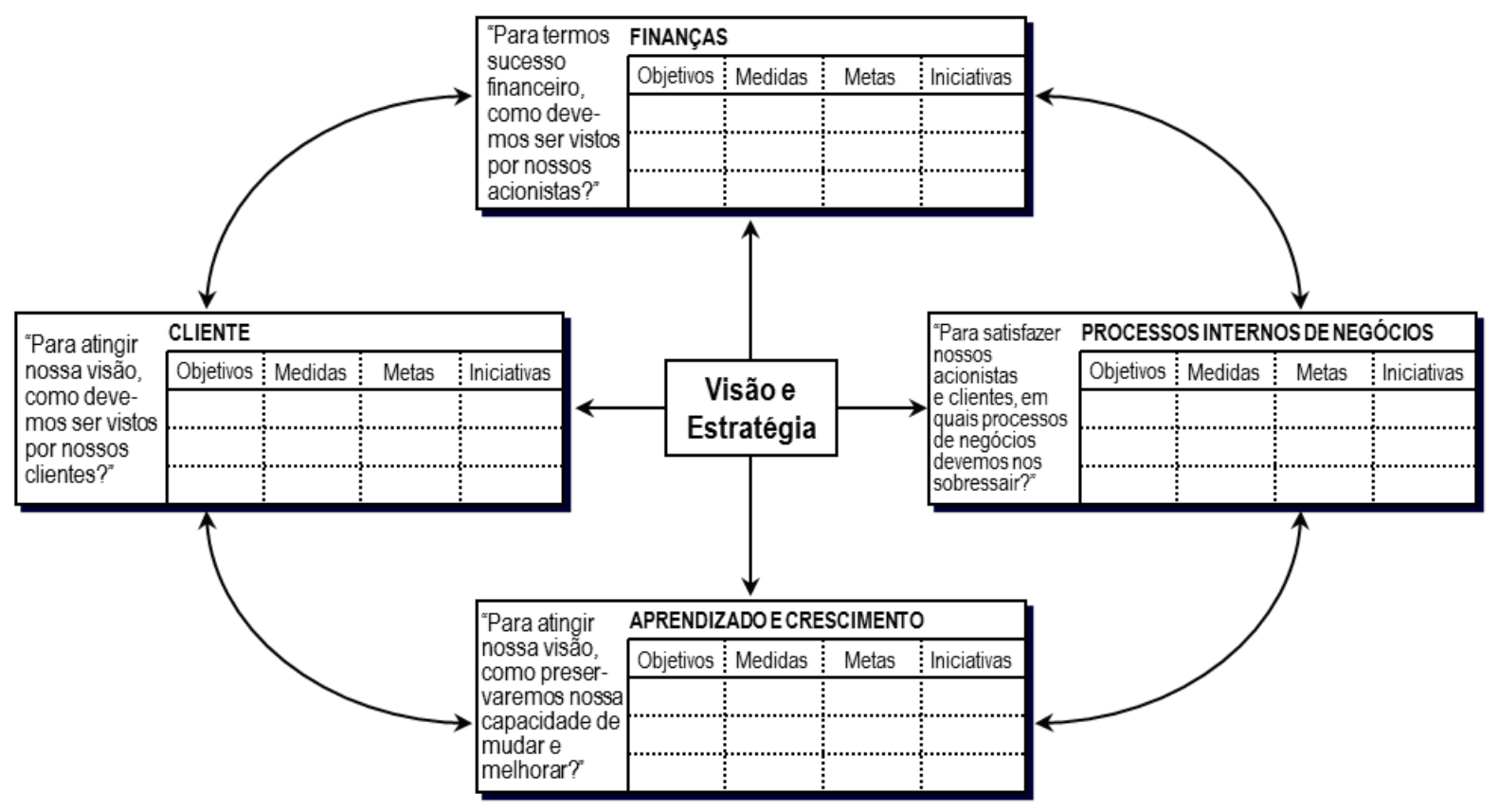

Figura 2.4 - Perspectivas do Balanced Scorecard

Fonte: Kaplan e Norton (1996)

Deve-se considerar que estas quatro perspectivas tem-se revelado adequadas a vários tipos de empresas e mercados, mas conforme Kaplan e Norton (1997) não devem ser vistas como uma camisa de força, pois se trata de um modelo, dependendo das circunstâncias do setor e da estratégia da unidade de negócio, talvez seja necessário agregar uma nova perspectiva.

\subsubsection{PERSPECTIVA FINANCEIRA}

A perspectiva financeira é tradicional em qualquer sistema gerencial (SILVA, 2002), inclusive no Balanced Scorecard. Elas são essenciais, pois estabelecem a intenção da empresa, quando definido os objetivos financeiros de longo prazo e permitem constatar se a estratégia e ações implementadas estão conduzindo aos resultados desejados.

Porter (2000) explicita que o retorno sobre o investimento no longo prazo é o ponto de partida para se chegar a uma boa estratégia. O objetivo principal de qualquer empresa é a geração de lucro (GOLDRATT e FOX, 2002). As medidas financeiras demonstram se a estratégia da organização e a sua implementação estão contribuindo para melhores resultados (CAMPOS, 1998). 
Os objetivos financeiros têm uma importância de vinculação com os demais, em função da necessidade que as empresas possuem de tornar rentáveis financeiramente suas operações, visto a escassez de recursos e a exigência dos acionistas por lucro empresarial (ROCHA, 2002). Portanto, as medidas financeiras servem como foco para o desenvolvimento das medidas das demais perspectivas (KAPLAN E NORTON, 1997). Ao selecionar uma medida é importante verificar se ela faz parte de uma relação de causa e efeito que tem como objetivo final a melhoria do desempenho financeiro (REIS, 2001).

Dessa forma, o scorecard deve contar a história da estratégia, começando pelos objetivos financeiros de longo prazo e relacionando-os com o conjunto de iniciativas que devem ser planejadas em relação aos clientes, processos internos, funcionários e sistemas para alcançar o desempenho financeiro planejado (KAPLAN E NORTON. 1997).

A perspectiva financeira, além de ser a primeira a ser definida, exerce um duplo papel, pois define o desempenho financeiro esperado da estratégia e também vai ser a base para os objetivos e metas das demais perspectivas (RECH, 2002).

A maioria das organizações que estão construindo o Balanced Scorecard adotam como temas financeiros o aumento da receita, a melhoria de custos e produtividade, o incremento na utilização de ativos e redução dos riscos, os quais servem de base para integrar as quatro perspectivas do scorecard (HERNANDES et al., 2000; KAPLAN E NORTON, 1997). Entretanto, os objetivos financeiros e, portanto, a escolha dos indicadores financeiros pode diferir, razoavelmente, em cada fase do ciclo de vida da empresa (OLVE et al., 2001).

De forma simplificada, Kaplan e Norton (1997) identificaram três fases pelas quais todas as empresas atravessam:

- crescimento - As empresas nesta fase, geralmente, encontram-se no início de seus ciclos de vida e têm um portfólio de produtos e serviços com elevado potencial de crescimento, mas que ainda não estão consolidados no mercado. Por este motivo, normalmente, devem realizar pesados investimentos com o intuito de aproveitar toda a potencialidade do produto, ou seja, devem investir em desenvolvimento e aprimoramento de novos produtos e serviços, construção e ampliação das instalações, sistemas e infraestrutura, rede de distribuição e relacionamento com os 
clientes. As empresas podem operar nesta fase com fluxos de caixa negativos e baixas taxas de retorno sobre capital investido, visto a necessidade de elevados investimentos. Os objetivos financeiros globais na fase de crescimento serão os percentuais de crescimento da receita e de aumento de vendas para determinados mercados, grupos de clientes e regiões.

- sustentação - Provavelmente a maior parte das empresas está nesta fase, em que ainda são necessários investimentos e reinvestimentos, porém os mesmos necessitam ter taxas de retorno excelentes. Deseja-se que as empresas mantenham a participação no mercado e consigam aumentá-la um pouco a cada ano. Os investimentos são direcionados para o aumento da capacidade e busca de melhoria contínua, em lugar dos investimentos de longo prazo. Os objetivos financeiros globais nesta fase estão associados à lucratividade. As medidas utilizadas normalmente para avaliar o desempenho destas organizações são receita contábil gerada com o nível de capital investido na unidade, retorno sobre o investimento, retorno sobre o capital empregado e valor econômico agregado.

- colheita - Corresponde a fase de maturidade do ciclo de vida, em que as organizações desejam colher os investimentos realizados. Assim, os investimentos não são mais justificados, apenas de forma incremental para manutenção de equipamentos, instalações e capacidades. Os projetos devem ter retornos rápidos e bem definidos. O objetivo principal é maximizar o fluxo de caixa e reduzir o capital de giro.

Evidencia-se, portanto, que cada uma das fases do ciclo de vida da empresa apresenta objetivos financeiros distintos. Assim, é fundamental que no início do desenvolvimento do Balanced Scorecard haja um intenso diálogo entre os gestores da organização para identificar em que fase se encontra a empresa e, dessa forma, estabelecer os objetivos e indicadores financeiros adequados (HERNANDES et al., 2000) (KAPLAN E NORTON, 1997), levando em consideração os temas estratégicos.

De acordo com Kaplan e Norton (1997), é possível identificar, em todas as fases do ciclo de vida da empresa, três temas financeiros que norteiam a estratégia empresarial:

- crescimento e mix de receita - Está relacionado à ampliação da oferta de produtos e serviços, conquista de novos clientes e mercados, mudança no mix 
ofertado para itens de maior valor agregado e modificação nos preços de produtos e serviços.

- redução de custos/ melhoria de produtividade - Refere-se às iniciativas no sentido de baixar os custos diretos de produtos e serviços, reduzir os custos indiretos e compartilhar recursos.

- utilização dos ativos/ estratégia de investimento - Refere-se às iniciativas para redução do capital de giro necessários para sustentar um determinado volume e mix de negócios, como também as iniciativas para melhor utilizar a base de ativo fixo, evitando a ociosidade de sua capacidade e portanto melhorando o retorno sobre os ativos físicos.

Conforme destaca Reis (2001) e Kaplan e Norton (1997), para cada fase e tema estratégico é possível sugerir indicadores financeiros comuns para as nove possibilidades, conforme Quadro 2.3 a seguir:

Quadro 2.3- Ciclo de vida vs. Temas financeiros

\begin{tabular}{|l|l|l|l|}
\hline & \multicolumn{3}{|c|}{ TEMAS ESTRATÉGICOS } \\
\hline Fases & Aumento e Mix de Receitas & $\begin{array}{l}\text { Redução de Custos/ } \\
\text { Aumento de Produtividade }\end{array}$ & Utilização dos Ativos \\
\hline Crescimento & $\begin{array}{l}\text { - aumento da taxa de vendas por } \\
\text { segmento } \\
\text {-percentual de receita gerado por } \\
\text { novos produtos, serviços e } \\
\text { clientes }\end{array}$ & -receita/funcionário & $\begin{array}{l}\text { - investimento (percentual } \\
\text { de vendas) }\end{array}$ \\
\hline Sustentação & $\begin{array}{l}\text { - fatia de clientes e contas-alvo } \\
\text { - vendas cruzadas }\end{array}$ & $\begin{array}{l}\text {-custos x custos dos } \\
\text { concorrentes }\end{array}$ & $\begin{array}{l}\text { - Pendas) (percentual de } \\
\text { viro (ciclo de caixa a }\end{array}$ \\
& $\begin{array}{l}\text { - percentual de receita gerada por } \\
\text { novas aplicações } \\
\text { caixa) }\end{array}$ \\
& $\begin{array}{l}\text {-lucratividade por clientes e linhas } \\
\text { de produtos }\end{array}$ & $\begin{array}{l}\text {-taxas de redução de custos } \\
\text {-despesas indiretas } \\
\text { (percentual de vendas) }\end{array}$ & $\begin{array}{l}\text { - ROCE por categoria- } \\
\text { chave de ativo }\end{array}$ \\
\hline Colheita & $\begin{array}{l}\text {-lucratividade por clientes e linhas } \\
\text {-percentual de clientes não- } \\
\text { lucrativos }\end{array}$ & $\begin{array}{l}\text { - custos unitários (por } \\
\text { unidade de produção, por } \\
\text { transação) }\end{array}$ & $\begin{array}{l}\text { - Taxas de utilização dos } \\
\text { ativos }\end{array}$ \\
\hline
\end{tabular}

Fonte: Kaplan e Norton (1997) 


\subsubsection{PERSPECTIVA DOS CLIENTES}

Até recentemente, as empresas se concentravam apenas em suas capacidades internas, enfatizando o desempenho de produtos e inovação tecnológica. Preocupavam-se em fazer um produto de alta qualidade, mas não verificavam se este produto iria atender às necessidades de seus clientes (REIS, 2001).

Entretanto as empresas que não compreendiam as reais expectativas de seus clientes passaram a perder mercado. Assim, tornou-se fundamental que as empresas monitorassem seus processos internos de modo a entregar real valor ao cliente correto.

Nesse cenário, muitas empresas estabeleceram como um dos seus objetivos principais atender as necessidades dos clientes (MARCHETTI E PRADO, 2001). Conforme exemplificou Kaplan e Norton (1997), as declarações de missão e visão afirmam rotineiramente a meta de ser "o principal fornecedor de nossos clientes". Conclui-se, assim, que a satisfação e retenção do cliente e o foco no mercado são as forças que impulsionam as organizações que desejam sobreviver e progredir em longo prazo (CAMPOS, 1998).

O propósito da perspectiva do cliente é identificar os melhores segmentos de clientes e mercados nos quais a empresa deseja competir (HERNANDES et al., 2000). Esses segmentos representarão os rendimentos, isto é, as fontes de receita que permitirão a empresa atingir os objetivos financeiros (MORONI, 2003).

A perspectiva dos clientes também permite que as empresas alinhem suas medidas essenciais de resultado relacionadas aos clientes com segmentos específicos, assim como, auxilia a empresa a identificar e avaliar as propostas de valor dirigidas a estes segmentos (KALLAS, 2003).

Portanto, além de aspirarem satisfazer e encantar os clientes, os executivos das unidades de negócios devem, na perspectiva dos clientes, traduzir suas declarações de missão e estratégia em objetivos específicos baseados no mercado e nos clientes selecionados (KAPLAN E NORTON, 1997). 
Em seus estudos, Kaplan e Norton (1997) identificaram que as empresas normalmente selecionam dois conjuntos de medidas para a perspectiva dos clientes. A primeira corresponde ao conjunto de medidas essenciais, as quais são praticamente utilizadas por todas as empresas, sendo elas:

- participação de mercado - Reflete a proporção de negócios num determinado mercado (em termos de clientes, valores gastos ou volume unitário vendido)

- captação de clientes - Mede em termos absolutos ou relativos, a intensidade com que uma unidade de negócio atrai ou conquista novos clientes ou negócios.

- retenção de clientes - Controla em termos absolutos ou relativos a intensidade com que uma unidade de negócio retém ou mantém relacionamentos contínuos com seus clientes. Esta medida é fundamental, pois conforme afirma Souki (2006) o custo de manter um cliente atual é cinco vezes mais barato do que conquistar um novo cliente.

- satisfação do cliente - Mede o nível de satisfação dos clientes de acordo com critérios específicos de desempenho dentro da proposta de valor. De acordo com Kotler (2002), somente clientes que tiverem suas expectativas ultrapassadas é que se tornarão clientes fiéis.

- lucratividade dos clientes - Mede o lucro líquido de clientes e segmentos, depois de deduzidas as despesas específicas necessárias para sustentar estes clientes. As empresas necessitam de algo mais do que clientes felizes e satisfeitos, é necessário que os mesmos sejam lucrativos. Nem todas as exigências do cliente podem ser atendidas com a manutenção da lucratividade. Assim a empresa precisa identificar aqueles clientes, dentro do público alvo, que não são lucrativos, de modo que possa agir para torná-los lucrativos ou mesmo eliminá-los.

Apesar de genéricas, as medidas devem ser customizadas para grupos específicos de clientes com os quais a unidade de negócios espera obter seu maior crescimento e lucratividade (ARANTES, 2006).

Kaplan e Norton (1997), agrupam estas medidas em uma cadeia formal de causa e efeito, conforme Figura 2.5 a seguir: 


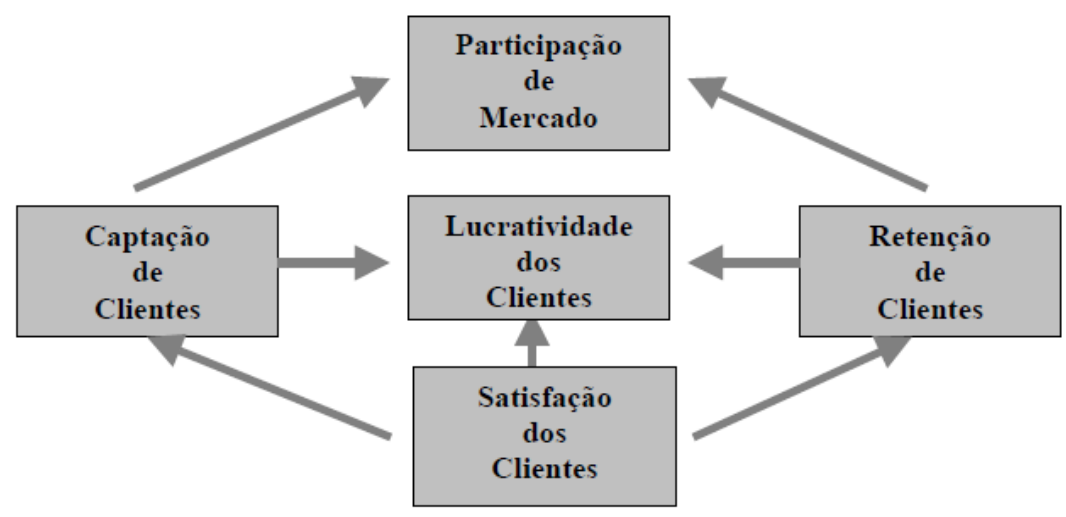

Figura 2.5 - Medidas Essenciais da perspectiva do Cliente Fonte: Kaplan e Norton (1996)

O segundo conjunto de medidas contém os vetores de desempenho (os diferenciadores) dos resultados fornecidos aos clientes. Eles respondem a pergunta: "O que uma empresa deve oferecer aos seus clientes para alcançar altos níveis de satisfação, retenção e, consequente, participação no mercado?". Assim, as medidas dos vetores de desempenho estão associadas às propostas de valor que a empresa irá fornecer aos seus segmentos específicos. (KAPLAN E NORTON, 1997).

As propostas de valor se referem a um conjunto de atributos dos produtos ou serviços capazes de atender ou superar as expectativas dos clientes e, assim, resultar em bons indicadores nas medidas essenciais (HERNANDES et al., 2000).

Embora as propostas de valor variem de acordo com o setor de atividade e os diferentes segmentos de mercado, Kaplan e Norton (1997) observam a existência de um conjunto comum de atributos que permite sua ordenação em todos os setores para os quais os scorecards são elaborados:

- Atributos dos produtos e serviços - Abrange a funcionalidade do produto/serviço, seu preço e qualidade.

- Relacionamento com os clientes - Refere-se à entrega do produto/serviço ao cliente, inclusive a dimensão do tempo de resposta da entrega e o conforto do cliente na relação de compra.

- Imagem e reputação - Reflete os valores intangíveis que atraem um cliente para a empresa. 
Dessa forma, a proposta de valor pode ser resumida, de forma genérica, conforme Figura 2.6 a seguir:

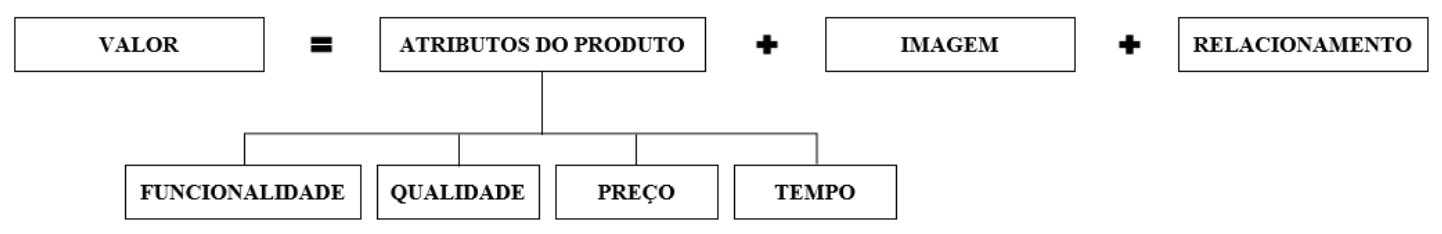

Figura 2.6 - Proposta de Valor

Fonte: Kaplan e Norton (1997)

Assim, a correta percepção da perspectiva do cliente e dos atributos da proposta de valor permite o direcionamento dos processos internos e esforços de desenvolvimento da organização (ARANTES, 2006).

\subsubsection{PERSPECTIVA DOS PROCESSOS INTERNOS}

Nesta perspectiva, a empresa é capaz de identificar aqueles processos internos críticos nos quais deve alcançar a excelência, de modo a atender os objetivos dos clientes e acionistas (RISCIFINA, 2015). Em outras palavras, para a organização atingir os resultados desejados nas perspectivas do cliente e financeira, ela se vale da perspectiva dos processos internos (LIMA, 2008).

Com o objetivo de oferecer produtos de valor aos clientes, capazes de atraí-los e retê-los e, ao mesmo tempo, ser capaz de criar valor para os acionistas, a empresa deve direcionar seus esforços para gestão e melhoria daqueles processos considerados críticos (PIETRO et al., 2006).

Por se tratar de uma perspectiva que suporta as demais, as empresas costumam desenvolver objetivos e medidas para os processos internos depois de formular objetivos e medidas para as perspectivas financeira e do cliente (KAPLAN E NORTON, 1997).

Para desenvolver esta perspectiva, os autores Kaplan e Norton (1997) recomendam que a empresa defina uma cadeia de valor completa dos processos internos que tenha início com o processo de inovação (identificação das necessidades atuais e futuras dos clientes e desenvolvimento de novas soluções para estas necessidades), prossiga com os processos de 
operação (entrega dos produtos e prestação dos serviços aos clientes existentes) e termine com o serviço pós venda (oferta de serviço pós-venda que complementem o valor proporcionado aos clientes pelos produtos ou serviços de uma empresa).

O conceito de cadeia de valor foi definido por SHANK e GOVINDARAJAN (1997) como um conjunto interligado de todas as atividades criadoras de valor desde as fontes de matériasprimas básicas, passando por fornecedores de componentes até o produto final entregue nas mãos do consumidor. Para Womack \& Jones (1998), só o cliente final pode definir o valor, motivo pelo qual é fundamental entender as necessidades do cliente para que se possa selecionar corretamente os processos críticos.

Essa perspectiva revela duas diferenças fundamentais entre a abordagem tradicional e a do Balanced Scorecard: os sistemas de medição de desempenho tradicionais tentam monitorar e melhorar os processos já existentes e são mais limitados, pois dependem exclusivamente de medidas financeiras. Já a abordagem do scorecard, pode resultar na identificação de processos inteiramente novos nos quais uma empresa deve atingir a excelência para alcançar os objetivos financeiros e dos clientes. (REIS, 2001).

A segunda diferença da abordagem do Balanced Scorecard é a incorporação de processos de inovação à perspectiva de processos internos, ao contrário dos processos tradicionais de medição de desempenho, os quais focalizam os processos de entrega de produtos e serviços atuais aos clientes. Isto é, procuram mensurar e controlar os processos operacionais rotineiros, o que representa a onda curta de criação de valor. (RISCIFINA, 2015).

Entretanto, Kaplan e Norton (1997) identificaram que para as empresas atingirem desempenho financeiros de longo prazo é fundamental integrar o processo de inovação a perspectiva dos processos internos. O processo de inovação é considerado a onda longa de criação de valor, em que as empresas identificam e cultivam novos mercados, novos clientes e as necessidades latentes dos clientes atuais.

Existem, literalmente, centenas de processo acontecendo simultaneamente dentro de uma organização, cada um criando valor de alguma forma. No entanto, poucos são os processos críticos que geram valor para o cliente. (LIMA, 2010). Conforme afirma Werkema (2012), as 
etapas que agregam valor representam, tipicamente, menos de $10 \%$ do tempo gasto com as demais atividades.

De acordo com a sua realidade e o mercado em que atual, cada empresa apresenta um conjunto específico de processos a fim de criar valor para os clientes e produzir resultados financeiros. Kaplan e Norton (1997) conseguiram determinar uma cadeia de valor genérica, a qual serve de modelo para as empresas. Esse modelo é composto de três processos principais, conforme Figura 2.7:

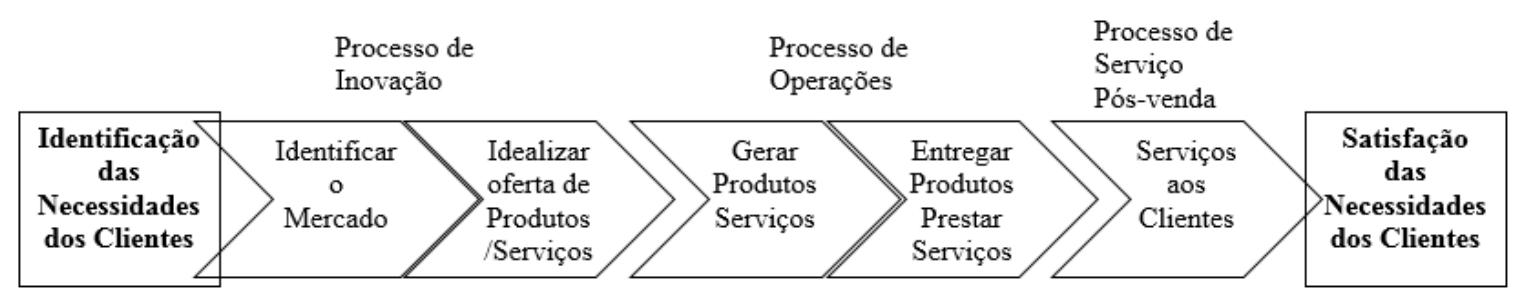

Figura 2.7 - Cadeia de valor genérica

Fonte: Kaplan e Norton (1997)

- processo de inovação - Para muitas empresas, eficácia, eficiência e oportunidade em processos de inovação constituem fatores mais importantes do que excelência em processos operacionais rotineiros (KAPLAN E NORTON 1997).

O processo de inovação pode ser radical, quando se trata do desenvolvimento e introdução de um novo produto, processo ou forma de organização da produção inteiramente nova ou incremental, quando se tratar de qualquer tipo de melhoria em um produto, processo ou organização da produção dentro de uma empresa, sem alteração na estrutura industrial (FREEMAN, 1988).

Em qualquer uma dessas situações, o processo de inovação é formado por dois componentes. O primeiro é a pesquisa de mercado, na qual se identifica o tamanho potencial, as preferências dos clientes e os preços que estão dispostos a pagar. Nesse sentido, Prahalad e Hamel (2005) afirmam que a função da empresa no processo de inovação não é satisfazer ou encantar os clientes, mas os surpreender.

O segundo componente são os processos de projeto e desenvolvimento de produtos / serviços, os quais utilizam as informações sobre mercados e clientes para subsidiar suas atividades. (KAPLAN E NORTON, 1997) 
- processo de Operação - Os processos de operação englobam todas as atividades do fluxo logístico "Supply Chain", desde o recebimento do pedido de um cliente até a entrega do produto final (FLEURY E FLEURY, 2003). O foco deste processo está na entrega eficaz, regular e pontual dos bens e serviços existentes aos atuais clientes. (VACCARI,2006).

As atividades operacionais, por serem repetitivas, permitem que técnicas de administração científica sejam diretamente aplicadas para controlar e melhorar o recebimento e o processamento dos pedidos do cliente e os processos de produção e entrega (KAPLAN E NORTON, 1997).

Tradicionalmente, esses processos eram monitorados e controlados por medidas financeiras, como custo-padrão. Entretanto, com a influência recente da gestão da qualidade total e das práticas baseada no tempo pela indústria japonesa, as empresas comtemplaram suas medidas tradicionais de custo e finanças com medidas de qualidade e tempo de ciclo (KAPLAN E NORTON, 1997).

De forma geral, ao controlar e monitorar as operações, o objetivo é dotar a empresa com níveis de desempenho mundial. Isto é, auxiliar a organização a atingir indicadores internacionais de preço e qualidade, através da racionalização do sistema de produção, com programas de produtividade e qualidade de inspiração japonesa e adoção de processos participativos, principalmente nos setores operacionais da organização (PORTER, 1986).

- processo de Serviço Pós-Venda ao Cliente - A fase final da cadeia de valor interna é representada pelo Serviço Pós Venda.

Este serviço não se restringe a apenas questões de garantia, mas envolve também atividades de conserto, correção de defeitos, devoluções, além do atendimento de demandas de clientes, relacionamento com os clientes, processamento dos pagamentos, faturamento e cobrança (BORCHARDT et al., 2008).

A satisfação que um bem manufaturado proporciona aos clientes não está relacionada apenas com o produto em si, mas também com o pacote de serviços agregado (MALTHOUSE et al., 2004 e STEWART, 2003). O serviço pós venda, sendo um dos elementos deste pacote, pode afetar a satisfação e consequente fidelização destes clientes, além de atrair novos clientes. Viardort (2004) quantifica o impacto de um bom serviço pós-venda. O autor estima que serviços de pós-venda, considerados excelentes, podem aumentar as vendas em 20 a $30 \%$. 
Dessa forma, por representar um diferencial competitivo na cadeia de valor das empresas, é essencial monitorar as atividades de pós-venda. De acordo com Lima (2010), os parâmetros de tempo, qualidade e custos são utilizados para avaliar o desempenho dos serviços pós venda das empresas que buscam atender às expectativas dos seus clientes potenciais.

Levando em consideração estes três processos principais, Kaplan e Norton (1997) identificaram uma série de potenciais indicadores de desempenho que podem ser utilizados por qualquer empresa para mensurar cada um destes processos, conforme Quadro 2.4 a seguir:

Quadro 2.4- Indicadores potenciais da perspectiva dos processos internos

\begin{tabular}{|c|c|c|}
\hline Processo & Tipo de Medida & Medida ou Indicador \\
\hline \multirow{11}{*}{ Inovação } & \multirow{6}{*}{$\begin{array}{l}\text { Pesquisa básica } \\
\text { aplicada }\end{array}$} & Percentual de vendas gerados por novos produtos \\
\hline & & Percentual de vendas gerados por produtos proprietários \\
\hline & & Lançamento de novos produtos vs. lançamentos dos concorrentes \\
\hline & & Lançamento de novos produtos vs. Planejado \\
\hline & & Capacidade técnica do processo de produção \\
\hline & & Tempo de desenvolvimento da próxima geração de produtos \\
\hline & \multirow{5}{*}{$\begin{array}{l}\text { Desenvolvimento de } \\
\text { produtos }\end{array}$} & \% volume de produção com sucesso para cada subprocesso \\
\hline & & Tempo de ciclo para cada subprocesso \\
\hline & & Custo de cada subprocesso \\
\hline & & Tempo de introdução de novos produtos \\
\hline & & Margem bruta de novos produtos \\
\hline \multirow{10}{*}{ Operações } & \multirow{3}{*}{ Medidas de tempo } & Tempo de ciclo \\
\hline & & Tempo de armazenamento inicial, final e em processo \\
\hline & & Eficácia do ciclo de produção (T. processamento / T. Troughput) \\
\hline & \multirow{6}{*}{ Medidas de qualidade } & Taxa de defeito por peça \\
\hline & & Índice de acerto da produção \\
\hline & & Desperdício \\
\hline & & Perdas \\
\hline & & Retrabalho \\
\hline & & Devolução \\
\hline & Medidas de custo & Custo de cada subprocesso \\
\hline \multirow{3}{*}{$\begin{array}{l}\text { Serviço Pós } \\
\text { venda }\end{array}$} & Tempo & Tempo de ciclo solicitação do cliente até resolução \\
\hline & Qualidade & \% de solicitações atendidas com uma visita \\
\hline & Custo & Custo dos recursos utilizados \\
\hline
\end{tabular}

Fonte: Kaplan e Norton (1997)

\subsubsection{PERSPECTIVA DO APRENDIZADO E CRESCIMENTO}

Uma das mudanças mais radicais no pensamento gerencial na era do conhecimento foi a modificação do papel do funcionário nas empresas. O trabalho físico e mental repetitivos foi substituído pelas máquinas e computadores. Neste contexto, o trabalho passou a ser uma série 
de aplicações de conhecimentos, onde os indivíduos voltam suas capacidades para a programação, controle, criatividade e geração de ideias. Tem-se, assim, um aumento das exigências de aptidões para o trabalho, considerando-se uma base de conhecimentos mais ampla, na qual os colaboradores devem ser capacitados para a resolução de problemas, tomada de decisão autônoma, abstração e comunicação escrita e verbal (SIQUEIRA, 2003).

Portanto, na era do conhecimento, o capital humano é considerado pelas organizações o ativo mais importante, sendo fundamental a sua medição (Quesado et al., 2007). Mais especificamente, inovação, flexibilidade, rapidez, conhecimento, capacidade de aprendizagem individual e coletiva, qualidade de relacionamento e processos, se tornaram mais importantes do que os bens tangíveis como máquinas, ferramentas, extensões territoriais e recursos naturais (MELLO et al., 2010).

Esta opinião é corroborada por Drucker (1993) quando refere: "No passado, as fontes de vantagem competitiva eram o trabalho e os recursos naturais, agora e no próximo século, a chave para construir a riqueza das nações é o conhecimento."

Assim, o modelo contábil tradicional, o qual apenas considerava os ativos tangíveis, não é mais capaz de medir o real valor da empresa. A partir dessa concepção, Stewart (2002) sugere que o valor econômico de uma empresa é o resultado da soma de seus ativos tangíveis e intangíveis. Nos dias atuais, a participação dos ativos intangíveis na constituição deste valor tem aumentado consideravelmente. Stewart (2002) constatou também que até os primeiros anos da década de 1980, os ativos intangíveis representavam apenas 5\% do valor de mercado das organizações. Hoje, em alguns casos, esse percentual chega a $95 \%$.

A quarta e última perspectiva do Balanced Scorecard desenvolve objetivos e medidas para orientar o aprendizado e crescimento organizacional (KAPLAN E NORTON, 1997). O objetivo desta perspectiva é identificar quais trabalhos (Capital Humano), quais sistemas e que tipo de clima organizacional são necessários para suportar a criação de valor nos processos internos (Kaplan e Norton, 2004). Ou seja, fornecer a infraestrutura necessária para que sejam atingidos os objetivos e metas ambiciosas nas outras três perspectivas.

Dessa forma, ao abordar a importância do capital humano para atender os objetivos estratégicos da empresa, o Balanced Scorcard enfatiza a importância de investir no futuro, e 
não apenas em áreas tradicionais de investimento, como novos equipamentos e pesquisa e desenvolvimento de novos produtos (KAPLAN E NORTON, 1997). Na visão de Olve et al. (2001) a perspectiva do aprendizado e crescimento permite à organização ampliar sua capacidade de renovação no longo prazo, ao investir na infraestrutura - pessoal, sistemas e procedimentos.

Baseado em suas experiências como consultores, Kaplan e Norton (1997) sugerem que a perspectiva do aprendizado e crescimento seja desenvolvida com base em três categorias básicas:

- capacidade dos funcionários - de acordo com Gerson (2001), funcionários sem treinamento representam má imagem para a empresa e não são capazes de atrair e fidelizar clientes. Portanto, o ambiente dinâmico das organizações requer o desenvolvimento de ações voltadas a constante capacitação das pessoas, com vista a torná-las mais eficazes (GIL, 2001). Diante deste cenário, é preciso capacitar continuamente os funcionários para que possam ter uma postura proativa e para que possam ser tomadores de decisão. Segundo Reis (2001), para estas ações tenham efeito, é fundamental alinhar as expectativas e habilidades dos colaboradores aos objetivos organizacionais.

- capacidade dos sistemas de informação - para que os funcionários desempenhem suas atividades com excelência no ambiente competitivo, é necessário que as empresas disponibilizem as informações de forma rápida e precisa, através de sistemas de informação (KAPLAN E NORTON, 1997). Na verdade, a empresa deverá fornecer todas as ferramentas capazes de elevar a eficiência e eficácia dos seus recursos humanos.

- motivação, empowerment e alinhamento - mesmo funcionários habilitados, que dispõem de excelente acesso às informações, não contribuirão para o sucesso organizacional se não forem motivados a agir no melhor interesse da empresa, ou se não tiverem liberdade para decidir ou agir (KAPLAN E NORTON, 1997). Para Mascarenhas (2008), pessoas motivadas e bem gerenciadas geram vantagens competitivas às empresas. Assim, a motivação precisa ser constantemente estimulada para que os trabalhadores queiram liberar seu potencial e, consequentemente, aumentem sua eficiência e eficácia (GROHMANN, 1999). É importante ressaltar que, 
além de aptos, os funcionários devem estar motivados e ter autonomia para influenciar nas mudanças e nos resultados organizacionais (REIS, 2001).

Conforme sugerido por Kaplan e Norton (1997) em seus estudos o Quadro 2.5 abaixo, lista algumas medidas que podem ser utilizadas para as três categorias listadas acima:

Quadro 2.5- Medidas para as três categorias

\begin{tabular}{|c|c|}
\hline Categoria & Medida ou Indicador \\
\hline \multirow{6}{*}{$\begin{array}{l}\text { Capacidade dos } \\
\text { funcionários }\end{array}$} & Satisfação dos funcionários \\
\hline & Retenção dos funcionários \\
\hline & Produtividade dos funcionários \\
\hline & Lucratividade por funcionário \\
\hline & Índice de cobertura de funções estratégicas \\
\hline & $\begin{array}{l}\text { Tempo necessário para que os funcionários existentes atinjam os patamares de } \\
\text { competência exigidos }\end{array}$ \\
\hline \multirow{3}{*}{$\begin{array}{l}\text { Capacidade dos } \\
\text { sistemas de } \\
\text { informação }\end{array}$} & Índice de cobertura de informações estratégicas \\
\hline & $\begin{array}{l}\text { Percentual de processos que oferecem feedback em tempo real sobre qualidade, tempo e } \\
\text { custo }\end{array}$ \\
\hline & $\begin{array}{l}\text { Percentual de funcionários que lidam diretamente com clientes e tem acesso on line às } \\
\text { informações referentes a eles }\end{array}$ \\
\hline \multirow{15}{*}{$\begin{array}{l}\text { Motivação, } \\
\text { empowerment } \\
\text { alinhamento }\end{array}$} & Número de sugestões por funcionário \\
\hline & Número de sugestões por funcionário implementadas \\
\hline & Medida da meia vida (período para que um processo melhore $50 \%$ ) \\
\hline & Taxa de melhoria efetivas por processos críticos \\
\hline & Índice de alinhamento das metas pessoais com o Balanced Scorecard \\
\hline & Mind Share de compreensão da nova visão e estratégia \\
\hline & Pesquisa interna sobre o desenvolvimento de equipes \\
\hline & Nível de ganhos compartilhados \\
\hline & Número de projetos integrados \\
\hline & Utilização do controle de perdas \\
\hline & Percentual de planos de negócios desenvolvidos pelas equipes \\
\hline & Percentual de equipes com incentivos compartilhados \\
\hline & Percentual de todos os projetos com participação do cliente nos ganhos \\
\hline & Percentual de projetos nos quais foram obtidos ganhos potenciais \\
\hline & $\begin{array}{l}\text { Percentual de projetos com incentivos individuais de equipes vinculados ao sucesso do } \\
\text { projeto }\end{array}$ \\
\hline
\end{tabular}

Fonte: Kaplan e Norton (1997)

\subsubsection{MAPAS ESTRATÉGICOS}

Não basta apenas uma combinação de medidas financeiras e não financeiras para tornar o Balanced Scorecard bem sucedido. Para se ter sucesso na implantação do BSC é fundamental que se transmita a estratégia através de um conjunto integrado de medidas financeiras e não financeiras. Ou seja, é necessário descrever a estratégia através de um conjunto de hipóteses sobre causas e efeitos. (KAPLAN E NORTON,1997). 
Um scorecard adequadamente elaborado deve contar a história da estratégia da empresa através dessa sequência de relações de causa e efeito e o sistema de medição deve ser capaz de explicar as relações (hipóteses) entre os objetivos (e as medidas) nas diversas perspectivas para que elas possam ser gerenciadas e validadas. (KAPLAN E NORTON,1997).

Após prestar consultoria em mais de 300 organizações, Kaplan e Norton (2004) perceberam que o mapa estratégico é a ferramenta capaz de representar de forma visual as relações de causa e efeito entre os componentes da estratégia de uma organização, permitindo uma maior clareza e disseminação da estratégia da empresa para os colaboradores, apresentando aos mesmos uma linha clara de como seus trabalhos estão conectados com os objetivos gerais da organização.

O mapa estratégico foi elaborado com o intuito de descrever a estratégia e as relações entre os objetivos das diferentes perspectivas. O recurso visual do mapa estratégico ao permitir uma melhor compreensão da estratégia, incentiva a criação da consciência estratégica na organização (CORRÊA et al., 2005). Assim, ao revelar a estratégia inserida no mapa estratégico, as organizações criam um ponto de referência comum e compreensível para todas as unidades e empregados. E essa referência é essencial, visto que, a estratégia não pode ser executada se sua compreensão não for possível, e não pode ser compreendida se não for possível descrevê-la (NASCIMENTO E CAVENAGHI, 2008).

A base da concepção sistêmica dos mapas do Balanced Scorecard está fundada na teoria dos sistemas, mais propriamente no conceito de Dinâmica de Sistemas (System Dynamics) desenvolvido por Jay Forrester (FORRESTER, 1961). Sendo a linguagem natural inadequada para descrever uma situação em que estão envolvidas influências mútuas dos elementos da realidade, a possibilidade de representação de um sistema através de relações de causa-efeito constitui uma nova linguagem que auxilia as pessoas na identificação da interdependência entre os elementos chaves do processo. Na abordagem do BSC através de mapas estratégicos, podemos estabelecer as inter-relações entre objetivos e indicadores nas diferentes perspectivas (FERNANDES, 2002).

Portanto, o mapa estratégico é a estrutura pela qual a história da estratégia será comunicada ao seu público-alvo. Entretanto, a função do mapa estratégico é contar a história da estratégia, e não sua elaboração (NASCIMENTO E CAVENAGHI, 2008). O mapa estratégico significa desenhar a estratégia no papel, mostrando em uma única página como os objetivos nas quatro 
perspectivas se integram e combinam para descrever a estratégia (KAPLAN E NORTON, 2004).

Para Kaplan e Norton (2004), o mapa estratégico representa a evolução do modelo simples das quatro perspectivas do Balanced Scorecard apresentados no livro a Estratégia em Ação. O mapa estratégico acrescenta uma segunda camada de detalhes que ilustra a dinâmica temporal da estratégia, além de melhorar sua clareza e foco. A Figura 2.8, a seguir, demonstra um modelo de mapa estratégico genérico desenvolvido pelos autores.

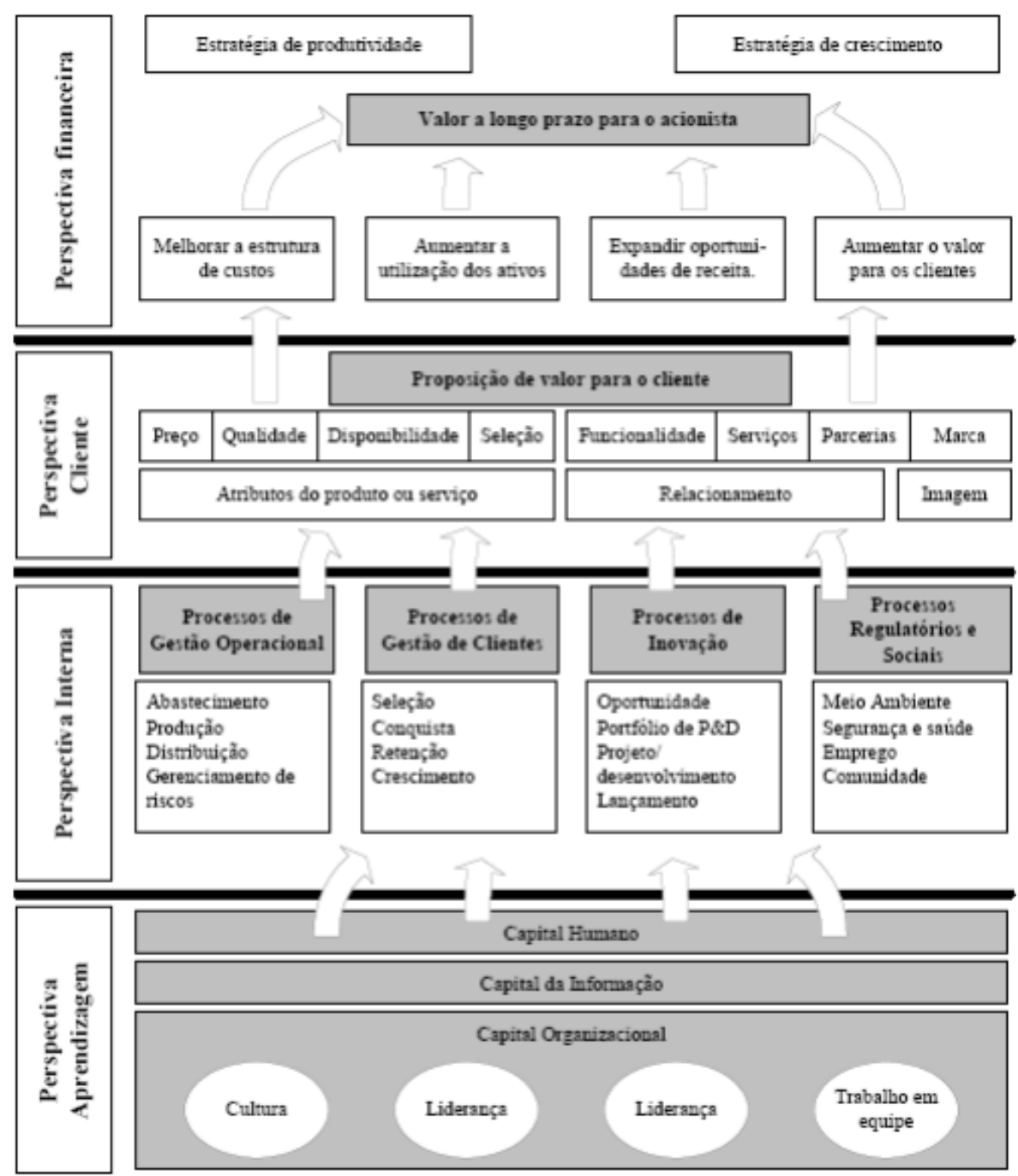

Figura 2.8 - O mapa estratégico representa como a empresa cria valor Fonte: Kaplan e Norton (2004)

O mapa estratégico baseia-se em alguns princípios: 
- A estratégia equilibra-se em forças contraditórias - Os investimentos em ativos intangíveis que buscam garantir o resultado a longo prazo normalmente conflitam com a racionalização dos custos para melhoras o desempenho a curto prazo. Assim, as organizações devem equilibrar e articular os objetivos financeiros de curto prazo com os objetivos de longo prazo.

- A estratégia baseia-se em proposição de valor diferenciada para os clientes A criação de valor pela empresa está diretamente relacionada com a satisfação dos clientes. A empresa deve ter a clara definição de qual é o seu público alvo e conhecer profundamente quais são suas exigências. Entender qual o valor esperado pelo cliente é uma das dimensões mais importantes da estratégia. Há quatro diferentes formas de proposição de valor:

- baixo custo total

- liderança do produto

- soluções completas para os clientes

- aprisionamento (lock-in)

- Cria-se valor por meio dos processos internos - Enquanto as perspectivas financeira e de clientes descrevem os resultados, isto é, o que a organização espera atingir, os processos da perspectiva interna e de aprendizado e crescimento mostram como a organização irá atingi-los. A organização deve focar nos poucos processos críticos que fornecem e sustentam a proposição de valor diferenciada e que mais contribuem para aumentar a produtividade da empresa. Os processos internos podem ser classificados em quatro grupos:

- Gestão operacional: Produção e entrega de produtos e serviços aos clientes.

- Gestão de clientes: Estabelecimento e alavancagem dos relacionamentos.

- Inovação: Desenvolvimento de nos produtos, serviços, processos e relacionamentos.

- Regulatório e social: Conformidade com as expectativas regulatórias e sociais e o desenvolvimento de comunidades mais fortes.

- A estratégia compõe-se de temas complementares e simultâneos - Cada grupamento de processos internos descritos anteriormente fornece benefícios em diferentes momentos. Assim, para que a empresa possa gerar e sustentar o valor ao longo do tempo, é necessário incorporar em seu Balanced Scorecard pelo menos 
um tema estratégico de cada um de seus quatro grupamentos de processos internos, havendo, assim, um equilíbrio entre os objetivos de curto e longo prazo.

- O alinhamento estratégico determina o valor dos ativos intangíveis -Os ativos intangíveis (perspectiva do aprendizado e crescimento) somente têm valor quando estão alinhados e contribuem para a realização da estratégia, não podendo ser medido de maneira separada e independente. Entretanto a maioria das empresas, não alinham seus programas de RH e TI a estratégia da empresa. De acordo com Kaplan e Norton (2004), há três abordagens básicas para garantir o alinhamento dos ativos intangíveis à estratégia:

- Funções estratégicas, que alinham o capital humano com temas estratégicos.

- Portfólio estratégico de TI, que alinha o capital da informação com temas estratégicos.

- Agenda de mudanças organizacionais, que integra e alinha o capital organizacional para o aprendizado e a melhoria contínua dos temas estratégicos.

Assim, quando todos os três componentes da perspectiva de aprendizado e crescimento (capital humano, capital da informação e capital organizacional) estão alinhados com a estratégia, a empresa desfruta de alto grau de prontidão, isto é, capacidade de mobilizar e sustentar o processo de mudança necessário para executar sua estratégia.

\subsubsection{ETAPAS DA CONSTRUÇÃO DO BALANCED SCORECARD}

Kaplan e Norton (1997) afirmam que devido às características próprias de cada organização, cada uma apresenta especificidades na construção do Balanced Scorecard. Entretanto é possível definir um plano típico e sistemático para o desenvolvimento do Balanced Scorecard. Os autores dividem o método de construção em quatro etapas: Definição da arquitetura de indicadores, Consenso em função dos objetivos estratégicos, escolha e elaboração dos indicadores e elaboração do plano de implementação. 


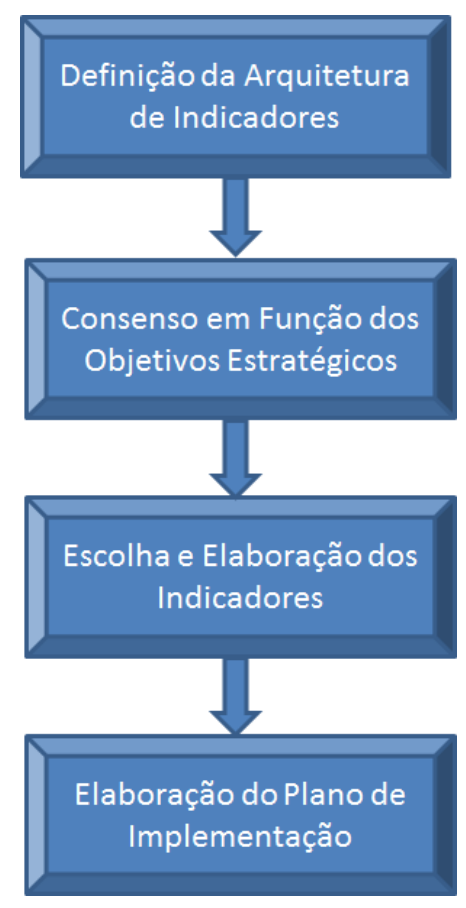

Figura 2.9 - Fluxo de Elaboração do Balanced Scorecard Fonte: Adaptado de Kaplan e Norton (1997).

De acordo com Soares (2001) e Kállas (2003), na primeira etapa, isto é, na fase de definição da Arquitetura de indicadores escolhe-se a unidade de negócio na qual será aplicado o Balanced Scorecard e realiza-se uma análise crítica dos elementos que direcionaram os negócios e da visão de futuro. Já na segunda etapa (consenso em função dos objetivos estratégicos) busca-se o consenso quanto aos objetivos estratégicos de cada uma das quatro perspectivas, juntamente com a sua descrição detalhada. Na terceira etapa (escolha e elaboração dos indicadores) são definidos os indicadores de tendência (que captam as tendências de resultados futuros) e de resultados (indicam efeitos de ações realizadas). Nesta etapa também é elaborado o material que irá comunicar as intenções e o conteúdo do Scorecard da empresa para os demais funcionários, ou seja, serão detalhados todos os objetivos, indicadores, assim como será apresentado às relações de causa e efeito entre os mesmos, por meio do Mapa Estratégico, e o Balanced Scorecad em si. Por fim, na etapa de elaboração do plano de implementação realiza-se a aprovação final dos objetivos estratégicos, indicadores e suas metas, assim como dos planos de ação para alcançar as metas e do plano de implementação do Balanced Scorecard. 


\subsection{O MODELO MULTICRITÉRIO}

As técnicas de análise multicritério tiveram seu surgimento nas décadas de 70 e 80, em substituição aos modelos ortodoxos de pesquisa operacional (HELMANN E MARÇAL, 2007). Conforme Costa (1999), neste período, a eficiência dos modelos ortodoxos de Pesquisa Operacional (P.O), em análises de problemas gerenciais complexos, começou a ser questionada. Enquanto o contexto decisório empresarial demonstrava a necessidade de se levar em consideração diversos critérios para a tomada de decisão, as metodologias de avaliação monocritério, como a P.O, forneciam a solução ótima com base em uma determinada função de avaliação de performance segundo um único critério considerado. Portanto, a grande limitação das metodologias monocritério é que elas não conseguem levar em conta os diversos critérios considerados relevantes em situações complexas (ENSSLIN et al., 2001).

Assim, parte da comunidade científica, passa a considerar que não mais se deva analisar problemas procurando uma solução ótima, e sim gerar projetos e soluções de compromisso que permitam ultrapassar a complexidade que cerca as situações problemáticas no contexto empresarial. Ou seja, passar do paradigma da otimização para as chamadas soluções de aprendizado e construtivismo, objetivando gerar conhecimento aos decisores sobre os seus problemas (WERNKE e BORNIA, 2001).

Neste contexto destaca-se a abordagem multicritério, caracterizada como um conjunto de métodos que buscam tornar claro um problema, no qual as alternativas são avaliadas por múltiplos critérios, os quais na maioria das vezes são conflitantes (GOMES et al., 2002). Cada critério é uma função matemática que mede o desempenho das ações potenciais com relação a um determinado aspecto ou objetivo, sendo a finalidade da ferramenta alcançar a otimização simultânea dessas funções (ENSSLIN et al., 2001). De acordo com Diehl (1997), a análise de multicritério não apresenta uma solução ótima para um dado problema, mas a mais coerente com a escala de valores e com o método utilizado.

Além disso, o método é recomendado para situações consideradas complexas, ou seja, situações em que: (i) envolvem incertezas sobre o caminho a seguir, os objetivos a serem alcançados, as diferentes alternativas de solução e os grupos de pessoas envolvidos; (ii) há conflitos de valores e objetivos entre os grupos interessados; (iii) existem diferentes relações 
de poder; (iv) são considerados múltiplos critérios na avaliação das alternativas; (v) envolvem quantidade de informações envolvidas, tanto qualitativas quanto quantitativas; (vi) as informações disponíveis são, usualmente, incompletas; e, (vii) exigem soluções criativas e muitas vezes inéditas (CHURCHILL, 1990 apud. ENSSLIN et al., 2001).

Para atingir seus objetivos o MDCA-C é composto por três fases (i) fase de estruturação; (ii) fase de avaliação; e (iii) fase de elaboração de recomendações (BORTOLUZZI et al., 2011), conforme Figura 2.10.

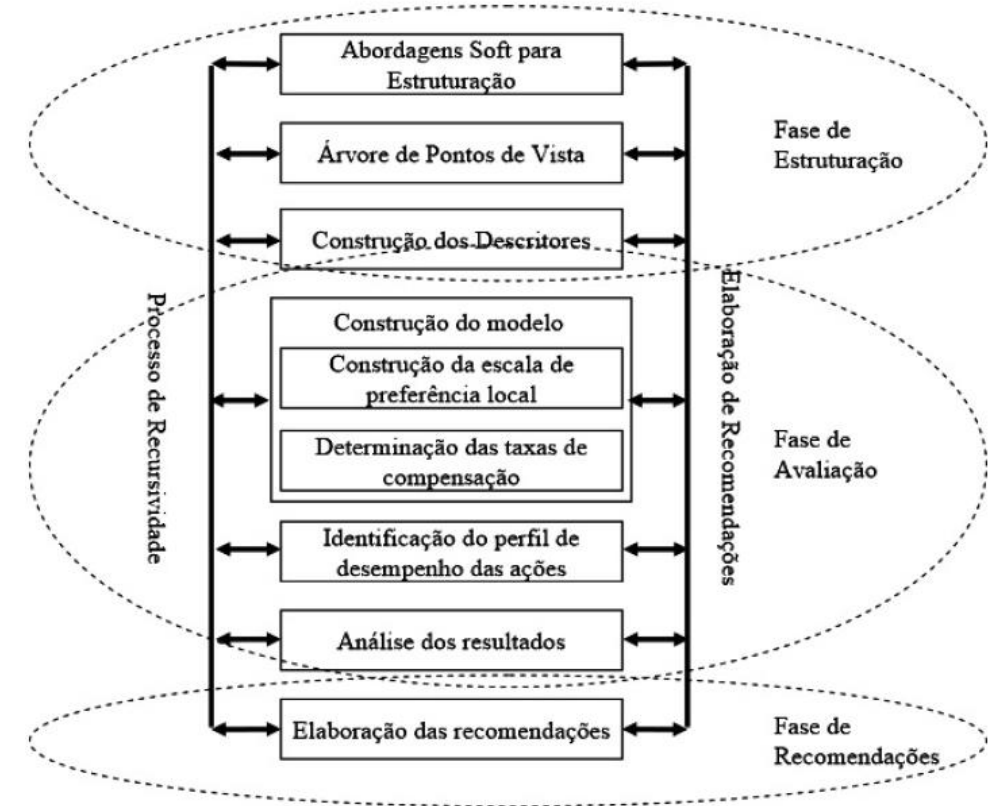

Figura 2.10 - Fases da metodologia MDCA-C

Fonte: Adaptado de Ensslin et al. (2001)

\subsubsection{FASE DE ESTRUTURAÇÃO}

A fase de estruturação busca identificar e gerar conhecimento sobre os seguintes aspectos: (i) contexto do problema, atores envolvidos e/ou indiretamente com o contexto e o rótulo do problema; (ii) Elementos Primários de Avaliação (EPA), conceitos orientados à ação e agrupamentos por áreas de preocupação; (iii) mapas de relações meios e fins e árvore de pontos de vista fundamentais, e (iv) estrutura hierárquica de valor e descritores. 
Ensslin et al. (2001) distinguem os atores em dois grupos, conforme a participação no processo decisório: os intervenientes e os agidos. Os atores intervenientes participam diretamente do processo decisório com o objetivo de fazer prevalecer nele seus sistemas de valores. Já os atores classificados como agidos, são os que sofrem de forma passiva as consequências da implementação da decisão tomada.

Ainda segundo Ensslin et al. (2001) os intervenientes podem ser subdivididos em dois atores: os decisores, para os quais são delegados formalmente o poder de decisão; e os facilitadores que tem a função de facilitar e apoiar o processo de tomada de decisão através de ferramentas (modelos) construídos com esta finalidade.

Os elementos primários de avaliação (EPA) correspondem às primeiras preocupações e campos de avaliação que o decisor externaliza em relação à situação decisional em que se encontra (KENNEY, 1992). Ou seja, nesta etapa pretende-se identificar os critérios considerados relevantes.

Após a definição dos EPA, esses são agrupados em áreas de preocupação e hierarquizados de acordo com suas relações de causa-efeito, em mapas de relações meios-fins (EDEN, 1988), utilizados para desenvolver conhecimento a respeito da realidade decisional, apresentando as variáveis que descrevem o fenômeno e as relações causais existentes entre elas (MONTIBELLER et al., 2007).

Uma vez elaborado o mapa meios-fins, a metodologia MCDA-C propõe, para continuar seu processo de construir o entendimento, que a estrutura de relações de influência seja convertida em uma estrutura hierárquica de valor. Isto permite incorporar o entendimento dos julgamentos preferenciais do decisor no modelo em construção (KEENEY, 1992).

Uma árvore de pontos de vista baseia-se no conceito de estrutura arborescente, uma forma de estruturação hierarquizada de informação que parte dos conceitos de "topo" para os conceitos hierarquicamente inferiores, seguindo uma abordagem top-down.

A estrutura arborescente utiliza a lógica de decomposição, em que um critério mais complexo de ser mensurado é decomposto em subcritérios de mais fácil mensuração. Portanto, o critério de nível hierárquico superior é determinado pelo conjunto de critérios de nível hierárquico 
inferior, ligados a ele na árvore (ENSSLIN et al., 2001). Uma estrutura genérica de um modelo multicritério, ou arborescência de pontos de vista, foi desenvolvida por Pereira Neto (2001), conforme Figura 2.11.

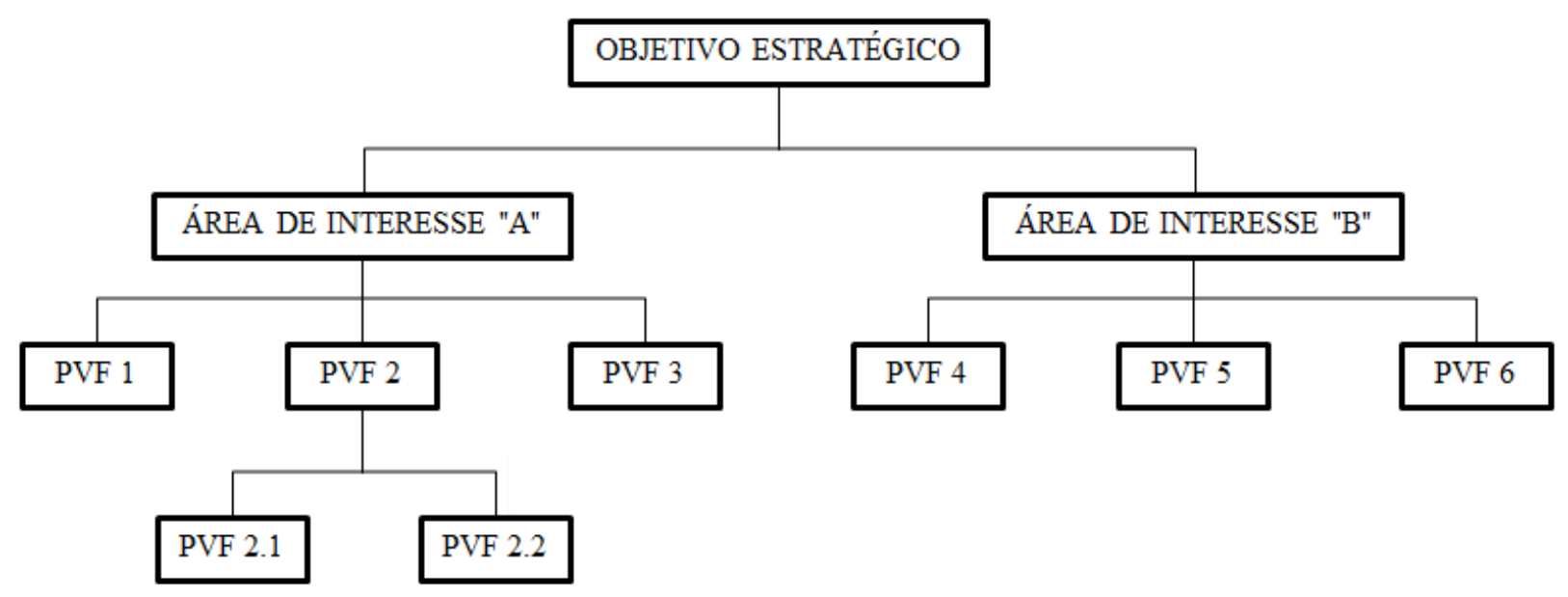

Figura 2.11 - Modelo de arborescência dos pontos de vista Fonte: Pereira Neto (2010)

De acordo com Pereira Neto (2001), a arborescência de pontos de vista é composta pelos seguintes elementos:

- objetivo estratégico: engloba todos os aspectos revelados pelos decisores no contexto decisório;

- área de interesse: compreende o agrupamento de conceitos que traduzem aspectos semelhantes revelados pelos decisores;

- ponto de vista fundamental (PVF): aspecto considerado fundamental pelos decisores para definir o contexto decisório.

- ponto de vista elementar (PVE): decomposição do PVF, com o objetivo de explicar e auxiliar na compreensão dos PVF.

Os pontos de vista fundamentais são aqueles aspectos considerados, por pelo menos um dos decisores, como fundamentais para avaliar as ações potenciais, ou seja, fundamentais para medição do desempenho dos transportadores rodoviários. Os PVF devem respeitar os critérios de essencialidade e de controlabilidade, isto é, devem ser fundamentais segundo os objetivos estratégicos definidos e devem apenas ser influenciados pelo contexto decisório (PEREIRA NETO, 2001). 
A última etapa da fase de estruturação do modelo é a construção dos descritores, que irão apresentar os possíveis níveis de desempenho para cada PVE (critério) de análise, os quais vão permitir a mensuração e avaliação da performance.

Um descritor é definido como um conjunto de níveis referentes a um critério de análise, que identificará as possíveis performances plausíveis das ações potenciais em termos de cada PVF (BANA E COSTA, 1992). Os níveis de impacto devem ser ordenados em termos de preferência, segundo os sistemas de valores dos decisores, sendo, o nível mais atrativo aquele correspondente a uma ação cuja performance seria a melhor possível e o menos atrativo correspondente a uma ação com a pior performance aceitável (ENSSLIN et al., 2001).

Ademais, para que o descritor possa ser utilizado como elemento de comparação deve ser estabelecido pelo decisor os Níveis de Referência denominados de nível bom e de nível neutro (GIFFHORN et al., 2009). Os níveis acima do nível Bom são considerados benchmarking, já os níveis abaixo do nível Neutro são considerados comprometedores e os níveis intermediários são considerados níveis de mercado (ENSSLIN et al., 2001).

Quadro 2.6 - Exemplo de descritor do MDCA-C

\begin{tabular}{|c|c|c|}
\hline \multicolumn{3}{|c|}{ Descritor } \\
\hline Níveis de impacto & Níveis de Referência & Descrição \\
\hline $\mathrm{N} 5$ & & Superior à Meta $+10 \%$ \\
\hline N4 & Bom & Até Meta + $10 \%$ \\
\hline N3 & & Meta \\
\hline $\mathrm{N} 2$ & Neutro & Até $10 \%$ abaixo da Meta \\
\hline N1 & & Inferior a $10 \%$ da meta \\
\hline
\end{tabular}

\subsubsection{FASE DE AVALIAÇÃO}

A fase de estruturação visa à construção de um modelo matemático, conforme a percepção dos decisores, o qual possibilitará o cálculo dos índices das perspectivas e do desempenho global das empresas. O modelo matemático será resultado da realização das seguintes etapas: i. construção das funções de valor; ii. identificação das taxas de compensação/substituição entre objetivos (ENSSLIN et al., 2001).

Construídos os descritores de cada PVE, é agora necessário quantificar a intensidade de preferência, ou diferença de atratividade, entre os diferentes níveis de impacto das ações 
potenciais, segundo o sistema de valores do decisor. Para isto, deve-se construir as funções de valor, pois é um recurso matemático que expressa os valores dos decisores a respeito dos critérios, com a utilização de escalas numéricas (PETRI, 2000).

Há na literatura várias técnicas para a construção de funções de valor, como a) pontuação direta (FISHBURN, 1967), b) método da bisseção (BODILY, 1985) e c) método do julgamento semântico (BEINAT, 1995). O método a ser utilizado neste trabalho é o método do julgamento semântico.

No método da pontuação direta, a função de valor é obtida através de notas atribuídas para cada descritor, as quais são posteriormente normalizadas. Já no método do julgamento semântico a função de valor é obtida através de comparações par-a-par da diferença de atratividade entre ações potenciais, para tal, os decisores devem expressar qualitativamente a intensidade de preferência de uma ação sobre a outra (ENSSLIN et al., 2001).

Nessa etapa será utilizado, como ferramenta, o software M-MACBETH (Measuring Attractiveness by a Categorical Based Evaluation Technique). O procedimento de uso do $M$ MACBETH consiste em solicitar ao decisor que expresse a diferença de atratividade entre duas ações potenciais a e b (a mais atrativa que b) com base em uma escala de sete categorias semânticas propostas, conforme Figura 2.12 a seguir (BANA e COSTA e VANSNICK, 1995):

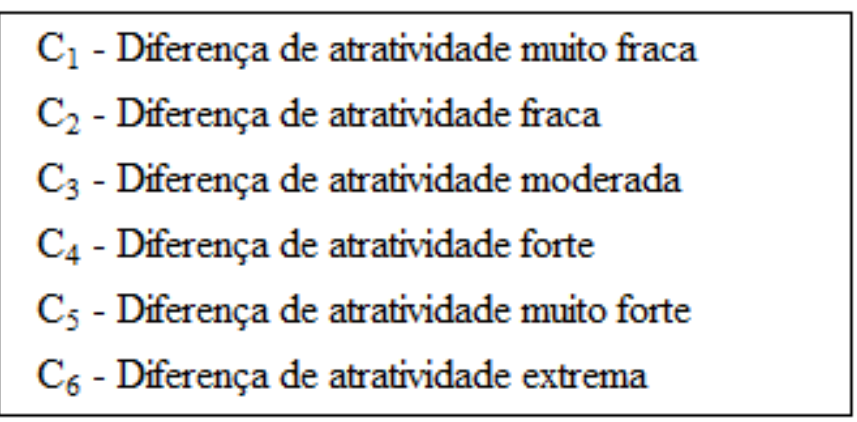

Figura 2.12 - Escala Semântica

Fonte: Bana e Costa e Vansnick (1995)

Com base nas respostas, constrói-se a matriz semântica, cujos valores devem alimentar o software, que, determina a função de valor (escala cardinal) para o PVF ou PVE, verificando, 
inclusive, a consistência dos julgamentos realizados. Estas preferências serão coletadas através do estudo de caso.

A etapa seguinte da construção do modelo matemático é a definição das taxas de substituição. O objetivo principal é permitir agregar as avaliações locais dos descritores, dadas por uma função de valor, num modelo global de avaliação (PEREIRA NETO, 2001). Entretanto, uma média simples entre os resultados das avaliações locais não representaria a realidade global, visto que o decisor pode julgar que um critério a é mais importante que um critério b. Assim, utilizam-se as taxas de substituição para traduzir as preferências dos tomadores de decisão.

Portanto, o que se realiza na avaliação global é a soma ponderada com a pontuação obtida em cada critério, multiplicado pelo peso correspondente ao critério (GIFFHORN et al., 2009). Ou seja, as taxas de substituição representam os pesos necessários para construção dos índices das perspectivas do Balanced Scorecard e da avaliação global do desempenho.

Para a obtenção das Taxas de substituição, muitos métodos podem ser utilizados, entre eles o Método Trade-off, o Swing Weights e o de Comparação Par a Par. O método de comparação Par a Par tem como vantagem não ser necessário que o decisor expresse suas preferências por meios numéricos, mas sim semânticos, o que garante uma maior naturalidade ao processo (GIFFHORN, 2007). Já o método Swing Weights, por utilizar a pontuação direta, é de mais fácil compreensão pelo decisor. Este último foi o método selecionado neste trabalho. Para isso, é necessário seguir os seguintes passos:

$1^{\circ}$ ) ordenar os PVF por níveis;

$2^{\circ}$ ) atribuir pontos para cada PVF; e

$3^{\circ}$ ) normalizar os valores atribuídos.

Para ordenação dos PVF pode ser utilizada a Matriz de Ordenação - Roberts, segundo o juízo de valor dos decisores ou os próprios decisores podem ordenar arbitrariamente os critérios (QUIRINO, 2002). Em seguida, os decisores atribuem pontos para cada PVF, partindo do maior preferência, que recebe 100 pontos. Por fim, o facilitador realiza a normalização dos valores atribuídos. 


\subsubsection{FASE DE RECOMENDAÇÕES}

Esta etapa de elaboração de recomendações tem por papel auxiliar o gestor na definição das ações que visem o aperfeiçoamento e melhoria do desempenho do objeto que está sendo avaliado (ENSSLIN et al., 2001). 


\section{CONSTRUÇÃO DO SISTEMA DE MEDIÇÃO DE DESEMPENHO BASEADO NO BALANCED SCORECARD}

Neste capítulo será desenvolvido o sistema de medição de desempenho, objeto deste trabalho, a partir da seleção dos indicadores de desempenho que deverão compor o Balanced Scorecard e da definição dos pesos dos indicadores, com o auxílio da metodologia MDCA-C. Ao final será apresentada uma ferramenta computacional do modelo proposto.

\subsection{SELEÇÃO DOS INDICADORES DE DESEMPENHO}

Para construção do sistema de medição de desempenho baseado no Balanced Scorecard, é necessário, inicialmente, definir os indicadores de desempenho que farão parte do modelo e classificá-los nas quatro perspectivas: financeira, do cliente, dos processos internos e do aprendizado e crescimento.

O processo de seleção deve definir de indicadores adequados com os requisitos do Balanced Scorecard. Para selecionar indicadores de desempenho adequados, inicialmente deve-se definir os objetivos estratégicos, os quais se deseja mensurar. $\mathrm{O}$ desenvolvimento dos objetivos estratégicos é realizado com base no modelo genérico do Balanced Scorecard desenvolvido por Kaplan e Norton (1997), que abrange três temas financeiros estratégicos, medidas essenciais e atributos de proposta de valor para o cliente, a cadeia de valor dos processos internos e três categorias na perspectiva de aprendizagem e crescimento.

O desenvolvimento do Balanced Scorecard inicia-se a partir da definição dos objetivos da perspectiva financeira, tal como se mostra no Quadro 3.1. O primeiro objetivo de longo prazo selecionado nesta perspectiva foi aumentar o retorno sobre o investimento, visto que a finalidade primordial das empresas é a obtenção de lucro. Para alcançar o retorno sobre o investimento desejado, foram definidos os demais objetivos. No tema crescimento e mix de receitas, os objetivos selecionados foram: aumentar as margens; aumentar taxa de vendas; aumentar participação no mercado; reduzir inadimplência no pagamento do frete. Já os temas produtividade, redução de custos e utilização de ativos foram agrupados e tiveram os seguintes objetivos definidos: reduzir os custos de não conformidade e maximizar a utilização dos ativos. 
Quadro 3.1- Objetivos da perspectiva financeira

\begin{tabular}{|l|c|l|}
\hline Perspectiva & Temas & \multicolumn{1}{c|}{ Objetivos } \\
\hline \multirow{4}{*}{ Financeira } & Retorno & Aumentar retorno sobre o investimento \\
\cline { 2 - 3 } & Crescimento do mix e & Aumentar margens \\
\cline { 2 - 3 } & receitas & Aumentar taxa de vendas \\
\cline { 2 - 3 } & & Reduzir prazo médio de recebimento \\
\cline { 2 - 3 } & Produtividade / & Reduzir inadimplência no pagamento do frete \\
\cline { 2 - 3 } & Redução de custos & Maximizar a utilização de ativos \\
\hline
\end{tabular}

Na perspectiva dos clientes, os objetivos são divididos em dois conjuntos: medidas essenciais e atributos de valor, conforme Quadro 3.2. No conjunto de medidas essenciais foram definidos os seguintes objetivos: aumentar taxa de novos clientes, aumentar taxa de retenção de clientes, aumentar satisfação dos clientes e aumentar participação no mercado. Já para o conjunto de atributos (medidas diferenciadoras), os objetivos selecionados foram: reduzir de reclamações, reduzir retornos ou devoluções e aumentar agilidade na resolução de problemas.

Quadro 3.2- Objetivos da perspectiva dos clientes

\begin{tabular}{|l|l|l|}
\hline Perspectiva & Medidas & \multicolumn{1}{c|}{ Objetivos } \\
\hline \multirow{4}{*}{ Essenciais } & Aumentar taxa de novos clientes \\
\cline { 3 - 3 } & \multirow{4}{*}{ Clientes } & Aumentar taxa de retenção de clientes \\
\cline { 3 - 3 } & & Aumentar satisfação dos clientes \\
\cline { 2 - 3 } & & Aumentar participação no mercado \\
\cline { 2 - 3 } & \multirow{3}{*}{ Atributos de valor } & Reduzir reclamações \\
\cline { 3 - 3 } & Reduzir retornos ou devoluções \\
\cline { 3 - 3 } & & Aumentar agilidade na solução de problemas \\
\hline
\end{tabular}

O desenvolvimento da perspectiva dos processos internos tem início após a definição dos objetivos dos acionistas e clientes. Adaptando a cadeia de valor genérica dos processos internos proposta por Kaplan e Norton (1997) à realidade das ETRC, considera-se necessária a inclusão de mais um grupo de processos internos: o processo de gestão de risco, visto que muitas empresas possuem setores exclusivos para realizar esta gestão, sendo também um diferencial competitivo no mercado. Ademais, pareceu ser mais aderente ao setor, a substituição do termo processos regulatórios e sociais por processos de gestão ambiental, visto o grande impacto no meio ambiente devido à emissão de poluentes.

Para cada um dos grupos de processos internos, define-se um conjunto de objetivos, conforme Quadro 3.3. Para o processo de inovação, entendeu-se como objetivo principal a modernizar a frota, visto que as empresas poderiam oferecer o equipamento mais inovador do mercado. Em relação aos processos de gestão de clientes, estabeleceram-se como objetivos: reduzir erros na 
emissão do conhecimento de transporte eletrônico (CT-E), flexibilizar o sistema, realizar contato pós-venda, melhorar desempenho na entrega. Os processos de gestão operacional foram divididos em dois objetivos: reduzir custo da frota e melhorar gestão da frota. No que tange os processos de gestão de risco, consideraram-se três aspectos: reduzir risco da carga, risco do veículo e risco do motorista. Por fim, em relação aos processos de gestão ambiental, os objetivos traçados foram zero acidentes ambientais e redução da emissão de CO2.

Quadro 3.3- Objetivos da perspectiva dos processos internos

\begin{tabular}{|l|l|l|}
\hline Perspectiva & Processos & \multicolumn{1}{c|}{ Objetivos } \\
\hline \multirow{4}{*}{ Processos Internos } & Inovação & Modernizar a frota \\
\cline { 2 - 3 } & \multirow{4}{*}{ Gestão de clientes } & Reduzir erros na emissão CT-E \\
\cline { 2 - 3 } & & Flexibilizar o sistema \\
\cline { 2 - 3 } & Gestão Operacional & Realizar contato pós-venda \\
\cline { 2 - 3 } & & Relhorar desempenho na entrega \\
\cline { 2 - 3 } & \multirow{3}{*}{ Gestão de risco } & Melhorar gestão da Frota \\
\cline { 2 - 3 } & & Reduzir risco da carga \\
\cline { 2 - 3 } & & Reduzir risco do veículo \\
\cline { 2 - 3 } & & Reduzir risco do motorista \\
\cline { 2 - 3 } & Gestão Ambiental & Zero Acidentes Ambientais \\
\cline { 2 - 3 } & & Reduzir emissão de Co2 \\
\hline
\end{tabular}

A última perspectiva a ser desenvolvida é do aprendizado e crescimento, conforme Quadro 3.4. Para capacitação dos funcionários são definidos como objetivos: treinar equipes, reter colaboradores e a reduzir a ausência dos colaboradores. Em relação à capacidade dos sistemas entende-se como objetivo para as empresas de transporte a utilização de sistemas de gestão da frota. Já a categoria motivação, empowerment e alinhamento é dividida em dois objetivos: aumentar bonificação dos funcionários e promover a satisfação dos colaboradores.

Quadro 3.4- Objetivos da perspectiva do aprendizado e crescimento

\begin{tabular}{|c|c|l|}
\hline Perspectiva & Categorias & \multicolumn{1}{|c|}{ Objetivos } \\
\hline \multirow{3}{*}{$\begin{array}{c}\text { Aprendizagem } \\
\text { e }\end{array}$} & Capacidade dos funcionários & Treinar equipes \\
\cline { 2 - 3 } crescimento & & Reter Colaboradores \\
\cline { 2 - 3 } & Capacidade dos sistemas & Utilizar sistemas de gestão de frota \\
\cline { 2 - 3 } & $\begin{array}{c}\text { Motivação, Empowerment e } \\
\text { alinhamento }\end{array}$ & Aumentar bonificação dos funcionários \\
\cline { 2 - 3 } & & Promover Satisfação dos colaboradores \\
\hline
\end{tabular}

Tendo como base os objetivos determinados anteriormente e as potenciais relações de causa e efeito, elabora-se o mapa estratégico para os transportadores rodoviários, conforme Figura 3.1 . 


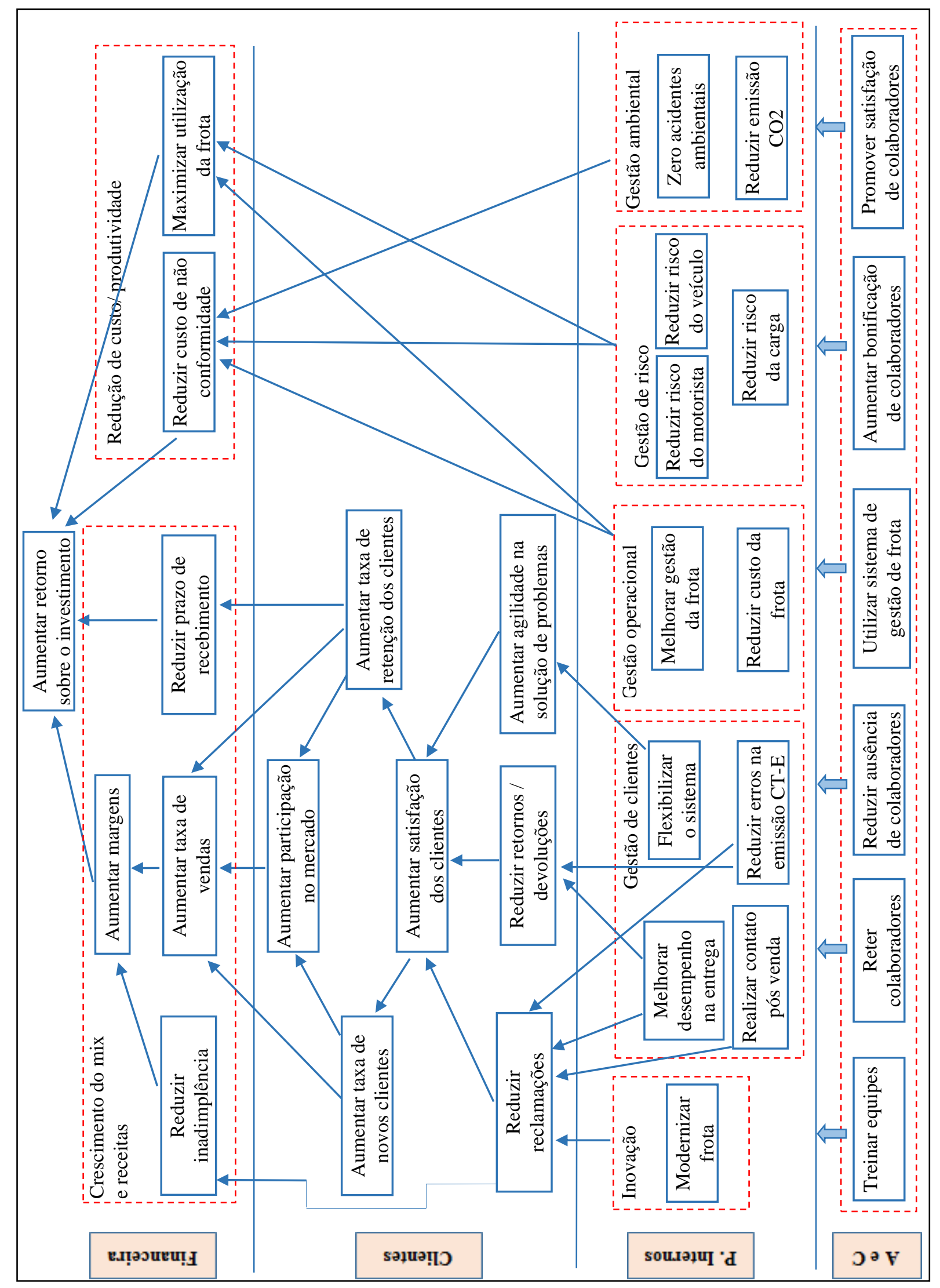

Figura 3.1 - Mapa estratégico para transportadores rodoviários 
Após refinar e consolidar os objetivos estratégicos identifica-se, para cada objetivo, o indicador ou indicadores que melhor captem e comuniquem a intenção do objetivo. A utilização de indicadores não alinhados com os objetivos estratégicos prejudica a avaliação do desempenho da organização.

Nesse sentido, realizou-se pesquisa bibliográfica em livros, artigos científicos e periódicos nacionais e internacionais, para identificar os indicadores de desempenho mais usuais aplicados aos transportadores rodoviários. O resultado destes indicadores foi apresentado no Quadro 2.2.

A partir dos indicadores encontrados na bibliografia e considerando os objetivos estabelecidos no mapa estratégico para os transportadores rodoviários, define-se o indicador ou indicadores que mensurar o desempenho dos objetivos. O Quadro 3.5 relaciona os objetivos estratégicos aos seus respectivos indicadores.

Para cada indicador proposto, deve-se detalhar a fórmula de medição, assim como identificar as fontes de informação necessárias e as ações que podem ser necessárias para a coleta destas informações. A descrição dos indicadores selecionados é apresentada no Quadro 3.6.

Com a definição dos indicadores de desempenho, para cada um dos objetivos pode-se, então, construir o mapa de indicadores de desempenho da organização, isto é o seu Balanced Scorecard. A Figura 3.2 ilustra o Balanced Scorecard para os transportadores rodoviários. 
Quadro 3.5- Relação dos objetivos estratégicos com os indicadores de desempenho

\begin{tabular}{|c|c|c|c|}
\hline Persp. & $\begin{array}{c}\text { Temas / } \\
\text { Categorias }\end{array}$ & Objetivos & Indicadores \\
\hline \multirow{7}{*}{ 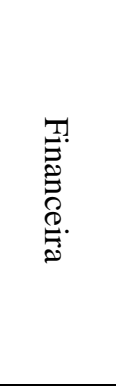 } & Retorno & Aumentar retorno sobre o investimento & Retorno sobre o investimento \\
\hline & \multirow{4}{*}{$\begin{array}{l}\text { Crescimento } \\
\text { do mix e } \\
\text { receitas }\end{array}$} & Aumentar margens & Margem líquida \\
\hline & & Aumentar taxa de vendas & Vendas incrementais \\
\hline & & Reduzir prazo médio de recebimento & Prazo médio de recebimento \\
\hline & & $\begin{array}{l}\text { Reduzir inadimplência no pagamento } \\
\text { do frete }\end{array}$ & \% de inadimplência sobre vendas \\
\hline & \multirow{2}{*}{$\begin{array}{c}\text { Custos/ } \\
\text { Produtividade }\end{array}$} & Reduzir custos de não conformidade & Custo com não conformidade \\
\hline & & Maximizar a utilização de ativos & Índice de produtividade da frota \\
\hline \multirow{7}{*}{ 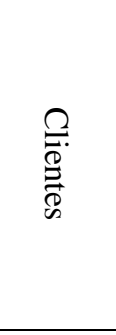 } & \multirow{4}{*}{ Essenciais } & Aumentar taxa de novos clientes & Taxa de novos clientes \\
\hline & & Aumentar taxa de retenção de clientes & Taxa de fidelização de clientes \\
\hline & & Aumentar satisfação dos clientes & Nível global de satisfação dos clientes \\
\hline & & Aumentar participação no mercado & Market-share \\
\hline & \multirow{3}{*}{$\begin{array}{l}\text { Atributos de } \\
\text { valor }\end{array}$} & Reduzir reclamações & Número de reclamações \\
\hline & & Reduzir retornos ou devoluções & Número de retornos ou devoluções \\
\hline & & $\begin{array}{l}\text { Aumentar agilidade na solução de } \\
\text { problemas }\end{array}$ & Tempo para resolução de problemas \\
\hline \multirow{20}{*}{ 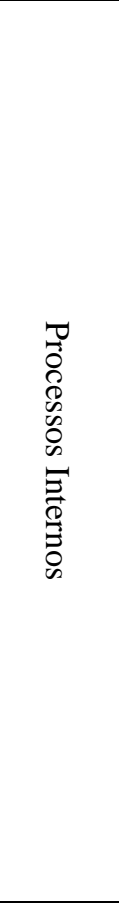 } & Inovação & Modernizar a frota & Idade média dos veículos \\
\hline & \multirow{4}{*}{$\begin{array}{l}\text { Gestão de } \\
\text { clientes }\end{array}$} & Reduzir erros na emissão CT-E & Acuracidade na emissão do CT-E \\
\hline & & Flexibilizar o sistema & Taxa de acompanhamento pós-serviço \\
\hline & & Realizar contato pós-venda & $\begin{array}{l}\text { Solicitações atendidas (Condições } \\
\text { especiais) }\end{array}$ \\
\hline & & Melhorar desempenho na entrega & Índice de coleta e entrega no prazo \\
\hline & \multirow{15}{*}{$\begin{array}{c}\text { Gestão } \\
\text { Operacional }\end{array}$} & \multirow{3}{*}{ Reduzir custo da Frota } & Custo de manutenção \\
\hline & & & Custo de pneu \\
\hline & & & Custo de combustível \\
\hline & & \multirow{4}{*}{ Melhorar gestão da Frota } & Tempo médio carga/descarga \\
\hline & & & Disponibilidade da frota \\
\hline & & & Utilização da capacidade de carga \\
\hline & & & Viagens vazias \\
\hline & & \multirow{2}{*}{ Reduzir risco da carga } & Avarias \\
\hline & & & Roubo de cargas \\
\hline & & \multirow[t]{2}{*}{ Reduzir risco do veículo } & Acidentes com fatalidades \\
\hline & & & Acidentes de trânsito \\
\hline & & \multirow[t]{2}{*}{ Reduzir risco do motorista } & Multas por motoristas \\
\hline & & & Ultrapassagem do tempo de viagem \\
\hline & & Zero Acidentes Ambientais & Contaminações/Derrames Zero \\
\hline & & Reduzir emissão de Co2 & Consumo de combustível \\
\hline \multirow{6}{*}{ 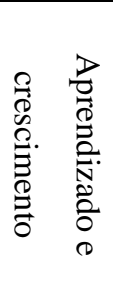 } & \multirow{3}{*}{$\begin{array}{l}\text { Capacidade } \\
\text { funcionários }\end{array}$} & Treinar equipes & Horas de treinamento \\
\hline & & Reter Colaboradores & Índice de rotatividade \\
\hline & & Reduzir ausência de colaboradores & Taxa de absenteísmo \\
\hline & Cap. Sistemas & Utilizar sistemas de gestão de frota & Índice de veículos rastreáveis \\
\hline & \multirow{2}{*}{$\begin{array}{l}\text { Motivação / } \\
\text { Empowerment }\end{array}$} & Aumentar bonificação dos funcionários & Gratificação por colaboradores \\
\hline & & Promover Satisfação dos colaboradores & Satisfação dos empregados \\
\hline
\end{tabular}


Quadro 3.6 - Descrição dos indicadores de desempenho do Balanced Scorecard

\begin{tabular}{|c|c|c|}
\hline Indicador & Conceito & Fórmula \\
\hline $\begin{array}{l}\text { Retorno sobre o } \\
\text { investimento }\end{array}$ & $\begin{array}{l}\text { Mede o retorno para os acionistas do } \\
\text { capital investido na empresa. }\end{array}$ & $\begin{array}{l}\text { Porcentagem de Lucro/Investimento } \\
\text { Inicial }\end{array}$ \\
\hline Margem líquida & $\begin{array}{l}\text { Determina o \% de cada real de frete } \\
\text { que restou após todas as despesas } \\
\text { (inclusive IR) }\end{array}$ & $\begin{array}{l}\text { ML = Lucro Líquido / Receita Líquida } \\
\text { de vendas }\end{array}$ \\
\hline Vendas incrementais & $\begin{array}{l}\text { Mede o aumento no número de } \\
\text { serviços prestados em um período. }\end{array}$ & $\begin{array}{l}\text { V.I = (número de vendas no período t - } \\
\text { número de vendas no período t- } \\
\text { 1)/(número de vendas no período t- } 1)\end{array}$ \\
\hline $\begin{array}{l}\text { Prazo médio de } \\
\text { recebimento }\end{array}$ & $\begin{array}{l}\text { Indica quanto tempo em média a } \\
\text { empresa leva para pagar receber suas } \\
\text { vendas }\end{array}$ & $\begin{array}{l}\text { PMR = Somatório (Data em que recebeu } \\
\text { o frete - Data em que prestou o serviço)/ } \\
\mathrm{N}^{\circ} \text { de serviços prestados }\end{array}$ \\
\hline $\begin{array}{l}\text { \% de inadimplência sobre } \\
\text { vendas }\end{array}$ & $\begin{array}{l}\text { Mede o \% das contas a receber } \\
\text { vencidas em relação ao a receber geral }\end{array}$ & $\begin{array}{l}\text { Valor Total dos fretes não pagos no } \\
\text { período/Valor total dos fretes realizados } \\
\text { no período. }\end{array}$ \\
\hline $\begin{array}{l}\text { Custo com não } \\
\text { conformidade }\end{array}$ & $\begin{array}{l}\text { Mede a participação de custos } \\
\text { decorrentes de não conformidades no } \\
\text { processo de transporte }\end{array}$ & $\begin{array}{l}\text { CFUE = custo adicional de transporte } \\
\text { com não conformidades }\end{array}$ \\
\hline $\begin{array}{l}\text { Índice de produtividade da } \\
\text { frota }\end{array}$ & $\begin{array}{l}\text { Mede o valor em média recebido por } \\
\text { veículo da frota no período. }\end{array}$ & Receita Total/número de veículos totais \\
\hline Taxa de novos clientes & $\begin{array}{l}\text { Mede o percentual de novos clientes } \\
\text { em um determinado período }\end{array}$ & $\begin{array}{l}\text { Número de clientes novos/número total } \\
\text { de clientes }\end{array}$ \\
\hline $\begin{array}{l}\text { Taxa de fidelização de } \\
\text { clientes }\end{array}$ & $\begin{array}{l}\text { Mede o percentual de clientes que } \\
\text { continuam contratando seus serviços. }\end{array}$ & $\begin{array}{l}\text { Número de clientes habituais/número } \\
\text { total de clientes }\end{array}$ \\
\hline $\begin{array}{l}\text { Nível global de satisfação } \\
\text { dos clientes }\end{array}$ & Mede a satisfação dos clientes atuais & Pesquisa de satisfação \\
\hline Market-share & $\begin{array}{l}\text { Mede o percentual de mercado que a } \\
\text { empresa detém. }\end{array}$ & $\begin{array}{l}\text { Número de fretes realizados/número de } \\
\text { fretes potenciais do mercado alvo }\end{array}$ \\
\hline Número de reclamações & $\begin{array}{l}\text { Percentual de pedidos que resultam em } \\
\text { reclamações }\end{array}$ & $\begin{array}{l}\text { Total de reclamações dos clientes/ Total } \\
\text { de pedidos realizados }\end{array}$ \\
\hline $\begin{array}{l}\text { Número de retornos ou } \\
\text { devoluções }\end{array}$ & $\begin{array}{l}\text { Mede o número de pedidos que tiveram } \\
\text { retorno/devolução }\end{array}$ & $\begin{array}{l}\text { Número de pedidos retornados ou } \\
\text { devolvidos / número total de pedidos }\end{array}$ \\
\hline $\begin{array}{l}\text { Tempo para resolução de } \\
\text { problemas }\end{array}$ & $\begin{array}{l}\text { Mede o cumprimento do tempo } \\
\text { acordado para a solução do problema }\end{array}$ & $\begin{array}{l}\text { Tempo total para solução do problema/ } \\
\text { Tempo acordado }\end{array}$ \\
\hline Idade média dos veículos & Mede a idade média da frota & $\begin{array}{l}\text { IM = Soma da idade da frota/número } \\
\text { total de veículos }\end{array}$ \\
\hline $\begin{array}{l}\text { Acuracidade na emissão } \\
\text { do CT-E }\end{array}$ & $\begin{array}{l}\text { Mede o percentual de CT-Es emitidos } \\
\text { corretamente da primeira vez }\end{array}$ & $\begin{array}{l}\text { Número de CTE emitidos } \\
\text { corretamente/número total de CTE }\end{array}$ \\
\hline $\begin{array}{l}\text { Taxa de acompanhamento } \\
\text { pós-serviço }\end{array}$ & $\begin{array}{l}\text { Mede o número de clientes contatados } \\
\text { após a prestação do serviço }\end{array}$ & $\begin{array}{l}\text { Número de clientes que foram } \\
\text { contatados } * 100 / \mathrm{n}^{\circ} \text { de entregas }\end{array}$ \\
\hline $\begin{array}{l}\text { Solicitações atendidas } \\
\text { (Condições especiais) }\end{array}$ & $\begin{array}{l}\text { Mede o número de entregas urgentes } \\
\text { atendidas no período com êxito. }\end{array}$ & $\begin{array}{l}\text { Total de solicitações com urgência } \\
\text { atendidas } * 100 / \text { Total de pedidos com } \\
\text { urgência }\end{array}$ \\
\hline $\begin{array}{l}\text { Índice de coleta e entrega } \\
\text { no prazo }\end{array}$ & $\begin{array}{l}\text { Mede o \% de entregas (ou coletas) } \\
\text { realizadas dentro do prazo combinado } \\
\text { com o cliente. }\end{array}$ & $\begin{array}{l}\text { \%ERP = número de entregas (coletas) } \\
\text { realizadas no prazo } * 100 / \text { total de } \\
\text { entregas (coletas) realizadas }\end{array}$ \\
\hline Custo de manutenção & $\begin{array}{l}\text { Mede o dispêndio com a manutenção } \\
\text { (corretiva e preventiva) do } \\
\text { equipamento por quilômetro percorrido }\end{array}$ & $\begin{array}{l}\mathrm{Cm} / \mathrm{km}=\text { Custo de manutenção } / \mathrm{km} \\
\text { percorrido }\end{array}$ \\
\hline Custo de pneu & $\begin{array}{l}\text { Mede o dispêndio com gastos com } \\
\text { pneu (compra e recapagem) por } \\
\text { quilômetro percorrido }\end{array}$ & $\mathrm{Cm} / \mathrm{km}=$ Custo de pneu $/ \mathrm{km}$ percorrido \\
\hline Custo de combustível & $\begin{array}{l}\text { Mede o dispêndio com consumo de } \\
\text { combustível por quilômetro percorrido }\end{array}$ & $\begin{array}{l}\mathrm{Cm} / \mathrm{km}=\text { Custo de combustível } / \mathrm{km} \\
\text { percorrido }\end{array}$ \\
\hline
\end{tabular}

Continua 


\begin{tabular}{|c|c|c|}
\hline Indicador & Conceito & Fórmula \\
\hline $\begin{array}{l}\text { Tempo médio } \\
\text { carga/descarga }\end{array}$ & $\begin{array}{l}\text { Mede o tempo em que o veículo } \\
\text { permanece parado para realizar as } \\
\text { operações de carga e descarga }\end{array}$ & $\begin{array}{l}\text { TM = Somatório dos tempos de carga e } \\
\text { descarga / número de operações de carga } \\
\text { e descarga }\end{array}$ \\
\hline Disponibilidade da frota & $\begin{array}{l}\text { Mede a quantidade de veículos } \\
\text { disponíveis para operação }\end{array}$ & $\begin{array}{l}\text { Veículos Ativos - Veículos em } \\
\text { manutenção / veículos em manutenção }\end{array}$ \\
\hline $\begin{array}{l}\text { Utilização da capacidade } \\
\text { de carga }\end{array}$ & $\begin{array}{l}\text { Mede o aproveitamento da capacidade } \\
\text { de carga útil dos equipamentos de } \\
\text { transporte utilizados }\end{array}$ & $\begin{array}{l}\text { UCC }=\text { Carga total transportada em ton } \\
\text { ou } \mathrm{m}^{3 *} 100 / \text { capacidade teórica do } \\
\text { equipamento em ton ou } \mathrm{m}^{3} .\end{array}$ \\
\hline Viagens vazias & $\begin{array}{l}\text { Mede a \% de quilômetros que os } \\
\text { veículos rodaram descarregados }\end{array}$ & $\begin{array}{l}\text { Somatório dos km rodados sem carga/ } \\
\text { Somatório de todos os km rodados }\end{array}$ \\
\hline Avarias & $\begin{array}{l}\text { Mede a \% de entregas cuja carga sofreu } \\
\text { avarias }\end{array}$ & $\begin{array}{l}\text { Número de entregas com avarias / } \\
\text { número total de entregas }\end{array}$ \\
\hline Roubo de cargas & $\begin{array}{l}\text { Mede a \% de entregas cuja carga foi } \\
\text { roubada }\end{array}$ & $\begin{array}{l}\text { Número de cargas roubadas / número } \\
\text { total de entregas }\end{array}$ \\
\hline Acidentes com fatalidades & $\begin{array}{l}\text { Mede a quantidade de acidentes com } \\
\text { fatalidade }\end{array}$ & $\begin{array}{l}\text { Número absoluto de acidentes com } \\
\text { fatalidades }\end{array}$ \\
\hline Acidentes de trânsito & $\begin{array}{l}\text { Mede o número de sinistros de trânsito } \\
\text { com a frota para cada } 1.000 .000 \text { de Km } \\
\text { rodados. }\end{array}$ & $\begin{array}{l}\mathrm{n}^{\circ} \text { total de sinistros de trânsito / milhão } \\
\text { de km rodados pela frota (própria e } \\
\text { terceira) }\end{array}$ \\
\hline Multas por motoristas & $\begin{array}{l}\text { Mede a quantidade de multas recebidas } \\
\text { por cada motorista }\end{array}$ & $\begin{array}{l}\text { Número de multas recebidas no } \\
\text { período/número total de motoristas }\end{array}$ \\
\hline $\begin{array}{l}\text { Ultrapassagem do tempo } \\
\text { de viagem }\end{array}$ & $\begin{array}{l}\text { Mede a quantidade de vezes que o } \\
\text { motorista descumpre as regras de } \\
\text { tempo de jornada estabelecida pela Lei } \\
\mathrm{n}^{\circ} 12.619 / 2012\end{array}$ & $\begin{array}{l}\text { Número de viagens em que o motorista } \\
\text { ultrapassou as regras da Lei } n^{\circ} 12.619 / \\
\text { número total de viagens realizadas }\end{array}$ \\
\hline $\begin{array}{l}\text { Contaminações/Derrames } \\
\text { Zero }\end{array}$ & $\begin{array}{l}\text { Mede a quantidade de acidentes } \\
\text { ambientais (contaminações e derrames) }\end{array}$ & $\begin{array}{l}\text { Número de acidentes ambientais/número } \\
\text { de entregas realizadas. }\end{array}$ \\
\hline Consumo de combustível & $\begin{array}{l}\text { Mede o nível de emissão de poluentes, } \\
\text { com base no consumo de combustível. }\end{array}$ & $\begin{array}{l}\text { Número de Km rodados/número de } \\
\text { litros de combustível }\end{array}$ \\
\hline 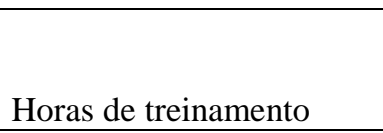 & $\begin{array}{l}\text { Mede a quantidade de horas de } \\
\text { treinamento ministradas para cada } \\
\text { funcionário }\end{array}$ & $\begin{array}{l}\mathrm{n}^{\circ} \text { total de horas de treinamento/n } \mathrm{n}^{\circ} \text { total } \\
\text { de funcionários no ano }\end{array}$ \\
\hline Índice d & $\begin{array}{l}\text { Mede o percentual de funcionários que } \\
\text { a empresa troca por período. }\end{array}$ & $\begin{array}{l}\text { Funcionários substituídos/Funcionários } \\
\text { Totais }\end{array}$ \\
\hline Taxa de absenteísmo & $\begin{array}{l}\text { Refere-se a atrasos, faltas e saídas } \\
\text { antecipadas, de maneira justificada ou } \\
\text { não }\end{array}$ & $\begin{array}{l}\text { Soma das horas de ausência/Total de } \\
\text { horas da jornada de trabalho. }\end{array}$ \\
\hline $\begin{array}{l}\text { Índice de veículos } \\
\text { rastreáveis }\end{array}$ & $\begin{array}{l}\text { Mede o número de veículos com } \\
\text { rastreadores operacionais e } \\
\text { informações disponíveis online }\end{array}$ & $\begin{array}{l}\text { Número de veículos com } \\
\text { rastreadores/Número de veículos totais }\end{array}$ \\
\hline $\begin{array}{l}\text { Gratificação por } \\
\text { colaboradores }\end{array}$ & $\begin{array}{l}\text { Verificar se o sistema de recompensas } \\
\text { oferecido é coerente com a realidade }\end{array}$ & $\begin{array}{l}\text { Número de colaboradores } \\
\text { bonificados/número total de } \\
\text { colaboradores }\end{array}$ \\
\hline $\begin{array}{l}\text { Satisfação dos } \\
\text { empregados }\end{array}$ & $\begin{array}{l}\text { Mede a satisfação dos colaboradores } \\
\text { com a empresa }\end{array}$ & Pesquisa de satisfação \\
\hline
\end{tabular}




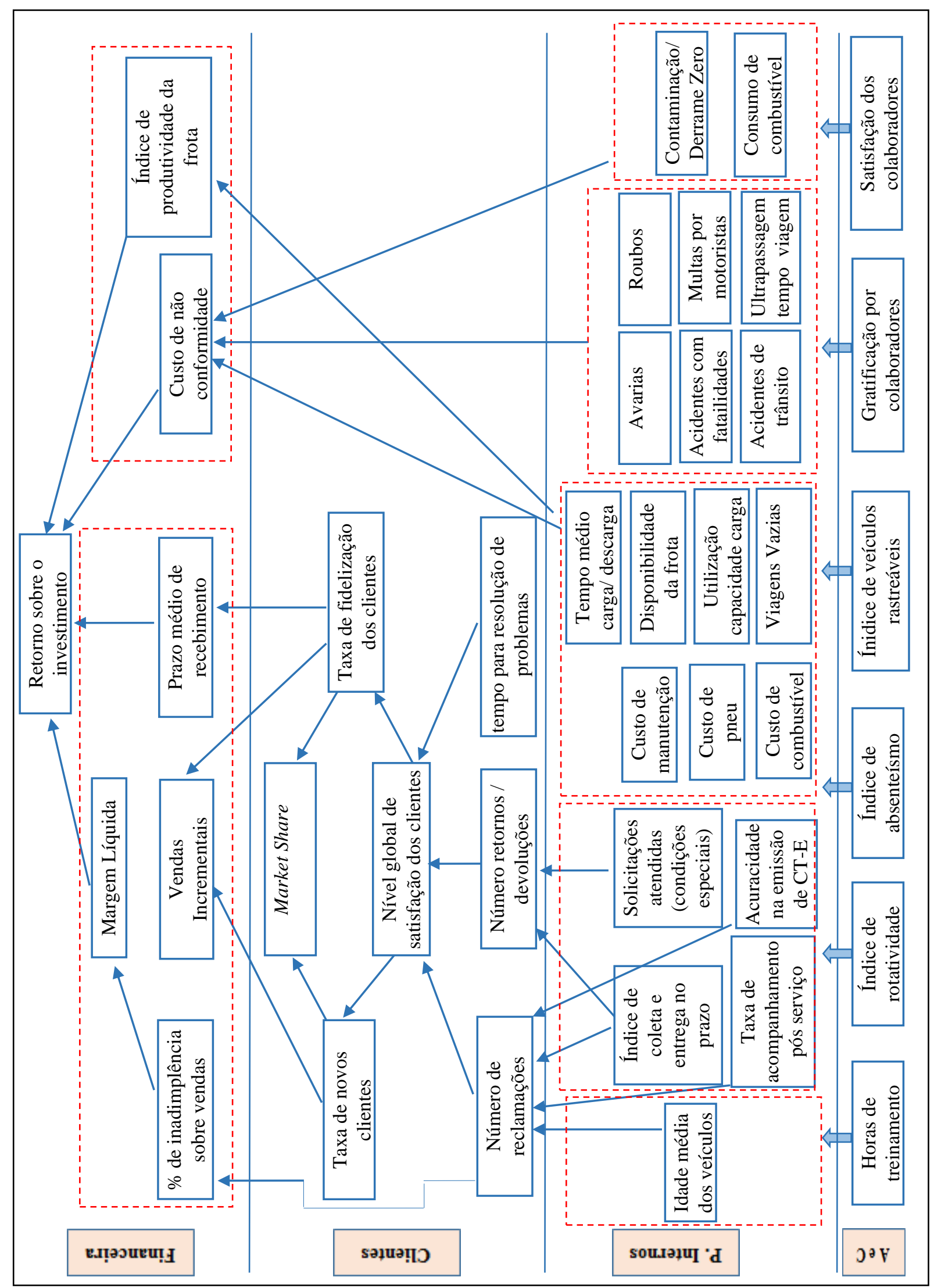

Figura 3.2 - Balanced Scorecard para transportadores rodoviários 


\subsection{DESENVOLVIMENTO DOS ÍNDICES DE DESEMPENHO}

No Balanced Scorecard, os indicadores de desempenho são mensurados individualmente e sua medição serve para avaliar se o objetivo vinculado ao indicador está sendo alcançado ou não. Não há, entretanto, no Balanced Scorecard uma avaliação quantitativa do desempenho de cada uma das perspectivas consolidada.

Isto é, uma perspectiva é composta por uma série de indicadores, os quais normalmente têm desempenhos distintos, podendo alcançar ou não a meta estabelecida. Ademais, não há uma distinção quanto ao grau de importância de cada indicador. Assim, em um contexto, em que alguns indicadores atingiram a meta e outros não atenderam, como se deve caracterizar o desempenho da perspectiva? O Balanced Scorecard não é capaz de responder este questionamento de forma quantitativa.

Dessa forma, este projeto propõe que, a partir da estrutura de indicadores de desempenho que compõem o Balanced Scorecard, sejam desenvolvidos índices para cada uma das perspectivas, assim como um índice de desempenho global da prestação do serviço.

Ou seja, no modelo de medição de desempenho proposto, atribui-se adicionalmente pesos a cada um dos indicadores de desempenho do Balanced Scorecard, de acordo com seu grau importância, para criar os índices financeiro, de clientes, de processos internos e de aprendizado e crescimento (índices de perspectiva), assim como o índice de desempenho global.

Com isso pretende-se que o Balanced Scorecard seja capaz de mensurar quantitativamente o desempenho das empresas em cada uma das perspectivas, assim como o seu desempenho global. Além disso, caso este modelo de medição seja adotado por uma série de empresas, os índices serviram como uma ferramenta para realizar benchmarking de desempenho.

Para a definição dos pesos e, consequente, construção dos índices de desempenho utiliza-se a metodologia multicritério de apoio à decisão construtivista (MDCA-C). Não será utilizada a metodologia por completo, apenas algumas de suas ferramentas. 


\subsubsection{ESTRUTURAÇÃO DO PROBLEMA}

Na fase de estruturação, entende-se que o contexto estabelecido para o problema é a criação de um índice global de desempenho com base nos indicadores desenvolvidos através do Balanced Scorecard. O rótulo definido que melhor representa o problema é: avaliação do desempenho global da prestação do serviço. Identificam-se, no momento da construção do Scorecard, os seguintes atores que direta e/ou indiretamente influenciam no desempenho da empresa: os gerentes e diretores são considerados os decisores, o autor da dissertação é o facilitador e os colaboradores são denominados agidos, conforme Quadro 3.7.

Quadro 3.7- Atores envolvidos

\begin{tabular}{|l|l|}
\hline Decisor & Gerente / Diretor \\
\hline Facilitador & Autor \\
\hline Agidos & Colaboradores \\
\hline
\end{tabular}

No presente projeto, os EPA foram identificados pelo autor (no papel de decisor), com base na literatura relativa aos indicadores de desempenho. Ou seja, os elementos primários de avaliação deste problema são os objetivos e indicadores de desempenho do sistema de medição desenvolvido, os quais constam do Quadro 3.5.

Após a definição dos EPA, esses são agrupados em áreas de preocupação de acordo com suas relações de causa-efeito. No presente estudo, o mapa de relações meios-fins é representado pelo Mapa Estratégico e pelo Balanced Scorecard desenvolvidos neste capítulo (Figuras 3.1 e 3.2), visto que agrupa os indicadores em áreas de medição, além de estabelecer relações de causa e efeito.

Uma vez construído o mapa meios-fins, a metodologia MCDA-C propõe que a estrutura de relações de influência seja convertida em uma estrutura hierárquica de valor. É a partir da transcrição do mapa cognitivo (Balanced Scorecard) para a árvore de pontos de vistas (estrutura hierárquica) que as ferramentas do MDCA-C serão incorporadas ao sistema de medição de desempenho.

Assim, a partir da tradução do mapa estratégico e do Balanced Scorecard, desenvolveu-se a arborescência dos pontos de vista, conforme Figura 3.3 a seguir: 


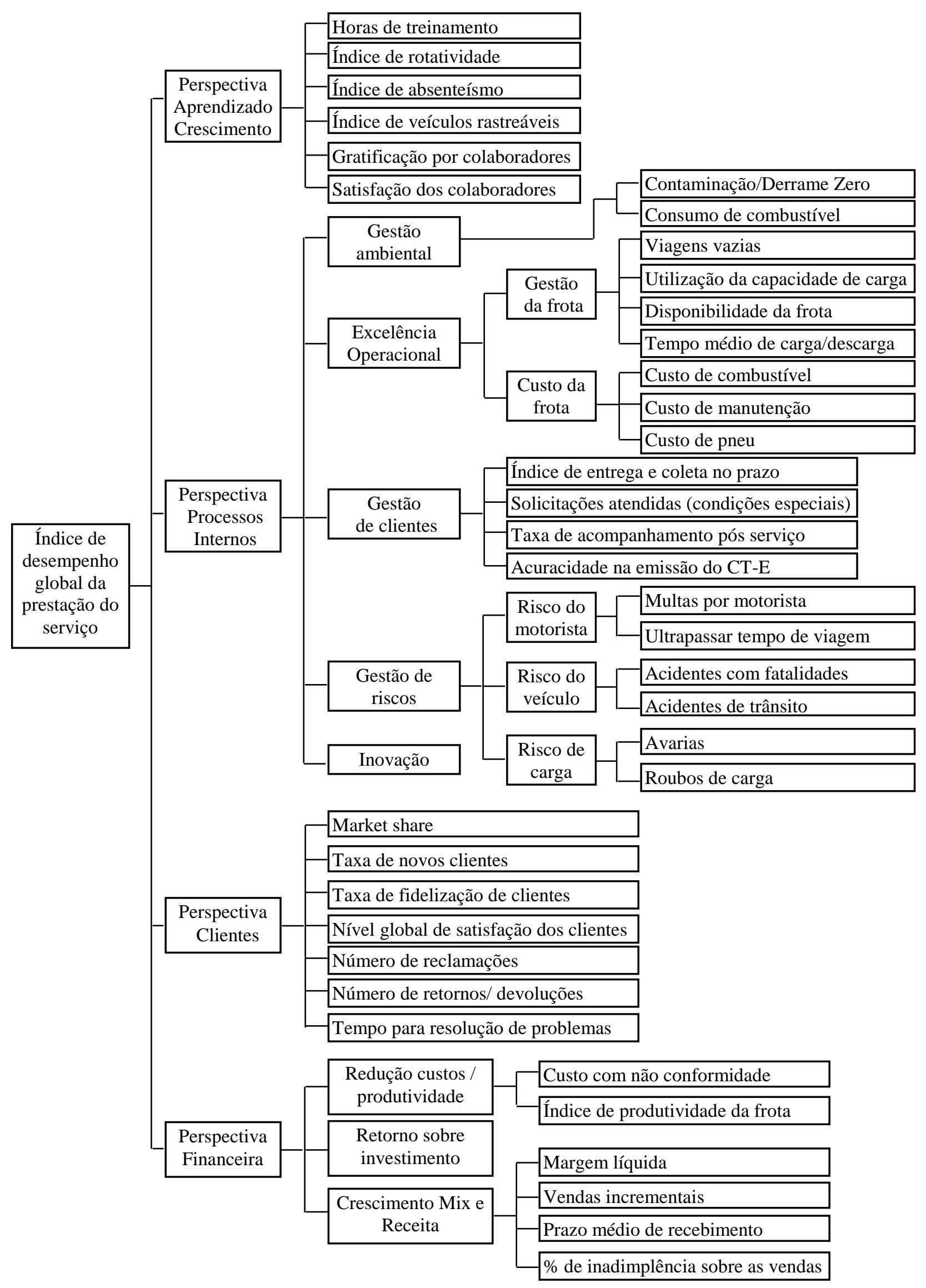

Figura 3.3 - Árvore dos pontos de vistas fundamentais 
A última etapa da fase de estruturação do modelo é a construção dos descritores, que irão apresentar os possíveis níveis de desempenho para cada PVE (critério) de análise, os quais vão permitir a mensuração e avaliação da performance. Na estrutura de arborescência desenvolvida, todos os pontos de vista fundamentais representam indicadores de desempenho construídos através do Balanced Scorecard. Assim entende-se que o descritor genérico para modelo em estudo pode ser representado, conforme Quadro 3.8. Destaca-se que os níveis aceitáveis para cada indicador foram selecionados através da revisão bibliográfica.

Quadro 3.8- Descritor Genérico

\begin{tabular}{|c|c|c|}
\hline \multicolumn{3}{|c|}{ Descritor } \\
\hline Níveis de impacto & Níveis de Referência & Descrição \\
\hline N10 & & Acima de $80 \%$ da Meta \\
\hline N9 & & Entre $60 \%$ e $80 \%$ da Meta \\
\hline N8 & & Entre $40 \%$ e $60 \%$ da Meta \\
\hline N7 & & Entre $20 \%$ e $40 \%$ da Meta \\
\hline N6 & Bom & Entre Meta e $20 \%$ da Meta \\
\hline N5 & & Atingiu a Meta \\
\hline N4 & Neutro & Entre Meta e $-20 \%$ da Meta \\
\hline N3 & & Entre $-20 \%$ e $-40 \%$ da Meta \\
\hline $\mathrm{N} 2$ & & Entre $-40 \%$ e $-60 \%$ da Meta \\
\hline N1 & & Entre $-60 \%$ e $-80 \%$ da Meta \\
\hline N0 & & Menor que $-80 \%$ da Meta \\
\hline
\end{tabular}

\subsubsection{DEFINIÇÃO DA FUNÇÃO DE VALOR}

A fase de avaliação visa à construção de um modelo matemático, conforme a percepção dos decisores, o qual possibilitará o cálculo dos índices das perspectivas e do desempenho global das empresas.

No estudo em questão, cada ponto de vista fundamental ou elementar representa um indicador de desempenho, o qual possui uma escala própria. De acordo com a medição, este indicador será classificado em um nível de impacto. Em seguida, através da função de valor, os níveis de impacto são transformados em valores quantitativos. Portanto, a função de valor permitirá quantificar os indicadores de desempenho em uma mesma unidade de medida de referência, possibilitando assim a construção dos índices de desempenho.

Para cada um dos intervalos de performance foi definido um valor quantitativo, por meio do método do julgamento semântico. Assim, de acordo com o intervalo selecionado pela 
empresa, será atribuído ao indicador de desempenho a seguinte função de valor (nota de performance):

Quadro 3.9 - Determinação das funções de valor

\begin{tabular}{|l|l|l|r|}
\hline \multicolumn{3}{|c|}{ Descritor } \\
\hline Níveis de impacto & Níveis de Referência & \multicolumn{1}{|c|}{ Descrição } & Função de Valor \\
\hline N10 & & Acima de 80\% da Meta & 10 \\
\hline N9 & & Entre 60\% e 80\% da Meta & 9 \\
\hline N8 & & Entre 40\% e 60\% da Meta & 7 \\
\hline N7 & & Entre 20\% e 40\% da Meta & 6 \\
\hline N6 & Eom & Atre Meta e 20\% da Meta & 5 \\
\hline N5 & & Entre Meta e -20\% da Meta & 4 \\
\hline N4 & Neutro & Entre -20\% e -40\% da Meta & 3 \\
\hline N3 & & Entre -40\% e -60\% da Meta & 2 \\
\hline N2 & & Entre -60\% e -80\% da Meta & 1 \\
\hline N1 & & Menor que - 80\% da Meta & 0 \\
\hline N0 & & &
\end{tabular}

\subsubsection{DEFINIÇÃO DAS TAXAS DE SUBSTITUIÇÃO}

A etapa seguinte da construção do modelo matemático é a definição das taxas de substituição. Para definir os pesos dos indicadores de desempenho propostos utilizou-se a técnica de grupo focal, na qual a coleta de dados ocorre através da interação de um grupo homogêneo sobre um tópico determinado pelo pesquisador (MORGAN, 1996).

Neste sentido, o pesquisador definiu um grupo composto por empresas de transporte rodoviário de cargas pertencentes à Associação Nacional do Transporte de Cargas e Logística. Em 23 de fevereiro de 2016, realizou-se a pesquisa em uma reunião com os transportadores, na qual foi apresentada a proposta do projeto de pesquisa e solicitado que as empresas contribuíssem com o desenvolvimento do sistema de medição de desempenho. Ao final da reunião, foi aplicado o questionário apresentado no Anexo I, junto a 15 especialistas das empresas de transporte rodoviário de cargas, que se disponibilizaram a participar do estudo em questão.

$\mathrm{Na}$ sequência, os questionários preenchidos foram analisados, com o intuito de verificar inconsistências no preenchimento. Três questionários foram excluídos por terem sido preenchidos de forma incompleta e outros dois excluídos por estarem com informação inconsistente. 
Os dados dos 10 questionários corretos foram agrupados, de modo a estabelecer a nota média para cada indicador de desempenho analisado. Observou-se que a maioria dos entrevistados atribuiu a mesma nota para o indicador Tempo de resposta às solicitações e para o indicador Tempo para resolução de problemas. Ao questioná-los, os entrevistados indicaram que os dois indicadores tinham o mesmo significado e objetivo de medição. Assim, optou-se por excluir o indicador tempo de resposta às solicitações do sistema de medição de desempenho. Excluiuse também o indicador porcentagem do custo de transporte sobre as vendas, pois para os entrevistados este indicador estaria associado ao embarcador, que necessita mensurar qual o impacto do transporte no preço final do produto.

Em seguida, foi realizada a normalização dos valores atribuídos, que consistiu em relativizar a participação de cada indicador em relação ao somatório de notas de seu respectivo grupo de indicadores. Ou seja, a normalização permite estabelecer os pesos de cada um dos indicadores do sistema de medição de desempenho. Os resultados são apresentados no Quadro 3.10 a seguir.

Vale destacar que os pesos estabelecidos para os indicadores não podem ser generalizados para todos os transportadores rodoviários, visto que representam o grau de importância estabelecido por um conjunto de empresas pré-selecionados. Assim antes de aplicar o modelo proposto, a transportadora deve calibrar os pesos dos indicadores para que o sistema de medição de desempenho possa traduzir sua realidade. 
Quadro 3.10 - Ponderação dos indicadores de desempenho

\begin{tabular}{|c|c|c|}
\hline \multirow{41}{*}{ 龸 } & Indicadores do Sistema de Medição de Desempenho & Pesos \\
\hline & 1.1.1. Margem líquida & $3,3 \%$ \\
\hline & 1.1.2. Vendas incrementais & $2,1 \%$ \\
\hline & 1.1.3. Prazo médio de recebimento & $1,8 \%$ \\
\hline & 1.1.4. \% de inadimplência sobre vendas & $1,3 \%$ \\
\hline & 1.2. Retorno sobre o investimento & $14,7 \%$ \\
\hline & 1.3.1. Custo com não conformidade & $2,8 \%$ \\
\hline & 1.3.2. Índice de produtividade da frota & $6,1 \%$ \\
\hline & 2.1. Taxa de novos clientes & $3,6 \%$ \\
\hline & 2.2. Taxa de fidelização de clientes & $4,0 \%$ \\
\hline & 2.3. Nível global de satisfação dos clientes & $4,4 \%$ \\
\hline & 2.4. Market-share & $1,9 \%$ \\
\hline & 2.5. Número de reclamações & $5,4 \%$ \\
\hline & 2.6. Número de retornos ou devoluções & $3,5 \%$ \\
\hline & 2.7. Tempo para resolução de problemas & $4,5 \%$ \\
\hline & 3.1.1.1. Custo de manutenção & $1,2 \%$ \\
\hline & 3.1.1.2. Custo de pneu & $0,9 \%$ \\
\hline & 3.1.1.3. Custo de combustível & $1,1 \%$ \\
\hline & 3.1.2.1. Tempo médio carga/descarga & $0,6 \%$ \\
\hline & 3.1.2.2. Disponibilidade da frota & $0,7 \%$ \\
\hline & 3.1.2.3. Utilização da capacidade de carga & $0,8 \%$ \\
\hline & 3.1.2.4. Viagens vazias & $0,6 \%$ \\
\hline & 3.2. Idade média dos veículos & $3,5 \%$ \\
\hline & 3.3.1. Acuracidade na emissão do CT-E & $1,2 \%$ \\
\hline & 3.3.2. Taxa de acompanhamento pós-serviço & $1,2 \%$ \\
\hline & 3.3.3. Solicitações atendidas (Condições especiais) & $1,3 \%$ \\
\hline & 3.3.4. Índice de coleta e entrega no prazo & $2,4 \%$ \\
\hline & 3.4.1. Contaminações/Derrames Zero & $1,3 \%$ \\
\hline & 3.4.2. Consumo de combustível & $1,4 \%$ \\
\hline & 3.5.1.1. Avarias & $0,9 \%$ \\
\hline & 3.5.1.2. Roubo de cargas & $0,6 \%$ \\
\hline & 3.5.2.1. Acidentes com fatalidades & $0,9 \%$ \\
\hline & 3.5.2.1. Acidentes de trânsito & $0,5 \%$ \\
\hline & 3.5.3.1. Multas por motoristas & $0,8 \%$ \\
\hline & 3.5.3.2. Ultrapassagem do tempo de viagem & $1,5 \%$ \\
\hline & 4.1. Horas de treinamento & $2,8 \%$ \\
\hline & 4.2. Índice de rotatividade & $3,7 \%$ \\
\hline & 4.3. Taxa de absenteísmo & $2,8 \%$ \\
\hline & 4.4. Índice de veículos rastreáveis & $1,3 \%$ \\
\hline & 4.5. Gratificação por colaboradores & $2,6 \%$ \\
\hline & 4.6. Satisfação dos empregados & $3,9 \%$ \\
\hline
\end{tabular}

\subsubsection{CÁLCULO DOS ÍNDICES DE DESEMPENHO}

De posse dos pesos atribuídos a cada indicador de desempenho é possível construir os índices propostos neste trabalho. Para calcular os índices das perspectivas e o global, utiliza-se a fórmula de agregação aditiva que é formada pela soma dos modelos de cada PVF. Assim, a fórmula será (ENSSLIN et al., 2001): 
$\mathrm{V}(\mathrm{a})=\Sigma_{\mathrm{i}=1}^{\mathrm{n}}$ wi $\mathrm{x}$ vi

Onde:

V(a) - Valor da pontuação obtida no índice a.

v 1 (a), v 2 (a), ... v n (a) - Valor parcial obtido nos indicadores $1,2, \ldots, n$ do índice a.

w 1 (a), w2 (a), ... wn (a) - Taxas de substituição dos indicadores 1, 2, .., n.

n - número de critérios do modelo.

Assim os índices das perspectivas do Balanced Scorecard são calculados da seguinte forma:

a) Índice da perspectiva financeira

$\mathrm{IPF}=100 *\left(3,3 * \mathrm{~V}_{1.1 .1}+2,1 * \mathrm{~V}_{1.1 .2}+1,8 * \mathrm{~V}_{1.1 .3}+1,3 * \mathrm{~V}_{1.1 .4}+14,7 * \mathrm{~V}_{1.2}+2,8 * \mathrm{~V}_{1.3 .1}+\right.$ $\left.6,1 \% * \mathrm{~V}_{1.3 .2}\right) / 32,1$

b) Índice da perspectiva dos clientes

$\mathrm{IPC}=100 *\left(3,6 * \mathrm{~V}_{2.1}+4,0 * \mathrm{~V}_{2.2}+4,4 * \mathrm{~V}_{2.3}+1,9 * \mathrm{~V}_{2.4}+5,4 * \mathrm{~V}_{2.5}+3,5 * \mathrm{~V}_{2.6}+4,5 \% * \mathrm{~V}_{2.7}\right) /$ 27,3

c) Índice da perspectiva dos processos internos

IPI $=100 *\left(1,2 * \mathrm{~V}_{3.1 .1 .1}+0,9 * \mathrm{~V}_{3.1 .1 .2}+1,1 * \mathrm{~V}_{3.1 .1 .3}+0,6 * \mathrm{~V}_{3.1 .2 .1}+0,7 * \mathrm{~V}_{3.1 .2 .2}+0,8^{*} \mathrm{~V}_{3.1 .2 .3}+\right.$ $0,6 \% * \mathrm{~V}_{3.1 .2 .4}+3,5 \% * \mathrm{~V}_{3.2}+1,2 * \mathrm{~V}_{3.3 .1}+1,2 * \mathrm{~V}_{3.3 .2}+1,3 * \mathrm{~V}_{3.3 .3}+2,4 * \mathrm{~V}_{3.3 .4}+1,3 * \mathrm{~V}_{3.4 .1}+$ $1,4 * \mathrm{~V}_{3.4 .2}+0,9 * \mathrm{~V}_{3.5 .1 .1}+0,6 * \mathrm{~V}_{3.5 .1 .2}+0,9 * \mathrm{~V}_{3.5 .2 .1}+$ $\left.0,5 * \mathrm{~V}_{3.5 .2 .2}+0,8 * \mathrm{~V}_{3.5 .3 .1}+1,5 * \mathrm{~V}_{3.5 .3 .2}\right) / 23,4$

d) Índice da perspectiva do Aprendizado e Crescimento

$\operatorname{IPAC}=100 *\left(2,8 * \mathrm{~V}_{4.1}+3,7 * \mathrm{~V}_{4.2}+2,8 * \mathrm{~V}_{4.3}+1,3 * \mathrm{~V}_{4.4}+2,6 * \mathrm{~V}_{4.5}+3,9 * \mathrm{~V}_{4.6}\right) / 17,2$

Por fim o índice de desempenho global da prestação do serviço é obtido através da seguinte equação:

$\mathrm{IDG}=32,1 * \mathrm{IPF}+27,3 * \mathrm{IPC}+23,4 * \mathrm{IPP}+17,2 * \mathrm{IPAC}$ 


\subsection{O MODELO PROPOSTO DO BALANCED SCORECARD}

O processo de coleta de dados permitiu validar os indicadores de desempenho selecionados na literatura, excluindo aqueles que a maioria dos entrevistados entendeu não se aplicar a empresas de transporte rodoviário de cargas, como aqueles duplicados, isto é, nos casos em que havia outro indicador medindo o mesmo objetivo. Ademais, permitiu mensurar o grau de importância de cada um dos indicadores, isto é, os pesos dos indicadores, que possibilitou a construção matemática dos índices propostos.

Buscando criar uma ferramenta útil e de fácil entendimento para os transportadores rodoviários, o sistema de medição de desempenho foi desenvolvido com o auxílio do programa Microsoft Excel 2013. O sistema é constituído por duas telas. A primeira tela é denominada de "Inputs da Avaliação de Desempenho", conforme Figura 3.4 a seguir. Nesta tela a empresa deverá indicar qual foi a sua real performance em cada um dos indicadores de desempenho. A tela é composta por 13 colunas:

- A "coluna A" descreve cada um dos indicadores de desempenho que constituem o sistema de medição de desempenho.

- A "coluna B" determina as metas de desempenho esperadas para os respectivos indicadores de desempenho. Estas metas foram definidas com base na literatura e podem ser ajustadas ao longo do tempo.

- As demais colunas representam os possíveis níveis de impacto para cada um dos indicadores de desempenho. Ou seja, representa o campo da tela em que a empresa deverá indicar o intervalo de sua performance.

Como se pode observar na Figura 3.4, o sistema de medição de desempenho foi desenhado com dez possíveis intervalos de performance. Para cada um dos intervalos de performance foi definido um valor quantitativo, com base na função de valor. 
Coluna A

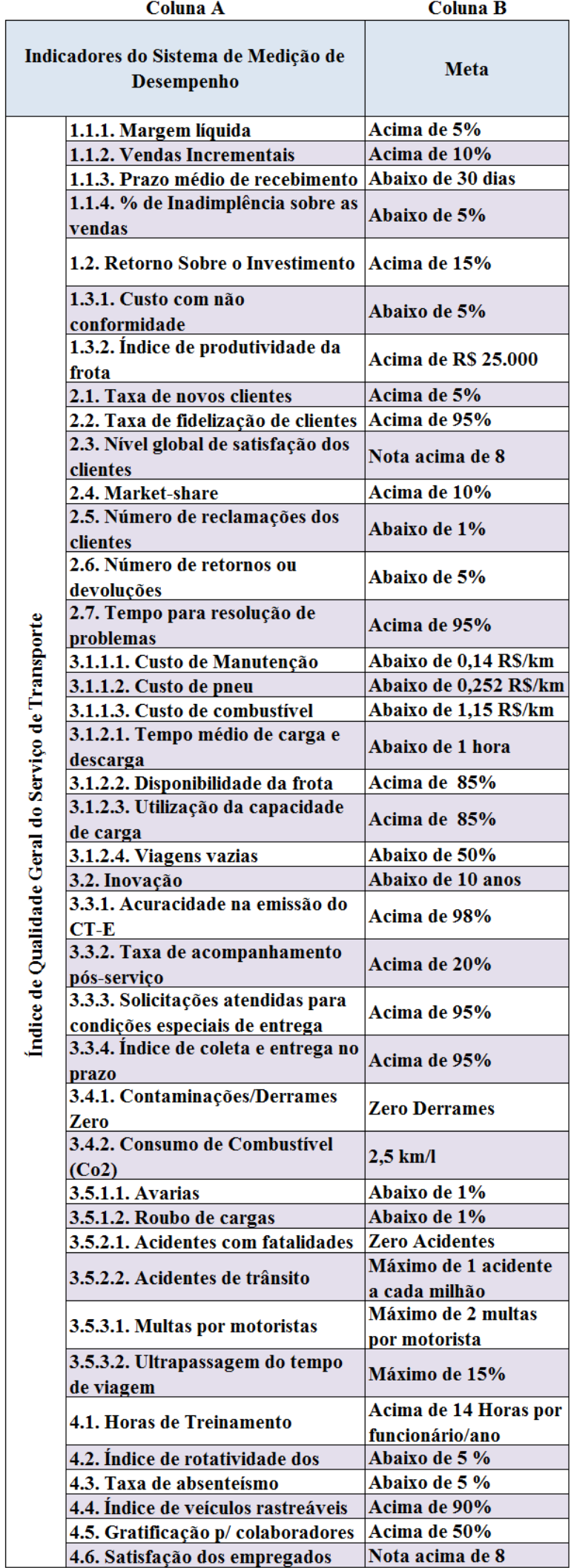

Coluna C

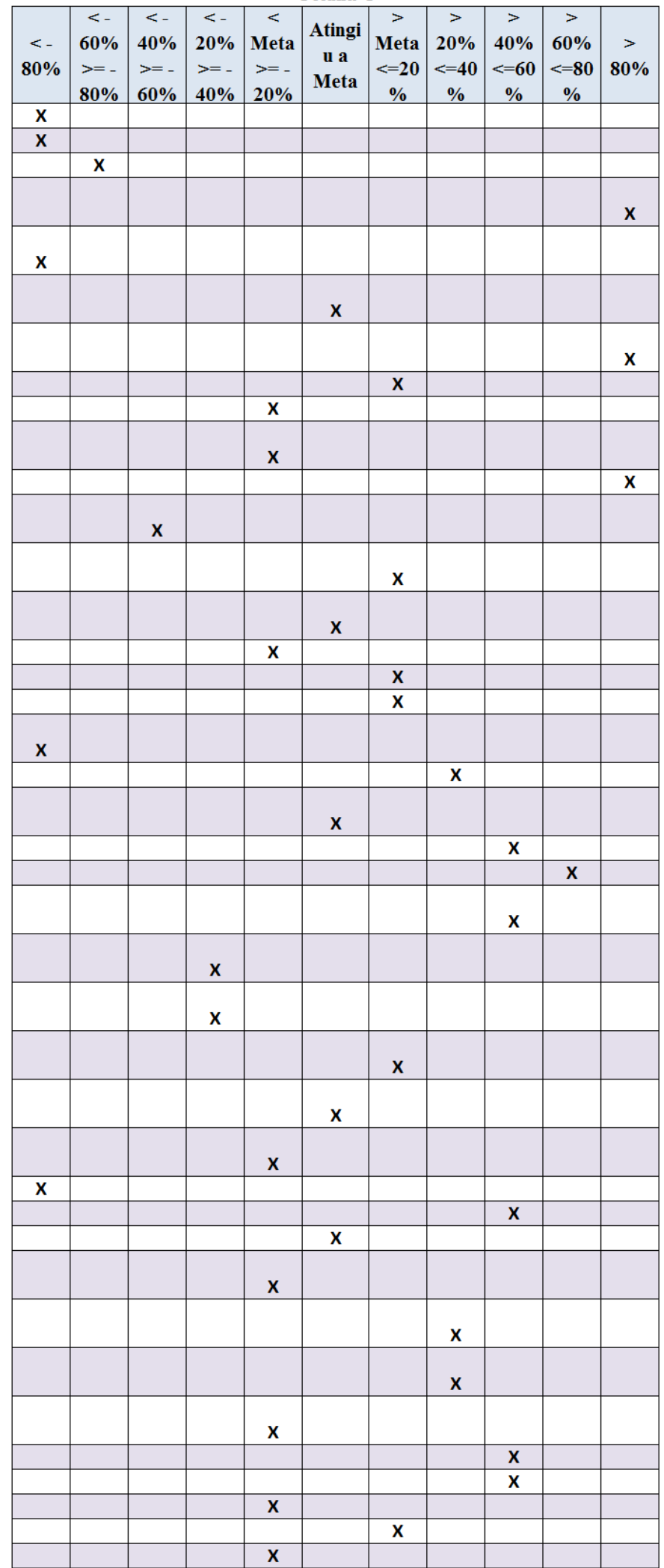

Figura 3.4 - Inputs de Avaliação de desempenho 
A segunda tela do sistema é denominada "Painel do Balanced Scorecard". Esta tela foi desenvolvida com a proposta de ser o painel de controle do Balanced Scorecard, permitindo um gerenciamento visual do sistema de medição de desempenho. Assim, a empresa poderá visualizar em uma única página toda sua performance de desempenho, através de uma comunicação simples e clara, que proporciona um "feedback" efetivo e imediato.

Conforme pode-se observar na Figura 3.5, os indicadores de desempenho estão subdivididos em cada uma das quatros perspectivas: financeira, dos clientes, dos processos internos e do aprendizado e crescimento. As perspectivas foram separadas por linhas tracejadas em azul. Os indicadores foram apresentados em caixas, que na parte superior contém a descrição do indicador e na parte inferior a nota atribuída ao mesmo, conforme indicado na tela "Inputs da Avaliação de Desempenho". De acordo com a performance atribuída ao indicador, a caixa assume uma gradação de cor, conforme escala apresentada a seguir:

Quadro 3.11 - Cor associada a performance

\begin{tabular}{|c|c|c|}
\hline Descritos & Função de Valor & Cor Associada \\
\hline Acima de $80 \%$ da Meta & 10 & \multirow[t]{3}{*}{ Verde escuro } \\
\hline Entre $60 \%$ e $80 \%$ da Meta & 9 & \\
\hline Entre $40 \%$ e $60 \%$ da Meta & 8 & \\
\hline Entre $20 \%$ e $40 \%$ da Meta & 7 & \multirow[t]{2}{*}{ Verde claro } \\
\hline Entre Meta e $20 \%$ da Meta & 6 & \\
\hline Atingiu a Meta & 5 & Azul \\
\hline Entre Meta e $-20 \%$ da Meta & 4 & \multirow[t]{2}{*}{ Amarelo } \\
\hline Entre $-20 \%$ e $-40 \%$ da Meta & 3 & \\
\hline Entre $-40 \%$ e $-60 \%$ da Meta & 2 & \multirow{3}{*}{ Vermelho } \\
\hline Entre $-60 \%$ e $-80 \%$ da Meta & 1 & \\
\hline Menor que $-80 \%$ da Meta & 0 & \\
\hline
\end{tabular}

O Painel de controle, também permite gerenciar os índices em cada uma das perspectivas. Os índices das quatro perspectivas estão dispostos na lateral da tela e são calculados de forma automática, associando as notas atribuídas a cada um dos indicadores à ponderação realizada no Quadro 3.11.

Por fim, o Painel de controle apresenta o índice de qualidade geral do transporte na parte superior da tela, o qual sintetiza o nível de serviço prestado pela empresa transportadora com base nos indicadores apresentados. 


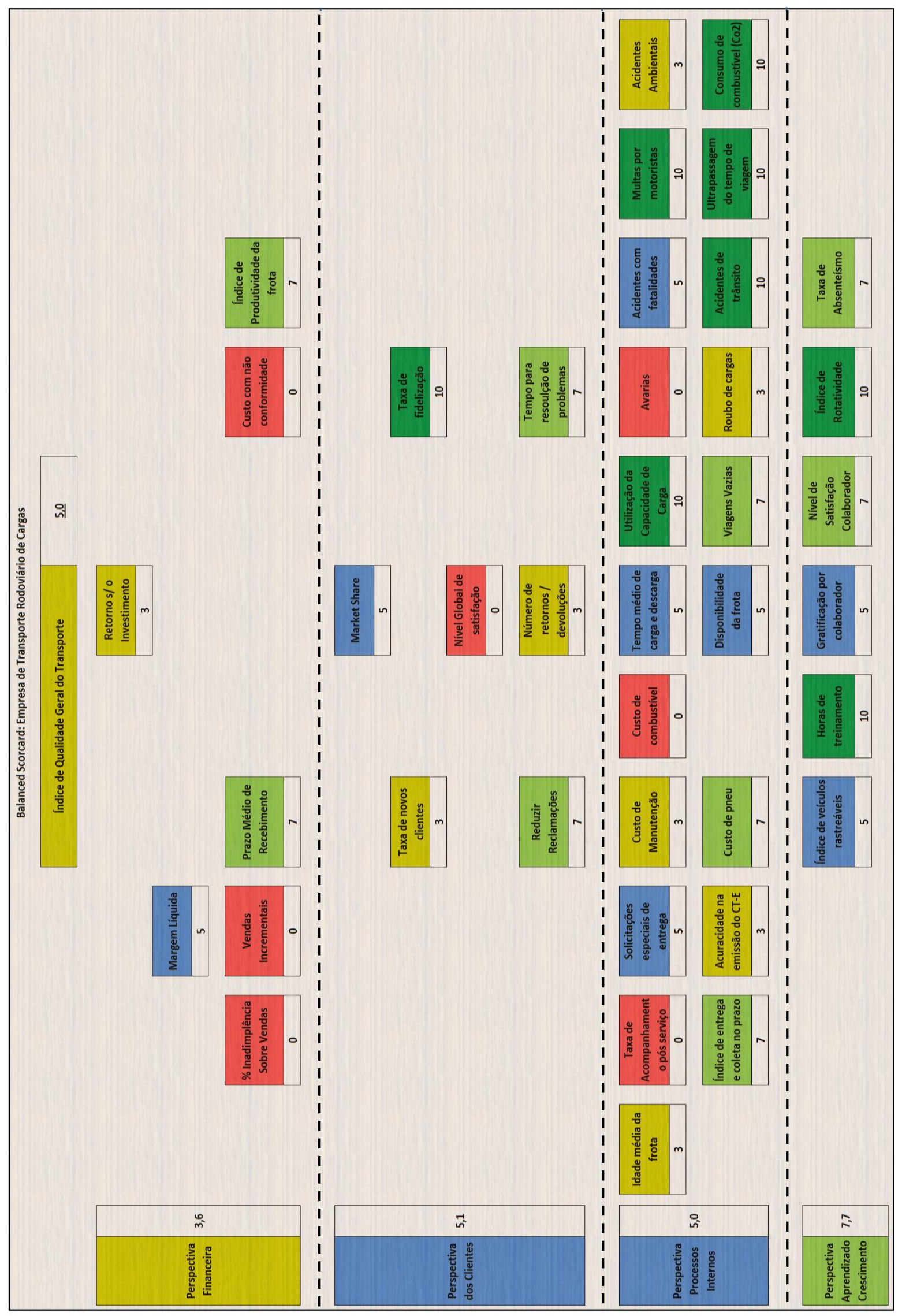

Figura 3.5 - Painel de controle do Balanced Scorecard 


\section{APLICAÇÃ̃O DO MÉTODO}

Neste capítulo, será aplicado o sistema de medição de desempenho em uma empresa de transporte rodoviário de cargas, com o intuito de demonstrar a forma de coleta de dados e a utilização do modelo.

\subsection{Utilização do modelo proposto.}

Para que o modelo proposto do Balanced Scorecard seja utilizado de forma efetiva, é necessário obter, previamente, os dados referentes a cada um dos indicadores de desempenho que compõem o sistema. Assim, neste tópico, para demonstrar como se deve proceder a coleta dos dados e a consequente construção dos indicadores de desempenho, será aplicado o modelo proposto em uma empresa de transporte rodoviário de cargas.

A aplicação será realizada na Transportadora X, empresa de capital aberto, cujas ações são cotadas na Bovespa e que é um dos maiores operadores logísticos do país. Decidiu-se selecionar esta empresa pelo fato de boa parte dos dados necessários para construção do Scorecard estarem disponíveis ao público. Deve-se destacar que para os dados não disponibilizados foram realizadas simulações de dados compatíveis com a realidade financeira e operacional da empresa, como forma de exemplificar a construção do modelo.

Inicialmente, será abordada a construção dos indicadores financeiros. Os dados referentes a Vendas incrementais, Margem Líquida, Retorno sobre o investimento e \% de inadimplência sobre as vendas podem ser obtidos diretamente da Demonstração de Resultados do Exercício (DRE) da empresa. Como exemplo, foi utilizada a DER da Transportadora X, cujos resultados são divulgados trimestralmente aos investidores.

O indicador vendas incrementais tem como objetivo medir o aumento, em reais, da prestação do serviço de transporte. Assim, comparando-se a receita bruta do período anterior com a receita bruta do período subsequente, obtém-se o incremento de vendas. Conforme o Quadro 4.1, no ano de 2014 a receita bruta foi de R\$ 1.787.295 milhões, enquanto que em 2015 a receita bruta foi de $\mathrm{R} \$ 1.392 .056$ milhões, o que representa uma redução nas vendas de $22 \%$. 
Quadro 4.1 - DRE Transportadora X (em R\$ Mil)

\begin{tabular}{|c|c|c|}
\hline Demonstração de resultado consolidado & 2014 & 2015 \\
\hline Receita bruta & 1.787.295 & 1.392 .056 \\
\hline Logística automotiva & 1.556 .989 & 1.149 .215 \\
\hline Logística integrada & 230.306 & 242.841 \\
\hline (-) Impostos e deduções & $(347.741)$ & $(269.492)$ \\
\hline Receita líquida & 1.439.554 & 1.122 .564 \\
\hline (-) Custo dos serviços prestados & $(1.195 .066)$ & $(974.323)$ \\
\hline Com pessoal & $(133.535)$ & $(121.282)$ \\
\hline Com agregados (terceiros) & $(957.147)$ & $(726.152)$ \\
\hline Outros & $(204.378)$ & $(208.421)$ \\
\hline Crédito de PIS/COFINS & 99.994 & 81.533 \\
\hline Lucro bruto & 244.488 & 148.242 \\
\hline (-) Despesas gerais e administrativas & $(97.922)$ & $(83.700)$ \\
\hline (-) Outras despesas e receitas & 7.028 & $(22.278)$ \\
\hline Lucro operacional & 153.594 & 42.264 \\
\hline (-) Resultado financeiro & $(38.845)$ & $(32.955)$ \\
\hline (-) Equivalência patrimonial & 2.376 & 1.867 \\
\hline Lucro antes do IR e da CS & $\mathbf{1 1 7 . 1 2 5}$ & $\mathbf{1 1 . 1 7 6}$ \\
\hline (-) Imposto de renda e contribuição social & $(46.035)$ & $(1.246)$ \\
\hline Lucro líquido sem operação descontinuada & 71.090 & 9.929 \\
\hline (-) Prejuízo da operação descontinuada & $(38.673)$ & - \\
\hline (-) Efeitos extraordinários relativo à venda da direct & $(55.363)$ & - \\
\hline (-) Participação de minoritários & $(17)$ & - \\
\hline Lucro líquido & $(22.963)$ & 9.929 \\
\hline
\end{tabular}

Fonte: TEGMA (2016)

O indicador Margem líquida mede a fração de cada real de vendas que resultou em lucro líquido e é obtida através da relação entre o Lucro líquido e a Receita Bruta. De acordo com o Quadro 4.1, o lucro líquido foi de $\mathrm{R} \$ 9.929$ milhões, enquanto que a receita bruta foi de $\mathrm{R} \$$ 1.392.056 milhões, o que representa uma margem líquida de 0,07\%.

O indicador Retorno sobre o investimento (ROI) mede o retorno para os acionistas do capital investido na empresa, através da relação entre o lucro líquido e o ativo total da empresa. A informação do Ativo Total não se encontra na DRE, mas sim no Balanço Patrimonial da empresa. Ademais, o mesmo representa uma média entre o valor do ativo no início do período e no final do período. De acordo com o Balanço divulgado pela Transportadora X, o Ativo Total da empresa em 2015 foi de R 903.173 milhões. Portanto, para um lucro líquido de R\$ 9.929 milhões, o retorno sobre o investimento foi de $1,1 \%$. 
Outro indicador que não se obtém exclusivamente a partir da DRE é a porcentagem de inadimplência sobre as vendas. A provisão para créditos de realização duvidosa pode ser obtida a partir da Demonstração de Fluxo de Caixa. Para 2015, esta previsão foi de R $\$ 1.200$ milhões. Assim, considerando uma receita bruta de R $\$ 1.392 .056$ milhões, a porcentagem de inadimplência representa $0,08 \%$ das vendas.

Já o índice de produtividade da frota mede a receita mensal por unidade veicular. Ou seja, sua medição é realizada pela relação entre a receita total e frota total da empresa. Conforme comunicado relevante emitido no quarto trimestre de 2015, a frota da empresa é de 1904 veículos. Assim, para uma receita bruta de R \$ 1.392.056 milhões em 2015, a receita mensal por veículo é de $\mathrm{R} \$ 60$ mil reais.

Os indicadores financeiros de Prazo médio de recebimento e de Custo com não conformidade não podem ser obtidos através das demonstrações contábeis. O prazo médio de recebimento é controlado, normalmente, nas empresas pelo setor de cobrança. Para a Transportadora X, o prazo médio de recebimento foi de 50 dias, conforme o comunicado emitido. Já o custo com não conformidade representa o custo adicional do serviço de transporte devido a erros na sua execução. Tal informação pode ser obtida diretamente com os gestores operacionais. Neste caso, não foi possível obter este indicador, a partir das informações publicadas pela Transportadora X. A meta para este indicador é de 5\%.

Observa-se, portanto, que a maioria dos indicadores financeiros é extraída, na totalidade ou em parte, por meio das demonstrações contábeis da empresa. Como foi possível mensurar todos os indicadores financeiros da empresa Transportadora X, com exceção do custo com não conformidade, pode-se simular seu desempenho na perspectiva financeira do Balanced Scorecard, conforme Figura 4.1 a seguir. Destaca-se que para o indicador custo com não conformidade considerou-se que a empresa atingiu a meta, para evitar que o mesmo enviesasse o resultado. 


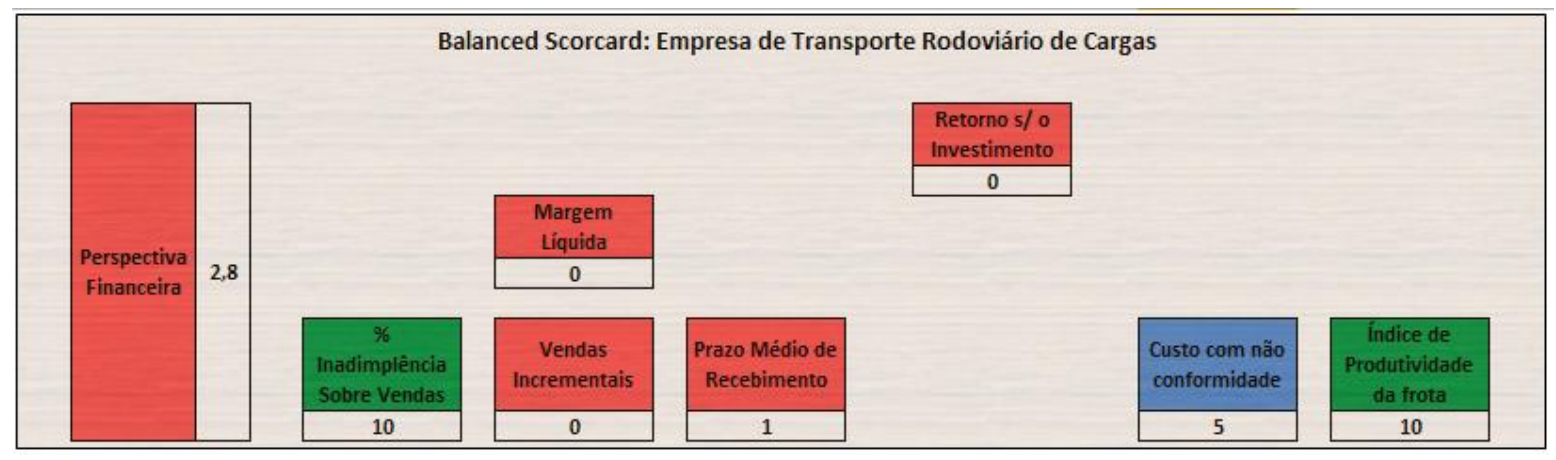

Figura 4.1 - Perspectiva Financeira da Transportadora X

De acordo com o modelo de medição proposto, o índice na perspectiva financeira do Balanced Scorecard foi de 2,8, uma vez que a maioria dos indicadores apresentou desempenho abaixo da meta. Interessante destacar que no ano de 2015, as ações da Transportadora X tiveram uma desvalorização de mais de $70 \%$. Ou seja, tanto os indicadores propostos quanto o desempenho no mercado de ações apontam para um baixa performance financeira. Portanto, verifica-se que o índice da perspectiva financeira é capaz de traduzir a visão dos acionistas.

Após demonstrar a obtenção dos indicadores da perspectiva financeira, será abordada a construção dos indicadores da perspectiva dos clientes. A maioria dos indicadores está diretamente relacionada com a área de vendas da empresa, responsável pelo fechamento dos contratos de prestação de serviço.

Os indicadores de Taxa de fidelização dos clientes e de novos clientes referem-se ao número de novos contratos realizados com os clientes habituais e com novos clientes. A informação sobre quantos contratos foram realizados no período e o tipo de contratante (cliente habitual ou novo) deve ser controlada pela área responsável por vendas. Assim pode-se verificar a porcentagem de cada tipo de contrato em relação à base de clientes já existente. De acordo com o relatório anual da Transportadora $\mathrm{X}$, a taxa de novos clientes foi de $6 \%$, enquanto que a taxa de fidelização de clientes foi $88,6 \%$.

O indicador Market-Share busca quantificar qual a participação da empresa no mercado em que atua. Dessa forma, primeiramente, a empresa deve determinar qual o seu escopo de atuação, levando em consideração a região de atuação, assim como o tipo de carga transportada. Em seguida, a área de vendas deve acompanhar os dados setoriais em relação ao 
volume transportado tanto em quantidade quanto em valores monetários. Assim, é possível verificar a porcentagem transportada pela empresa em relação ao volume do mercado. Conforme Quadro 4.2 abaixo, a Transportadora X acompanha trimestralmente sua participação no mercado, sendo, em 2015, o Market Share da empresa de 28,3\%.

Quadro 4.2- Market Share Transportadora X

\begin{tabular}{|l|c|c|c|c|c|}
\hline Indicadores operacionais & $\mathbf{1 T 1 5}$ & $\mathbf{2 T 1 5}$ & $\mathbf{3 T 1 5}$ & $\mathbf{4 T 1 5}$ & $\mathbf{2 0 1 5}$ \\
\hline Volume Transportado pela empresa & 197.140 & 188.680 & 179.085 & 200.591 & 765.496 \\
\hline Volume Transportado pelo setor & 683.502 & 715.352 & 659.638 & 649.088 & 2.707 .580 \\
\hline Market Share Transportadora X & $28,8 \%$ & $26,4 \%$ & $27,1 \%$ & $30,9 \%$ & $28,3 \%$ \\
\hline
\end{tabular}

Fonte: TEGMA (2016)

Em empresas de médio e grande portes, com vários departamentos, os indicadores nível global de satisfação dos clientes e tempo de resposta às solicitações são gerenciados pelas áreas de qualidade e atendimento ao cliente (SAC), respectivamente. Entretanto, para empresas de pequeno porte, normalmente, a área de vendas deverá assumir esta responsabilidade, visto que é a principal interface com os clientes.

O nível global de satisfação deve ser mensurado com base em uma pesquisa de satisfação estruturada, a qual deve ser aplicada periodicamente junto aos clientes. Conforme dados divulgados pela Transportadora $\mathrm{X}$, após realizar amplo mapeamento da percepção do cliente, verificou-se que o índice de satisfação é de 7,8.

Já o indicador número de reclamações dos clientes é medido através da relação entre o número total de reclamações dos clientes e quantidade total de fretes realizados. De acordo com a Transportadora $\mathrm{X}$, de todos os fretes realizados no período, apenas para $1,6 \%$ dos serviços prestados houve reclamações.

O indicador número de retornos ou devoluções é medido em relação ao número de fretes realizados. Já o tempo para resolução de problemas serve para verificar se a empresa cumpre os prazos estabelecidos para solucionar possíveis intercorrências no transporte, ou seja, mede quantos problemas foram solucionados no prazo acordado. Como tais informações apresentam um caráter mais operacional, as mesmas não constavam nos relatórios divulgados pela Transportadora $\mathrm{X}$ e, portanto foi realizada uma simulação, levando em conta os resultados financeiros e o volume total transportado divulgados, para obtenção de tais dados. 
Para o indicador número de retornos ou devoluções, a empresa deve manter uma tabela atualizada na qual contenha o volume de carga transportada e o volume de carga retornada no período. Tais informações podem ser obtidas por meio dos conhecimentos de transportes emitidos. O Quadro 4.3 exemplifica como deve ser realizado o controle. Observa-se que o índice de retorno ou devolução no período foi de $4 \%$.

Quadro 4.3 - Controle de retornos e devoluções

\begin{tabular}{|c|c|c|c|}
\hline Período & $\begin{array}{c}\text { Quantidade } \\
\text { Transportada (a) }\end{array}$ & $\begin{array}{c}\text { Quantidade Retorno } \\
(\mathbf{b})\end{array}$ & $\begin{array}{c}\text { Indicador de Retorno / } \\
\text { Devolução = (b/a) }\end{array}$ \\
\hline $1 \mathrm{~T}$ & 197.140 & 5.914 & $3 \%$ \\
\hline $2 \mathrm{~T}$ & 188.680 & 7.547 & $4 \%$ \\
\hline $3 \mathrm{~T}$ & 179.085 & 3.582 & $2 \%$ \\
\hline $4 \mathrm{~T}$ & 200.591 & 10.030 & $5 \%$ \\
\hline 2015 & 765.496 & 26.792 & $4 \%$ \\
\hline
\end{tabular}

Já em relação ao indicador tempo para resolução de problemas deve-se manter um controle do prazo estabelecido para sua solução e do tempo efetivamente utilizado. Assim, ao final do período deve-se somar as horas efetivamente utilizadas e comparar com as horas programadas. Caso este valor seja superior ao programado, a empresa não foi capaz de cumprir os prazos estabelecidos. O Quadro 4.4 exemplifica como deve ser realizado o controle. Observa-se que o indicador tempo para resolução de problemas no período foi de 95\%, ou seja, os problemas foram solucionados abaixo do prazo estabelecido.

Quadro 4.4- Controle do tempo para resolução de problemas

\begin{tabular}{|c|c|c|c|}
\hline Período & $\begin{array}{c}\text { Tempo programado } \\
(\mathbf{H})(\mathbf{a})\end{array}$ & $\begin{array}{c}\text { Tempo realizado } \\
(\mathbf{H})(\mathbf{b})\end{array}$ & $\begin{array}{c}\text { Tempo de Resposta as } \\
\text { solicitações }=(\mathbf{b} / \mathbf{a})\end{array}$ \\
\hline $1 \mathrm{~T}$ & 40 & 35 & $88 \%$ \\
\hline $2 \mathrm{~T}$ & 50 & 55 & $110 \%$ \\
\hline $3 \mathrm{~T}$ & 30 & 28 & $93 \%$ \\
\hline $4 \mathrm{~T}$ & 30 & 25 & $83 \%$ \\
\hline 2015 & 150 & 143 & $95 \%$ \\
\hline
\end{tabular}

Após calcular os indicadores de desempenho relacionado aos clientes, é possível construir a perspectiva dos clientes do Balanced Scorecard, assim como o índice desta perspectiva, conforme Figura 4.2 a seguir. Observa-se o índice da perspectiva dos clientes foi 4,7, próximo à meta de 5 . 


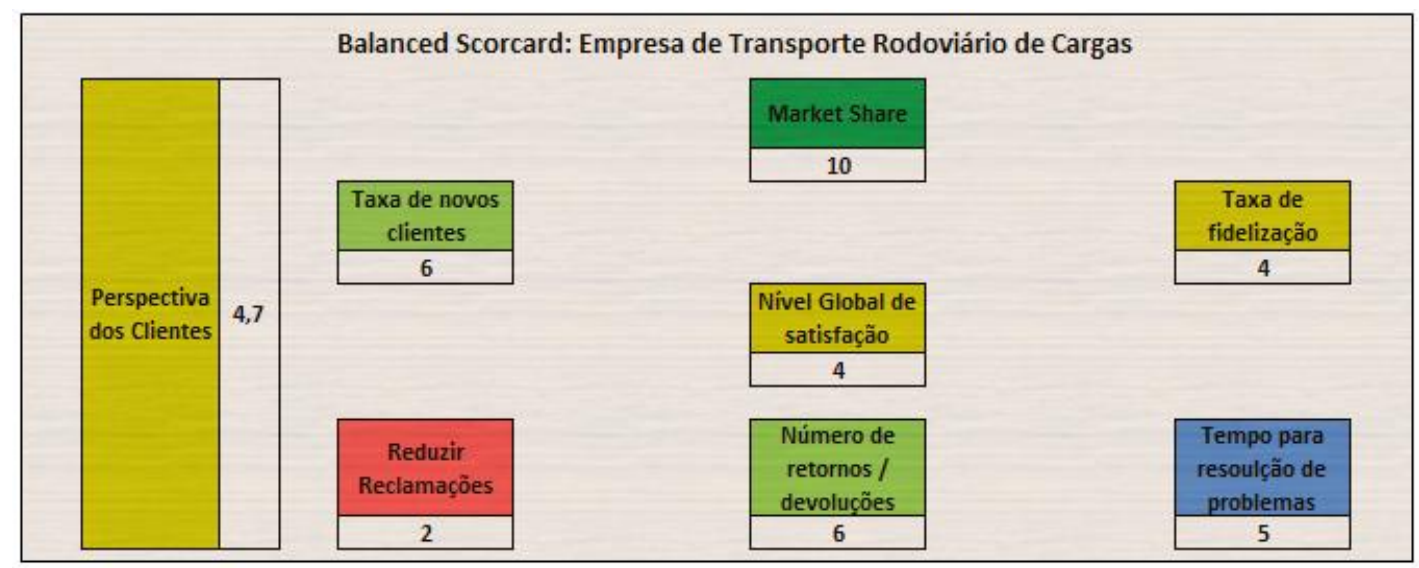

Figura 4.2 - Perspectiva dos clientes da Transportadora $X$

Na sequência, deve-se determinar os indicadores relativos a perspectivas dos processos internos. Tais indicadores estão diretamente relacionados com as áreas de operação e manutenção da empresa. Como estas informações não são divulgadas nos relatórios da empresa foi realizada uma simulação dos dados.

Os indicadores custo de manutenção, custo de pneu, custo de combustível e consumo de combustível podem ser obtidos diretamente do software de manutenção da empresa. Normalmente, estes sistemas permitem relacionar o volume ou valor do insumo consumido com a quilometragem percorrida. Caso a empresa não possua um sistema de manutenção, a mesma poderá construir planilhas de controle, para que possa controlar o consumo destes insumos em um determinado período.

O Quadro 4.5, a seguir, apresenta uma planilha de controle de abastecimento, na qual a transportadora gerencia cada abastecimento por veículo, computando o volume de combustível, o preço do insumo, assim como a quilometragem do hodômetro na hora do abastecimento. Dessa forma é possível verificar ao final do período a quilometragem percorrida da frota, assim como o volume de combustível e o custo de combustível total. De acordo com dados da Transportadora X, em 2015, a frota percorreu um total de 76.039.270 quilômetros, consumindo 29.245.873 litros de combustível, o que representa um custo com combustível de $\mathrm{R} \$$ 84.288.114. Dessa forma, o indicador custo de combustível foi $1,1 \mathrm{R} \$ / \mathrm{km}$ e o indicador consumo de combustível foi de $2,6 \mathrm{~km} / \mathrm{l}$. 
Quadro 4.5 - Planilha de controle de combustível

\begin{tabular}{|c|c|c|c|c|c|c|c|c|c|}
\hline Data & Hora & Placa & Combustível & $\begin{array}{l}\text { Volume } \\
\text { (L) }\end{array}$ & $\begin{array}{l}\text { Valor } \\
(\mathbf{R} \$)\end{array}$ & Hodômetro & $\begin{array}{l}\text { Tanque } \\
\text { Cheio? }\end{array}$ & $\begin{array}{l}\text { Distância } \\
\text { (Km) }\end{array}$ & $\begin{array}{c}\text { Média } \\
\text { de } \\
\text { consumo } \\
(\mathrm{Km} / \mathrm{L})\end{array}$ \\
\hline $01 / 01$ & $10: 00$ & AA01 & Diesel & 300,00 & 2,88 & 1000,00 & Sim & $1^{\circ}$ valor & \\
\hline $01 / 01$ & $10: 10$ & AA02 & Diesel & 300,00 & 2,88 & 1000,00 & Sim & $1^{\circ}$ valor & \\
\hline $01 / 01$ & 15:00 & AA03 & Diesel & 300,00 & 2,88 & 1000,00 & Sim & $1^{\circ}$ valor & \\
\hline $10 / 01$ & $14: 00$ & AA01 & Diesel & 100,00 & 2,88 & 1250,00 & Sim & 250,00 & 2,50 \\
\hline $11 / 01$ & $08: 00$ & AA02 & Diesel & 200,00 & 2,88 & 1540,00 & Sim & 540,00 & 2,70 \\
\hline $11 / 01$ & $10: 00$ & AA03 & Diesel & 250,00 & 2,88 & 1525,00 & Sim & 525,00 & 2,10 \\
\hline
\end{tabular}

Em relação ao custo de manutenção e de pneus, pode-se utilizar planilhas de controle semelhantes à de combustível, Quadros 4.6 e 4.7, a seguir. Estes controles indicam para cada veículo (placa), o tipo de serviço, a data em que ocorreu e o custo para realizá-lo. Assim, ao final do período, somam-se esses custos e, em seguida, divide-se o total pela quilometragem total percorrida. De acordo com dados da Transportadora X, o custo total com manutenção, no período de 2015 , foi de $\mathrm{R} \$ 11.405 .890$ e o custo com pneus foi de $\mathrm{R} \$ 18.249 .424$. Considerando que a frota percorreu um total de 76.039.270 quilômetros, o índice custo de manutenção foi de $0,15 \mathrm{R} \$ / \mathrm{KM}$, enquanto que o custo de pneu foi de $0,24 \mathrm{R} \$ / \mathrm{km}$.

Quadro 4.6 - Planilha de controle de manutenção

\begin{tabular}{|c|c|c|c|c|}
\hline \multicolumn{5}{|c|}{ Manutenção } \\
\hline Data & Placa & Tipo de serviço & Estabelecimento & Custo total R\$ \\
\hline $01 / 01 / 2015$ & AA01 & Lataria e pintura & Oficina 2 & 350,00 \\
\hline $10 / 01 / 2015$ & AA02 & Mecânica & Oficina 2 & 600,00 \\
\hline $15 / 02 / 2015$ & AA03 & Lavagem & Oficina 4 & 60,00 \\
\hline $15 / 02 / 2015$ & AA01 & Lavagem & Oficina 4 & 50,00 \\
\hline $01 / 03 / 2015$ & AA02 & MOBIL 15W-40 & Oficina 1 & 344,00 \\
\hline $10 / 03 / 2015$ & AA03 & MOBIL 15W-40 & Oficina 2 & 250,00 \\
\hline $15 / 03 / 2015$ & AA01 & MOBIL 5W-40 & Oficina 3 & 600,00 \\
\hline
\end{tabular}

Quadro 4.7 - Planilha de controle de pneus

\begin{tabular}{|c|l|l|l|r|}
\hline \multicolumn{1}{|c|}{ Controle de Pneus } \\
\hline Data & \multicolumn{1}{|c|}{ Tipo de serviço } & \multicolumn{1}{c|}{ Código Pneu } & Custo total R\$ \\
\hline $01 / 01 / 2015$ & AA01 & Troca Pneu Dianteiro & xxx1 & 900,00 \\
\hline $10 / 01 / 2015$ & AA02 & Recapagem 1 & xxx2 & 600,00 \\
\hline $15 / 02 / 2015$ & AA03 & Recapagem 2 & xxx3 & 260,00 \\
\hline $15 / 02 / 2015$ & AA01 & Recauchutagem 1 & xxx4 & 270,00 \\
\hline $01 / 03 / 2015$ & AA02 & Troca de Pneu Traseiro & xxx6 & $1.000,00$ \\
\hline $10 / 03 / 2015$ & AA03 & Troca de Pneu Dianteiro & xxx7 & 850,00 \\
\hline $15 / 03 / 2015$ & AA01 & Recapagem 2 & & 300,00 \\
\hline
\end{tabular}


Outro indicador relacionado com a área de manutenção é a disponibilidade da frota, cujo objetivo é mensurar a porcentagem de ativos disponíveis para operação em relação ao total de ativos da empresa. Assim, a empresa deve controlar diariamente a quantidade de veículos disponíveis para operação, conforme Quadro 4.8 a seguir. Assim, ao final do período, a empresa deve calcular a média de disponibilidade. Conforme a Transportadora X, o indicador de disponibilidade, em 2015, foi de $86 \%$.

Quadro 4.8- Disponibilidade da frota

\begin{tabular}{|c|c|c|c|}
\hline Data & Ativos Disponíveis (a) & Ativos em Manutenção (b) & Disponibilidade (b/a) \\
\hline $01 / 01 / 2015$ & 1.524 & 380 & $80 \%$ \\
\hline $02 / 01 / 2015$ & 1.619 & 285 & $85 \%$ \\
\hline $03 / 01 / 2015$ & 1.714 & 190 & $90 \%$ \\
\hline $04 / 01 / 2015$ & 1.562 & 342 & $82 \%$ \\
\hline $05 / 01 / 2015$ & 1.809 & 95 & $95 \%$ \\
\hline
\end{tabular}

Já os indicadores, índice de coleta e entrega no prazo, tempo médio de carga e descarga, utilização da capacidade de carga, viagens vazias, avarias, roubo de cargas, acidentes de trânsito devem ser gerenciados pela área operacional e podem ser obtidos através do software de gestão operacional ou por planilhas de controle. Para obter estes indicadores, é necessário realizar o controle operacional de cada uma das viagens realizadas pela frota da empresa. A seguir, segue um modelo de planilha para controle de viagens da frota.

Quadro 4.9- Planilha de controle de viagens da frota

\begin{tabular}{|c|c|c|c|c|c|c|c|c|c|c|c|c|}
\hline 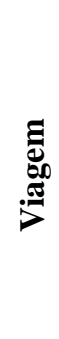 & 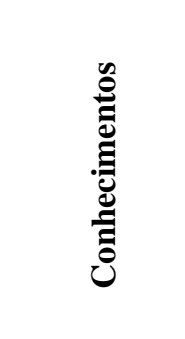 & 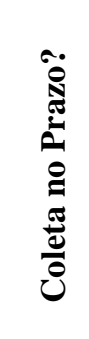 & 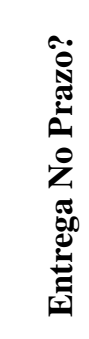 & 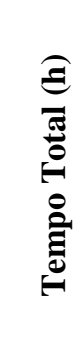 & 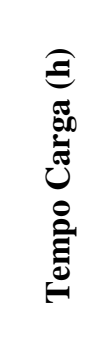 & 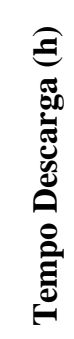 & 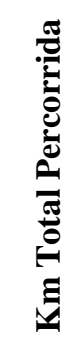 & 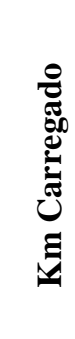 & 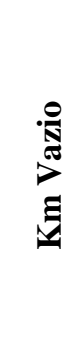 & 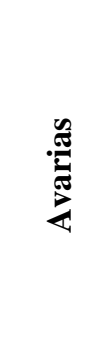 & $\begin{array}{l}\tilde{0} \\
\overline{0} \\
\tilde{0}\end{array}$ & 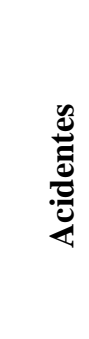 \\
\hline 1 & 25 & Sim & Sim & 4,5 & 1 & 0,5 & 240 & 240 & 0 & Sim & Não & Sim \\
\hline 2 & $26 / 27 / 28$ & Sim & Sim & 7 & 2 & 1 & 320 & 320 & 0 & Não & Sim & Não \\
\hline 3 & $29 / 30$ & Não & Sim & 6,35 & 0,25 & 0,1 & 480 & 420 & 60 & Não & Não & Sim \\
\hline 4 & 31 & Não & Não & 7,6 & 0,5 & 0,1 & 560 & 560 & 0 & Não & Não & Não \\
\hline 5 & 32 & Sim & Sim & 5,3 & 0,2 & 0,1 & 400 & 200 & 200 & Não & Não & Não \\
\hline 6 & $33 / 34 / 35 / 36$ & Não & Não & 2,5 & 0,3 & 0,2 & 160 & 140 & 20 & Não & Sim & Não \\
\hline 7 & $37 / 38$ & Sim & Sim & 4,5 & 0,2 & 0,3 & 320 & 320 & 0 & Sim & Não & Sim \\
\hline 8 & 39 & Sim & Sim & 1,3 & 0,2 & 0,1 & 80 & 40 & 40 & Não & Não & Não \\
\hline
\end{tabular}

Conforme dados da Transportadora X, foram realizadas no período de 2015, 63.791 viagens. Em 2.551 viagens houve atrasos na coleta e/ou na entrega, sendo o índice de coleta e entrega no prazo de $96 \%$. O tempo médio de carga e descarga nestas viagens foi de 2 horas. Em 
relação à utilização da capacidade de carga, foram transportados no período 842.045 toneladas de uma capacidade máxima permitida de 1.052 .500 toneladas, tendo, portanto, um aproveitamento de capacidade de $80 \%$.

No período de 2015, em 30\% das viagens houve percursos realizados vazios, contabilizando um total de 26.613.750 quilômetros rodados vazio. Visto que o total de quilômetros percorrido foi de 76.039.270, o indicador de viagens vazias obteve performance de $35 \%$.

Em relação ao risco da carga, foram contabilizadas, no período, 1.275 viagens em que ocorreram avarias e 318 viagens em que houve registros de roubo. Sendo assim, o índice de avaria calculado foi de $2 \%$, enquanto que o índice de roubo foi de $0,5 \%$. Em relação ao risco do veículo, houve 63 registros de acidentes de trânsito sem fatalidade. Sendo assim, o indicador de acidentes de trânsito contabilizou 1,2 acidentes a cada 1 milhão de quilômetros rodados.

Além dos indicadores já analisados, também compõem a perspectiva dos processos internos os seguintes indicadores: idade média dos veículos, taxa de acompanhamento pós-serviço, acuracidade na emissão do CT-E, solicitações atendidas em condições especiais de entrega, acidentes com fatalidade e contaminação/ derrame zero.

Em relação à idade média dos veículos, deve-se verificar no controle da frota a idade de cada veículo motor, tendo como base o ano de fabricação, e dividir pelo total de veículos motores. De acordo com a Transportadora X, a idade média é de 3 anos. Já a taxa de acompanhamento pós-serviço tem o objetivo de verificar quantos clientes foram contatados após a realização da viagem, para verificar se a entrega foi realizada conforme suas expectativas. De um total de 63.791 viagens, houve contato após a prestação do serviço em 9.500 viagens, o que representa uma taxa de pós-serviço de $15 \%$.

O indicador acuracidade na emissão do CT-E busca mensurar a excelência operacional da atividade de faturamento. De um total de 319.000 conhecimentos eletrônicos emitidos no período, apenas 2.871 conhecimentos apresentaram inconsistências. Sendo assim, o índice de acuracidade foi de $99 \%$. 
O indicador solicitações atendidas em condições especiais busca avaliar a capacidade da empresa em atender de forma diferenciada aos clientes, como, por exemplo, realizar entregas em prazo inferior ao acordado. Em 2015, foram realizadas 2.000 solicitações de entregas em condições especiais. Destas, foram possíveis atender 1.500 pedidos urgentes, sendo assim o indicador foi de $75 \%$.

Por mensurarem questões de elevada gravidade, os indicadores acidentes com fatalidade e contaminação/derrames apresentam meta zero. O indicador acidentes com fatalidade é mensurado de forma absoluta, enquanto que o índice de contaminações/derrames mede a porcentagem de viagens em que houve acidentes ambientais. No período de 2015 , não foram registrados acidentes com fatalidades, tampouco houve contaminações.

Por fim, há dois indicadores da perspectiva dos processos internos que devem ser controlados pela área de recursos humanos: multas por motorista e ultrapassagem do tempo de viagem. $\mathrm{O}$ primeiro indicador é importante para verificar se o motorista está atendendo a legislação de trânsito e para programar treinamentos de trânsito, caso seja necessário. Já o segundo é importante para verificar se a empresa está cumprindo às normas referentes à legislação trabalhista.

Em 2015, a Transportadora X recebeu 5.712 notificações de multas. Considerando que a empresa apresenta em seu quadro de pessoal 3.808 motoristas, foram aproximadamente 1,5 multas por motorista. Em relação ao tempo de viagem, verificou-se que em 12.758 viagens foi ultrapassado o tempo estabelecido pela Lei $n^{0} 12.619$. Sendo assim, houve não conformidade em 20\% das viagens. O Quadro 4.10 a seguir apresenta um resumo da forma de cálculo dos indicadores da perspectiva dos processos internos apresentados anteriormente. 
Quadro 4.10- Forma de cálculo dos indicadores da perspectiva dos processos internos

\begin{tabular}{|c|c|c|c|}
\hline Indicador & Numerador & Denominador & Resultado* \\
\hline Custo de combustível & $\mathrm{R} \$ 84.288 .114$ & $76.039 .270 \mathrm{~km}$ rodados & $1,1 \mathrm{R} \$ / \mathrm{Km}$ \\
\hline Custo de manutenção & $\mathrm{R} \$ 11.405 .890$ & $76.039 .270 \mathrm{~km}$ rodados & $0,15 \mathrm{R} \$ / \mathrm{Km}$ \\
\hline Custo de pneu & $\mathrm{R} \$ 18.249 .424$ & $76.039 .270 \mathrm{~km}$ rodados & $0,24 \mathrm{R} \$ / \mathrm{Km}$ \\
\hline Consumo de combustível & $76.039 .270 \mathrm{~km}$ rodados & 29.245.873 litros & $2,6 \mathrm{~km} / \mathrm{l}$ \\
\hline Disponibilidade da frota & $\begin{array}{l}1637 \text { veículos disponíveis } \\
\text { em média }\end{array}$ & 1904 frota total & $86 \%$ \\
\hline $\begin{array}{l}\text { Índice de coleta e entrega } \\
\text { no prazo }\end{array}$ & 2.551 viagens com atraso & 63.791 viagens realizadas & $96 \%$ \\
\hline $\begin{array}{l}\text { Tempo médio de carga/ } \\
\text { descarga }\end{array}$ & $\begin{array}{l}127.582 \text { horas para carga e } \\
\text { descarga }\end{array}$ & 63.791 viagens realizadas & 2 horas/viagem \\
\hline $\begin{array}{l}\text { Utilização da capacidade } \\
\text { de carga }\end{array}$ & $\begin{array}{l}842.045 \text { toneladas } \\
\text { transportadas }\end{array}$ & $\begin{array}{c}1.052 .500 \text { cap. máxima } \\
\text { carga }\end{array}$ & $80 \%$ de utilização \\
\hline Viagens vazias & $\begin{array}{l}26.613 .750 \mathrm{~km} \text { rodados } \\
\text { vazio }\end{array}$ & $76.039 .270 \mathrm{~km}$ rodados & $\begin{array}{c}35 \% \text { de viagens } \\
\text { vazias }\end{array}$ \\
\hline Avarias & $\begin{array}{l}1275 \text { viagens com registro } \\
\text { de avaria }\end{array}$ & 63.791 viagens realizadas & $2 \%$ \\
\hline Roubo de cargas & $\begin{array}{l}318 \text { viagens com registro } \\
\text { de roubo }\end{array}$ & 63.791 viagens realizadas & $0,5 \%$ \\
\hline Acidentes de Trânsito & $\begin{array}{l}63 \text { viagens com registro de } \\
\text { acidentes }\end{array}$ & $76.039 .270 \mathrm{~km}$ rodados & $\begin{array}{c}1,2 \text { acidentes por } \\
\text { milhão de } \mathrm{Km} \text { rodado }\end{array}$ \\
\hline Idade Média dos veículos & Soma das idades $=5712$ & 1904 frota total & 3 anos \\
\hline $\begin{array}{l}\text { Taxa de acompanhamento } \\
\text { pós serviço }\end{array}$ & $\begin{array}{l}9.500 \text { viagens houveram } \\
\text { contatos }\end{array}$ & 63.791 viagens realizadas & $15 \%$ \\
\hline $\begin{array}{l}\text { Acuracidade na emissão do } \\
\text { CT-E }\end{array}$ & $\begin{array}{l}\text { 2.871 CT-Es emitidos com } \\
\text { erro }\end{array}$ & 319.000 CT-Es & $99 \%$ \\
\hline $\begin{array}{l}\text { Solicitações atendidas } \\
\text { (condições especiais) }\end{array}$ & $\begin{array}{l}1.500 \text { solicitações } \\
\text { atendidas }\end{array}$ & $\begin{array}{l}2.000 \text { solicitações } \\
\text { realizadas }\end{array}$ & $75 \%$ \\
\hline Acidentes com fatalidade & 0 acidentes com fatalidade & & \\
\hline $\begin{array}{l}\text { Contaminações / Derrames } \\
\text { zero }\end{array}$ & 0 contaminações & 63.791 viagens realizadas & $0 \%$ \\
\hline Multas por motoristas & $\begin{array}{l}5.712 \text { notificações de } \\
\text { multa }\end{array}$ & 3.808 motoristas & 1,5 multas/motorista \\
\hline $\begin{array}{l}\text { Ultrapassagem do tempo } \\
\text { de viagem }\end{array}$ & $\begin{array}{l}12.758 \text { viagens com } \\
\text { excesso de jornada }\end{array}$ & 63.791 viagens realizadas & $20 \%$ \\
\hline
\end{tabular}

*Os resultados dos indicadores da perspectiva dos processos internos foram simulados. 
Após calcular todos os indicadores de desempenho relacionados aos processos, é possível consolidar a perspectiva dos processos internos do Balanced Scorecard, assim como calcular o índice desta perspectiva, conforme Figura 4.3 a seguir. Observa-se que o índice da perspectiva dos processos internos foi 5,7, isto é, acima da meta estabelecida.

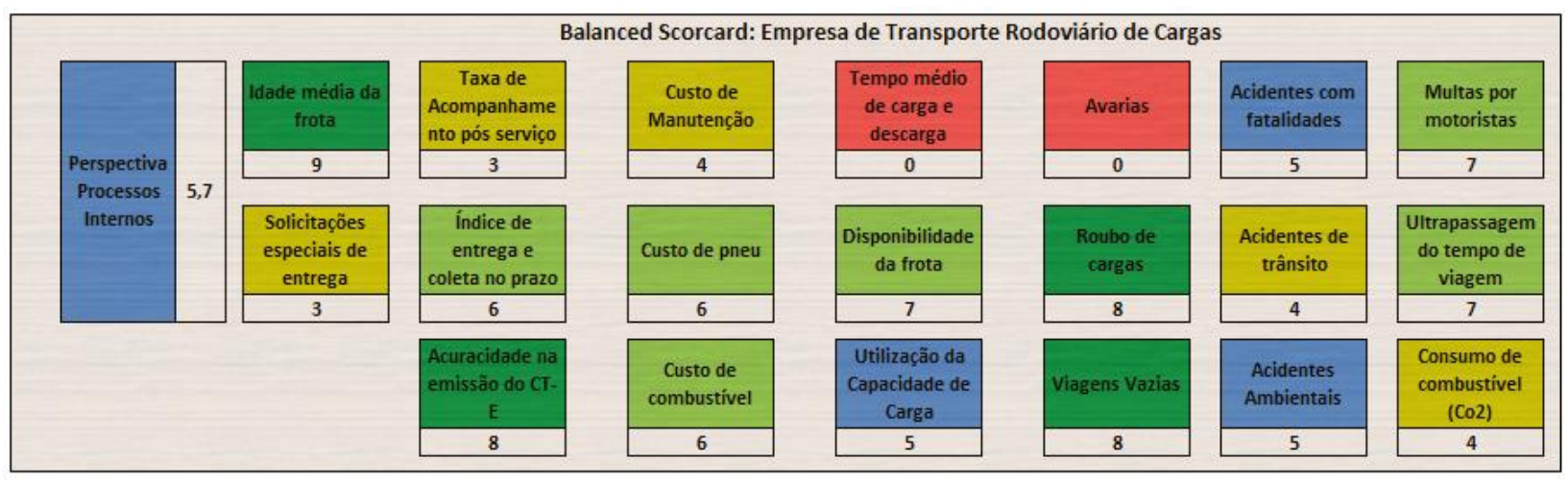

Figura 4.3 - Perspectiva dos processos internos da Transportadora $X$

Por fim, é necessário mensurar os indicadores relativos à perspectiva do aprendizado e crescimento. Todos os indicadores desta perspectiva, com exceção do índice de veículos rastreáveis, são gerenciados pela área de recursos humanos. Destaca-se que os resultados foram obtidos através de simulação, visto que estas informações não foram divulgadas pela empresa.

O indicador taxa de absenteísmo deve ser controlado através do sistema de marcação de ponto ou da folha de ponto. Ao final do período deve-se somar as horas ausentes do funcionário e dividir pela carga horária do período. Em 2015, a soma da carga horária de todos os trabalhadores da Transportadora X foi 8.467.200 de horas. Já a soma das horas ausentes foi 237.081 horas. Sendo assim, a taxa de absenteísmo para o ano de 2015 foi de 2,8\%.

O indicador de rotatividade dos funcionários pode ser obtido por meio dos dados referentes às admissões e demissões realizadas no período para os cargos já existentes. O quadro atual da Transportadora X conta com 4.200 funcionários, sendo 3.808 motoristas e 392 colaboradores da área administrativa. No período foram substituídos 105 colaboradores da empresa, ocasionando um índice de rotatividade igual a 2,5\%.

O indicador horas de treinamento é essencial para garantir a prontidão do capital humano para execução das atividades críticas. $\mathrm{O}$ indicador tem como objetivo garantir uma quantidade 
média de horas de treinamento por ano por colaborador. Foram ministradas, em 2015, 48.300 horas de treinamento. Considerando um total de 4.200 funcionários, a média horária de treinamento por colaborador foi de 11,5.

O indicador satisfação dos empregados é mensurado a partir de uma pesquisa de satisfação, cuja realização deve ser anual e coordenada pelo setor de recursos humanos. Em 2015, a pesquisa de satisfação obteve nota 7 .

Para manter os colaboradores empenhados na consecução dos objetivos da empresa, é fundamental oferecer uma remuneração variável, além do salário, para aqueles que atingirem as metas. Do total de 4.200 colaboradores, 2.200 receberam bonificação por desempenho, sendo assim, o índice de bonificação dos colaboradores foi de $52 \%$.

O último indicador desta perspectiva é o índice de veículos rastreáveis. Não adianta apenas preparar os colaboradores, para atingir a excelência operacional é necessário fornecer aos mesmos as ferramentas adequadas, que no caso em estudo, são os veículos com tecnologia embarcada. Da frota total de 1.904 veículos, 1.000 apresentam tecnologia de rastreamento via GPSR, enquanto que 600 estão equipados com tecnologia de telemetria. Sendo assim o índice de veículos rastreáveis é de $84 \%$.

A seguir, apresenta-se a perspectiva do aprendizado e crescimento do Balanced Scorecard, assim como o cálculo do índice desta perspectiva, Figura 4.4. Observa-se que o índice da perspectiva dos clientes foi 5,8 , isto é, acima da meta de 5 .

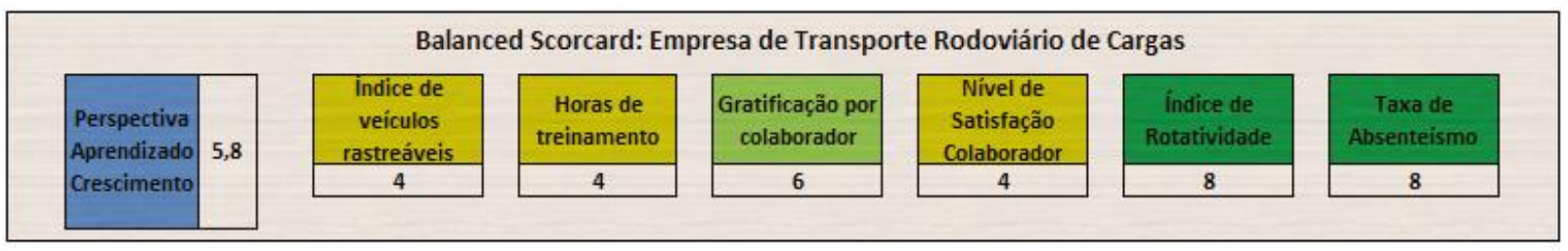

Figura 4.4 - Perspectiva do aprendizado e crescimento da Transportadora X

Após a construção dos indicadores de desempenho de cada perspectiva, assim como o cálculo de seus respectivos índices, é interessante apresentar o Balanced Scorecard completo da Transportadora $\mathrm{X}$, de forma a proporcionar uma visão holística dos processos críticos da empresa. 
Observa-se que as perspectivas financeiras e dos clientes apresentaram nota inferior à meta estabelecida, e o desempenho na perspectiva financeira ficou abaixo de $80 \%$ da meta. $\mathrm{O}$ índice da perspectiva financeira foi afetado pela baixa performance nos indicadores margem líquida, vendas incrementais e retorno sobre o investimento, os quais obtiveram nota zero e pelo indicador prazo médio de recebimento, cujo desempenho foi igual a 1. Já a perspectiva dos clientes teve desempenho 6\% abaixo da média, sendo prejudicado principalmente pela performance do indicador referente às reclamações.

Por outro lado, os índices das perspectivas dos processos internos e do aprendizado e crescimento apresentaram nota superior à meta estabelecida em cerca de $15 \%$. Na perspectiva dos processos internos, 10 indicadores tiveram performance acima da meta, três indicadores atingiram a meta e sete indicadores ficaram abaixo da meta. Já na perspectiva do aprendizado e crescimento três indicadores ficaram acima da meta e três ficaram abaixo da meta.

Por fim, destaca-se o índice geral de qualidade da Transportadora X, resultado da ponderação das quatro perspectivas, cujo valor foi de $4,5 \%$, isto é, $9 \%$ abaixo da meta estabelecida. O não atendimento da meta, deve-se, primordialmente, à performance muito abaixo da meta da perspectiva financeira, que representa $32 \%$ do índice geral. 


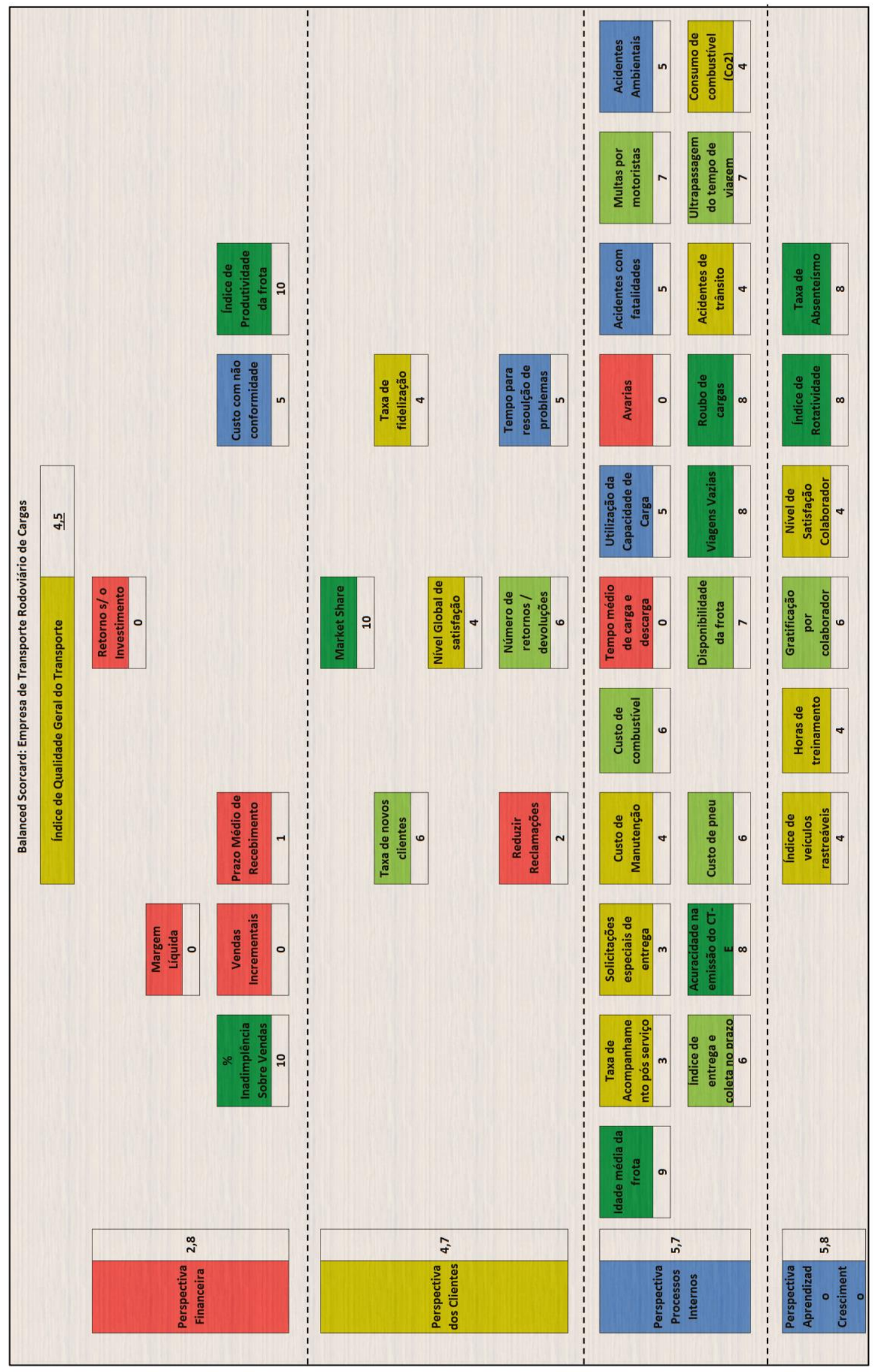

Figura 4.5 - Balanced Scorecard da Transportadora X 


\section{CONCLUSÃO}

\section{$\underline{\text { Resultados }}$}

A principal contribuição desta dissertação é a proposição de um sistema de medição de desempenho baseado no Balanced Scorecard para os transportadores rodoviários. O sistema permite avaliar o desempenho das atividades críticas da empresa em quatro perspectivas (financeira, dos clientes, processos internos e aprendizado e crescimento), garantindo à administração uma visão holística de toda a empresa.

Contudo para obter o sistema de medição de desempenho proposto, foi necessário: a) realizar revisão bibliográfica para identificar os indicadores de desempenho utilizados nas empresas de transporte rodoviário de cargas; b) adaptar a metodologia do Balanced Scorecard aos objetivos e às atividades dos transportadores rodoviários; c) utilizar a Análise Multicritério de Apoio à Decisão - Construtivista (MCDA-C), com o apoio do software M-MACBETH, para definir os índices das perspectivas e o índice geral de qualidade do transporte. Sendo assim, todos os objetivos específicos propostos foram alcançados, bem como foi respondido o problema levantado nesta dissertação.

Além do desenvolvimento teórico do sistema de medição de desempenho, foi construída uma ferramenta computacional, em ambiente Microsoft Excel 2013, para as empresas realizarem a gestão de seus Balanced Scorecard, alcançando o objetivo principal. Para estimular a utilização deste sistema de medição de desempenho, a ferramenta foi construída em uma interface amigável, permitindo a gestão visual de todos os indicadores de desempenho em uma única tela (Painel). Além disso, todos os parâmetros são modificáveis, permitindo as empresas adaptarem o modelo às suas especificidades.

Para demonstrar a correta utilização do modelo proposto, definiu-se por aplicar o modelo em uma empresa de transporte rodoviário de cargas. Observou-se que o modelo é capaz de avaliar a performance das atividades críticas da empresa. Entretanto, é fundamental que a empresa mantenha procedimentos para a coleta das informações necessárias para gerar os indicadores. Também é essencial que a empresa estabeleça rotinas para manutenção dos indicadores atualizados. 


\section{Dificuldade e limitacões}

A maior dificuldade para a realização da pesquisa foi encontrar uma empresa disposta a fornecer os dados necessários para construção dos indicadores de desempenho. A maior parte das empresas negou acesso aos dados, alegando que se tratam de informações estratégicas que poderiam afetar a competitividade da empresa. Outras empresas informaram que não dispunham de controles para gerar os dados solicitados. Sendo assim, optou-se por selecionar uma empresa de capital aberto, visto que diversos dados, principalmente financeiros, estão disponíveis ao público. Para as informações não publicadas, em especial as operacionais, realizou-se uma simulação, levando em consideração a realidade financeira da empresa.

Uma grande limitação para utilização do modelo proposto é a falta de dados para alimentar o sistema de medição de desempenho. Muitas empresas não possuem procedimentos para coleta e armazenamento de informações. Sendo assim, é necessário verificar previamente se a empresa tem à sua disposição todos os dados necessários para utilização do modelo e, em caso negativo, estabelecer processos de coleta de dados. Também foi sugerida, neste trabalho, uma série de planilhas para o controle das informações essenciais para a efetiva utilização do sistema de medição de desempenho.

\section{Vantagens do modelo proposto}

O sistema de desempenho, baseado no Balanced Scorecard, proporciona a mensuração de diversos aspectos críticos da companhia. A maioria dos modelos de medição de desempenho apresentados na literatura aborda a medição sob uma única ótica, como por exemplo, abordando somente indicadores financeiros ou indicadores operacionais. Sendo assim, o modelo proposto diferencia-se na medida em que propõe uma avaliação do desempenho, em relação a quatro perspectivas (financeira, dos clientes, processos internos e aprendizado e crescimento), garantindo uma visão integral, balanceada e mais verossímil da performance da empresa.

Ademais o modelo proposto torna-se singular e mais completo em relação aos demais Balanced Scorecards, uma vez que propõe a adição de índices para cada uma das perspectivas e um índice geral da qualidade do serviço, por meio da utilização conjunta das metodologias do BSC e do MDCA-C. 
Os índices permitem a alta administração ter uma visão sintética do desempenho por perspectiva e também geral da empresa, permitindo estabelecer planos de ações rápidos para melhoria das perspectivas cujo desempenho estiver abaixo da expectativa.

Além disso, a utilização de um sistema de medição padronizado por diversas empresas possibilita a realização de benchmarking entre as mesmas e a criação de um ranking, a partir dos índices das perspectivas e do índice geral de qualidade do transporte.

É importante destacar que a ponderação dos indicadores de desempenho e a consequente definição dos índices teve como base o conhecimento de um grupo específico. Sendo assim, ao aplicar o mesmo questionário em outro conjunto de empresas, os pesos obtidos podem ser distintos.

\section{$\underline{\text { Trabalhos futuros }}$}

A primeira sugestão para o desenvolvimento de trabalhos futuros é a aplicação do método proposto em outras empresas de transporte rodoviário de cargas, para comparar os pesos e resultados encontrados.

Outra proposta para trabalhos futuros é a aplicação da metodologia utilizada nesta dissertação para construção de um modelo que vise classificar empresas de transporte de cargas em outros modos, como o ferroviário e o aquaviário. 


\section{Referências Bibliográficas}

AHN, H. "Applying the Balanced Scorecard concept: An experience report". Long Range Planning, 2001.

Agência Nacional de Transportes Terrestres -ANTT (2012). Disponível em http://www.antt.gov.br/index.php/content/view/4929/RNTRC__Registro_Nacional_de _Transportadores_Rodoviarios_de_Cargas.html

AGÊNCIA NACIONAL DE TRANSPORTES TERRESTRES. Registro Nacional de Transporte Rodoviário de Cargas - RNTRC, 3 de julho de 2015. Disponível em www.antt.gov.br.

AKMANLIGIL, M.; PALVIA, P. Strategies for global information systems development. Information \& Management. Disponível em : www.elsevier.com/locate/ dsw em 25/07/2004.

ALMIR, S. Estabelecendo indicadores de desempenho para uma organização pública uma abordagem segundo preceitos do Balanced Scorecard. Dissertação de Mestrado, Programa de Mestrado Profissionalizante em Engenharia, Escola de Engenharia, Universidade Federal do Rio Grande do Sul, Porto Alegre, RS, 2002.

ALVES, M. R. P. Logística Agroindustrial. In: BATALHA, M. O. (Coord.). Gestão agroindustrial. São Paulo: Atlas, v. 1, 2001.

ÂNGELO, L. B. Indicadores de Desempenho Logístico. GELOG, 2005.

ARANTES,G.R. Análise do processo de implantação do Balanced Scorecard: o caso do painel corporativo de uma empresa brasileira do setor público. Dissertação de Mestrado, Mestrado em Administração Pública, Fundação Getúlio Vargas, Rio de Janeiro, RJ, 2006.

ARAÚJO, M. P. S. BANDEIRA, R. A. M, CAMPOS, V. B. G. Custos e fretes praticados no transporte rodoviário de cargas: uma análise comparativa entre autônomos e empresas. Journal of Transport Literature, vol.8, 2014.

ARAUJO, J. G. Transporte Rodoviário De Cargas No Brasil Mercado Atual E Próximas Tendências. ILOS - Instituto de Logística e Supply Chain, 2011. Disponível em: . Acessado em: 10/01/2015.

ARRUDA JÚNIOR, J.S. (2014). Desenvolvimento de um método para redução do consumo de combustível no transporte rodoviário de cargas. Capacitação, aplicações de torque e telemetria para veículos pesados. Dissertação de Mestrado Programa de Pós-graduação em Transportes, Universidade de Brasília, Brasília, DF.

BANA E COSTA, C.A. Structuration, Construction et Exploitation d'un Modèle Multicritère d'Aide à la Décision. Tese de Doutorado, Universidade Técnica de Lisboa. Portugal, 1992. 
BANA E COSTA, C. A; VASNICK, J. C. Uma Abordagem ao Problema de Construção de uma Função de Valor Cardinal: MACBETH. Investigação Operacional, v. 15, 1995.

BARBOSA, D.H. et al. Sistema de medição de desempenho logístico em um ambiente de cadeia de suprimentos: Um estudo de caso. In: ENCONTRO NACIONAL DE ENGENHARIA DE PRODUÇÃO, 27., 2007, Foz do Iguaçu. Anais... Rio de Janeiro: ABEPRO, 2007.

BARBOSA, M.S. O desenvolvimento de uma ferramenta para identificação dos custos do transporte de carga realizado por transportadores autônomos. Monografia de Especialização, Departamento Acadêmico de Gestão e Economia, Universidade Tecnológica Federal do Paraná, Curitiba, PR, 2013.

BASTOS, C. L.; KELLER, V.; MARTIM, I.; LENGRAND, P.. Aprendendo a aprender: introdução à metodologia científica. 16. ed. Petrópolis: Vozes, 2002.

BELÉM JR, J.S. Proposta metodológica para avaliação do nível de serviços das empresas de transporte rodoviário de cargas . Dissertação de Mestrado, Programa de Pósgraduação em Transportes, Universidade de Brasília, Brasília, DF, 2007.

BERLINER, C.; BRIMSON, J. A. Gerenciamento de custos em indústrias avançadas: base conceitual CAM-I. São Paulo: Fundação Salim Farah Maluf, 1992.

BIMBATTI, M. TOLEDO,N.N. Gerenciamento Estratégico através do Balanced

Scorecard apoiado pela T.I. In: Simpósio de Engenharia de Produção, 9., 2002, São Paulo. Anais...São Paulo, 2002. CD-ROM.

BERTAGLIA, P. L. Logística e gerenciamento da cadeia de abastecimento. São Paulo: Saraiva, 2002.

BODILY, S. E. Modern Decision Making: A Guide to Modeling with Decision Support Systems. New York: McGraw-Hill, 1985.

BONGIOLO DA SILVA, T. Desenvolvimento de um planejamento estratégico para uma empresa de transportes rodoviários. Monografia, Especialização em Comunicação e Estratégias de Marketing, Universidade do Extremo Sul Catarinense, Criciúma, SC, 2014.

BORCHARDT, M.; SELlitTO, M.A.; PEREIRA, G.M. Serviço de Pós-Venda para produtos fabricados em base tecnológica. Revista Produção, vol. 8, 2008.

BORTOLUZZI, S. C; ENSSLIN, S. R.; ENSSLIN, L. Avaliação de desempenho multicritério como apoio à gestão de empresas: aplicação em uma empresa de serviços. Gestão e Produção, v. 18, 2011.

BOWERSOX, D. J.; CLOSS, D. J. Logística Empresarial: O Processo de Integração da Cadeia de Suprimentos. Ed. Atlas. São Paulo. 2001. 
BOWERSOX, D. J.; CLOSS, D. J.; COOPER, M. B. Gestão Logística de Cadeias de Suprimentos. Porto Alegre. Bookman, 2006.

BRASIL. Lei No 11.442, de 5 de janeiro de 2007. Dispõe sobre o transporte rodoviário de cargas por conta de terceiros e mediante remuneração. Casa Civil Subchefia para Assuntos Jurídicos, Brasília, DF, 5 de jan. 2007. Disponível em: <http://www.planalto.gov.br/ccivil_03/_ato2007-2010/2007/lei/111442.htm> Acesso

em: 20/08/2013.

BEINAT, E. Multiattribute Value Functions for Environmental Management. Amsterdan: Timbergen Institute Research Series, 1995.

BREWER, P.C. e SPEH, T.W. Using the balanced scorecard to measure supply chain performance. Journal of business logistics, vol.21, 2000.

BROWN, J.B.; MCDONNELL, B. The balanced score-card: Short-term guest or longterm resident?. International Journal of Contemporary Hospitality Management, 1995.

MELLO,L.B.B. contribuição para a gestão dos ativos intangíveis organizacionais: proposição de um modelo baseado no Balanced Scorecard. IN: Congresso Nacional de Excelência em Gestão, 6, 2010.

BROWN, J., AND MCDONNELL, B. The Balanced Score-card: short-term guest or longterm resident?. International Journal of Contemporary Hospitality Management, 1995.

Buarque, R. C. S. et al. (2003). Medição de Desempenho em Empresas de Transporte Rodoviário de Cargas: uma Investigação em Recife/PE. Disponível em http://eco.unne.edu.ar/contabilidad/costos/VIIIcongreso/281.doc. $\quad$ Acesso $\mathrm{em}$ 22/05/2015.

CAIXETA-FILHO, J. V.; MARTINS, R. S.; FONTANA, A. M.; MONTEIRO, A. B. F. C.;

NOVAES, A. G.; AGUIAR, E. M.; SANTOS, E. C.; RODRIGUES, F. H.; JUNIOR, G. C.;REZENDE, M. L.; CASTRO, N.; LIMA JR. O. F. L.; MARTINS, W. C. Gestão Logística do Transporte de Cargas. São Paulo: Editora Atlas, $1^{\mathrm{a}}$ ed., 2001.

CAIXETA-FILHO J. V.; MARTINS R. S. (Org.). Gestão logística do transporte de cargas. São Paulo: Atlas, 2010.

CAMARGO, L. L. Uso de indicadores da qualidade para o gerenciamento estratégico de empresas do ramo comercial. Dissertação de Mestrado, Programa de Pós-Graduação em Engenharia de Produção, Universidade Federal de Santa Catarina. Florianópolis, SC, 2000 .

CAMPOS, J.A. Cenário Balanceado: painel de indicadores para a gestão estratégica dos negócios. São Paulo: Aquariana, 1998.

CARVALHO, L. Indicadores de desempenho gerencial. 1995. Apostila (Projeto Gestão Empresarial e Qualidade) - Serviço Nacional da Indústria (SENAI), Federação das Indústrias do estado do Rio Grande do Sul (FIERGS), Porto Alegre. 
CARVALHO, F. M. A. Medição de desempenho empresarial: um estudo nas organizações do setor salieneiro no Estado do Rio Grande do Norte. Dissertação de Mestrado, Programa Multiinstitucional e Interegional de Pós-Graduação em Ciências Contábeis, Universidade Federal do Rio Grande do Norte, Natal, RN, 2007.

CELESTINO, M. S. Utilização de indicadores financeiros e não financeiros na gestão de hotéis no rio grande do norte: um estudo sob a ótica do balanced scorecard. 2003. Dissertação (Mestrado em Contabilidade) - Programa Multiinstitucional e InterRegional de Pós-Graduação em Ciências Contábeis da UNB/UFPE/UFPB/UFRN, Natal, 2003.

CERVO, A. L.; BERVIAN, P. A.. Metodologia científica. 5. ed. São Paulo: Prentice Hall, 2002.

CHAN, F. Performance measurement in a supply chain. The International Journal of Advanced Manufacturing Technology, v. 21, 2003.

CLARK JR., L.A. Development, application and evaluation of na organizational performance measurement system. Tese de Doutorado, Industrial and System Engineering Department, Virgina Polytechnic Institute and State University, Blacksburg, Estados Unidos, 1995.

CNT, Confederação Nacional do Transporte, disponível em http://www.cnt.org.br/Imagens\%20CNT/BOLETIM\%20ECONOMICO/2014/2014/201 501\%20-\%20Boletim\%20Estatistico\%20CNT\%20-\%20Dezembro.pdf . Acesso em 25 junho de 2015.

CNT/COPPEAD. CONFEDERAÇÃO NACIONAL DOS TRANSPORTES/ INSTITUTO DE PESQUISA E PÓS-GRADUAÇÃO EM ADMINISTRAÇÃO DE EMPRESAS DA UNIVERSIDADE FEDERAL DO RIO DE JANEIRO (UFRJ). Diagnóstico do Transporte de Cargas no Brasil, Rio de Janeiro, 2002.

CORRÊA, A. C.; COELHO, C. C. de S. R.; SELIG, P.M.; Mapas estratégicos do Balanced Scorecard como um SCA: abordagem quântica á estratégia. Porto Alegre, RS, 2005. Disponível em: http://sigmees.com.br/files/ENEGEP2005_Enegep0702_1704 .pdf. Acesso em: 13/09/2015

COSTA, José Fabiano da Serra. Uma aplicação de metodologia multicritério na qualidade do ensino. In: Encontro Nacional de Engenharia de Produção, 19, 1999, Rio de Janeiro, Anais... UFRJ, 1999. CD-ROOM.

DEPARTMENT OF TRANSPORT UK. Key Performance Indicators for Non-Food Retail Distribution. Reino Unido, 2003.

DIAS, J.S. et al. Balanced Scorecard: uma análise estatística das relações causa e efeito. In: Congresso Brasileiro de Custos, 15, 2008, Curitiba. Anais... São Leopoldo, 2008.

DIEHL, Carlos Alberto. Proposta de um sistema de avaliação de custos intangíveis. Dissertação (mestrado), Universidade Federal do Rio Grande do Sul, Porto Alegre, RS, 1997. 
DRUCKER, P.F. Administrando para o Futuro. $1^{\text {a }}$ ed. São Paulo: Ed. Pioneira, 1992.

DRUCKER, P. F. Post-Capitalist Society. New York: Harper Collins.1993

ECCLES, R. G. Manifesto da mensuração de desempenho. In: Medindo o Desempenho Empresarial. Rio de Janeiro: Campus, 2000.

ENSSLIN, L.; MONTIBELlER, G. N.; NORONHA, S. M. Apoio à Decisão: Metodologias para Estruturação de Problemas e Avaliação Multicritério de Alternativas. São Paulo: Insular, 2001.

EMPRESA BRASILEIRA DE PLANEJAMENTO DE TRANSPORTES - GEIPOT (2001), Transporte no Brasil: Histórias e Reflexões. Brasília, Editado por Geipot.

FACHIN, O. Fundamentos de metodologia. 4. ed. São Paulo: Saraiva, 2003.

GERHARDT. T. E. e SILVEIRA, D. T. Métodos de pesquisa. Porto Alegre: Editora da UFRGS, 2009.

FARIA, A. C.; COSTAS, M. F. G. Gestão de Custos Logísticos. 1 ed. São Paulo. Atlas, 2008.

FAWCETT, S. E., CLINTON, S. R. Enhancing logistics performance to improve the competitiveness of manufacturing organizations. Transportation Journal, Arlington, v. 37, 1997.

FERNANDES, A. C. Mapas Estratégicos do Balanced Scorecard: Contribuições ao seu desenvolvimento. In: XXII Encontro Nacional de Engenharia de Produção. Anais ENEGEP 2002. ABEPRO. Curitiba. Paraná. Outubro de 2002.

FERREIRA, V.V. Balanced Scorecard e sua eficácia como sistema de avaliação de desempenho. Monografia de Especialização, Especialização em Administração da Qualidade, AVM Faculdade Integrada, Rio de Janeiro, RJ, 2012.

FIGUEIREDO, K. F.; FLEURY, P. F. WANKE, P. Logística e Gerenciamento da Cadeia de Suprimentos. Planejamento do Fluxo de Produtos e dos Recursos. São Paulo. Atlas, 2010.

FISHBURN, P. Methods of estimating additive utilities. Manegement Science, v.13, 1967.

FLEURY, P. Gestão Estratégica do Transporte. Publicado em: 2002. Disponível em: www.ilos.com.br. Acesso em 10/10/2015.

FLEURY, A. C. C.; FLEURY, M. T. .L. Estratégias competitivas e competências essenciais: perspectivas para a internacionalização da indústria no Brasil. Gestão e Produção, v.10, 2003.

FORRESTER, J.W. Industrial Dynamics. MIT Press: Cambridge, 1961. 
FREITAS, J.R., et al. Indicadores de desempenho como instrumento para gestão de custos logísticos de transportes - estudo de caso: Lima transportes. In: Congresso Brasileiro de Custos, 19., 2012, Bento Gonçalves. Anais...São Leopoldo, 2012.

FREEMANN, C. Introdução In: DOSI, Giovani et al.Technical change and economic theory.London: Printer Publishers, 1988.

FUNDAÇÃO PARA O PRÊMIO NACIONAL DA QUALIDADE (FPNQ). Indicadores de desempenho. São Paulo: FPNQ, 1995.

GALAS, E.S.; PONTE, V.M.R. O Balanced Scorecard e o alinhamento organizacional: um estudo de casos múltiplos. In: EnANPAD, 29., 2005. Brasília. Anais ... Rio de Janeiro: ANPAD, 2005. CD-ROM.

GALO, N. R. et al. Medição de desempenho e seleção de fornecedores: Um estudo de caso em um operador logístico. In: Encontro Nacional de Engenharia de Produção,33, 2013. Anais ... Rio de Janeiro, 2013.

GERSON, R. F. A excelência no atendimento a clientes: mantendo seus clientes por toda a vida: programas eficazes para manter clientes. Rio de Janeiro: Qualitymark, 2001.

GIL, A. C. Métodos e técnicas de pesquisa social. São Paulo: Atlas, 1995.

GIL, A. C. Como Elaborar Projetos de Pesquisa. São Paulo: Editora Atlas, 1999. $3^{\text {a }}$ Edição.

GIL, Antonio Carlos. Gestão de pessoas: enfoque nos papéis profissionais. São Paulo: Atlas, 2001.

GOESSLER, L.G.M. Uso de sistemas de medição de desempenho para melhoria contínua: um estudo da influência do estilo de gestão. Dissertação de Mestrado, Programa de Pós-Graduação em Engenharia de Produção, Universidade Federal de São Carlos, São Carlos, SP, 2009.

GOLDRATT, E. M; FOX, R.E. A Meta: um processo de melhoria contínua. São Paulo: Nobel, 2002.

GOMES, L. F. M. A.; GOMES, C. F. S. \& ALMEIDA, A. T. Tomada de decisão Gerencial: Enfoque Multicritério. Rio de Janeiro: Atlas, 2002.

GOMES, R.A. Transporte rodoviário de carga e desenvolvimento econômico no Brasil: uma análise descritiva. Dissertação de Mestrado, Programa de Pós-graduação em Transportes, Universidade de Brasília, Brasília, DF, 2006.

GIFFHORN, E. Construção de modelo de avaliação de desempenho de empresas terceirizadas com a utilização da metodologia MCDA-C. Dissertação de Mestrado em Engenharia de Produção, Universidade Federal de Santa Catarina, UFSC, Florianópolis, SC, 2007. 
GIFFHORN, E., ENSSLIN, L., ENSSLIN, S.R., VIANNA, W.B. Aperfeiçoamento da gestão organizacional por meio da abordagem multicritério de apoio à decisão. Revista Gestão Industrial, v. 5, 2009.

FREDERICO, G. Medição de desempenho no transporte ferroviário de cargas: uma abordagem baseada no Balanced Scorecard. Novas Edições Acadêmicas, 2015.

Grohmann, M.Z. Novas abordagens de motivação no trabalho: identificação do nível de conhecimento e utilização. In: ENCONTRO NACIONAL DE ENGENHARIA DE PRODUÇÃO, 19., 1999, Rio de Janeiro. Anais... Rio de Janeiro: ABEPRO, 1999.

GUNASEKARAN, A.; PATEL, C.; TIRTIROGLU, E. Performance measures and metrics in a supply chain environment. International Journal of Operations \& Production Management, v. 21, 2001.

HARRINGTON, H. J. Aperfeiçoando processos empresariais. São Paulo: Makron Books, 1993.

HEAVER, G.C.T.D., HENRIKSSON, L.E. Logistics Performance, International Journal of Physical Distribution \& Logistics Management, Vol. 24, 1994.

HELMANNI, K.S; MARÇAL, R. F. M. Método multicritério de apoio à decisão na gestão da manutenção: aplicação do método ELECTRE I na seleção de equipamentos críticos para o processo. Revista Gestão Industrial. v. 3, 2007.

Hernandes, C.A.M, Cruz, C.S, Falcão, S.D. Combinando o Balanced Scorecard com a gestão do conhecimento. Caderno de pesquisa em administração, v.01, São Paulo, 2000 .

HIJAR, M. F.; GERVÁSIO, M. H.; FIGUEIREDO, K. F. Mensuração de desempenho logístico e o modelo World Class Logistics - Partes 1 e 2. Rio de Janeiro, 2005.

HOLANDA, F. M. A. Indicadores de desempenho: uma análise nas empresas de construção civil do município de João Pessoa-PB. Dissertação de Mestrado, Programa Multiinstitucional e Interegional de Pós-Graduação em Ciências Contábeis, Universidade Federal da Paraíba, João Pessoa, PB, 2007.

HORNGREN, C. T.; SUNDEM, G. L.; STRATTON, W. O. Contabilidade Gerencial. São Paulo: Prentice Hall, 2004.

HRONEC, S. M. Vital Signs - Using Quality, Time, and Cost Performance Measurements to Chart your Company's Future. New York: Arthur Andersen Co., 1993.

HRONEC S. M. Sinais Vitais São Paulo: Makron Books, 1994.

INEAVAR (2011), $\mathbf{1}^{\text {o }}$ Inventário Nacional de Emissões atmosféricas por veículos automotores rodoviários. Disponível em: <http://www.antt.gov.br>. Acesso em: 01/04/2015. 
JOLIVET, R. Curso de Filosofia. 13ª Edição. Rio de Janeiro: Agir. 1979.

JURAN, J.M. A qualidade desde o projeto: novos passos para o planejamento da qualidade de produtos e serviços. São Paulo: Pioneira, 2003.

KAYDOS, W. Measuring, Managing, and Maximizing Performance: What Every Manager Needs to Know About Quality and Productivity to Make Real Improvements in Performance. Productivity Press Inc. 1991.

KALLÁS, D. Balanced Scorecard: aplicação e impactos - Um estudo com jogos de empresas. Dissertação de Mestrado, Mestrado em Administração. Faculdade de Economia, Administração e Contabilidade, Universidade de São Paulo, São Paulo, SP, 2003.

KAPLAN, R.S, NORTON, D.P. Using the Balanced Scorecard as a Strategic Management System. Harvard Business Review. Boston, v.74, 1996.

KAPLAN, R.S., Norton, D.P. A Estratégia em Ação: Balanced Scorecard. $32^{\mathrm{a}}$ ed. Rio de Janeiro: Elsevier, 1997.

KAPLAN, R.S., Norton, D.P. The balanced scorecard - measures that drive performance. Harvard Business Review. Harvard Business School Press, 1992.

KAPLAN, R.S., Norton, D.P. Mapas estratégicos: convertendo ativos intangíveis em resultado tangível. 4 ed., Rio de Janeiro: Campus, 2004.

KAPLAN, R.S., NORTON, D.P. Alignment. Using the Balanced Scorecard to create corporate synergies. Harvard Business School Press, 2006.

KARDEC, A. Gestão estratégica e avaliação do desempenho. Rio de Janeiro: Qualitymark: Abraman, 2002.

KARDEC, A., FLORES, J. F., SEIXAS, E. Gestão Estratégica e Indicadores de Desempenho. Rio de Janeiro: Qualitymark Editora, 2002.

KEEDI, Samir. ABC do Comércio Exterior: abrindo as primeiras páginas. 4. ed. São Paulo: Aduaneiras, 2012.

KEENEY, R. L. Value Focused-Thinking: A Path to Creative Decision-making. Cabridge: Harvard Univ. Press, 1992.

KINGESKI. Medição de Desempenho em cadeia de suprimentos: Um estudo descritivo em uma empresa do setor automobilístico - GKN do Brasil. In: ENCONTRO NACIONAL DE ENGENHARIA DE PRODUÇÃO, 30., 2010, São Carlos. Anais... Rio de Janeiro: ABEPRO, 2010.

KOTlER, P., HAVES, T., BLOOM, P.N. Marketing de Serviços Profissionais Estratégias inovadoras para impulsionar sua atividade, sua imagem e seus lucros. São Paulo: Editora Manole, $2^{a}$ Ed., 2002. 
KOURI, M. G.; SPINA, E. Sistema de acompanhamento logístico de baixo custo para o transporte rodoviário de cargas. Revista Tecnologística. Disponível em: <http://www.tecnologistica.com.br/tipo_revista/especial-locacao-de-equipamentos-demovimentacao-2007/ >. Acesso em 27 de jun de 2015.

KUENG, P.; MEIER, A.; WETTSTEIN, T. Computer-based performance measurement in SMEs: Is there any option? Switzerland: University of Fribourg, Institute of Informatics. Internal Working Paper, 2000.

LAI, K.H., NGAI, E.W.T, CHENG, T.C.E. Measures for evaluating supply chain performance in transport logistics. Transportation Research, 2002.

LAKATOS, E. M. e MARCONI, M. A. Metodologia Científica. $2^{\text {a }}$ Edição. S. Paulo: Ed. Atlas, 1995.

LIMA, R.H.P. Desenvolvimento e aplicação de uma ferramenta de medição de desempenho. Dissertação de Mestrado, Programa de Pós-Graduação em Engenharia de Produção, Universidade de São Paulo, São Carlos, SP, 2008.

LIMA, R.S. Proposta de modelo para implantação de um sistema de indicadores de desempenho. Dissertação de Mestrado, Mestrado em Engenharia, Universidade de São Paulo, São Paulo, SP, 2010.

MACHADO, D. Panorama do Setor: Eficiência Energética e Metodologia de Avaliação de Empresas. Seminário Internacional Frotas e Fretes Verdes, IV, 2015, Rio de Janeiro $(\mathrm{RJ})$.

MASCARENHAS, A.O. Gestão estratégica de pessoas. Cengage Learning, 2008.

MATTAR, F.N. Pesquisa de Marketing: metodologia, planejamento. 6. ed. São Paulo: Atlas, 2005.

MALTHOUSE, E. et al. Customer Satisfaction Across Organizational Units. Journal of Service Research, Vol. 6, 2004.

MARCHETTI, R.; PRADO, P. H. M. Um Tour pelas Medidas de Satisfação do Consumidor. Revista de Administração de Empresas. v. 41, 2001

MARTINS, R. A. Sistemas de medição de desempenho: um modelo para estruturação. Tese de Doutorado em Engenharia de Produção, Escola Politécnica, Universidade de São Paulo, 1999.

MIRANDA, L. C.; SILVA, J. D. G. Medição de desempenho. In: Schmidt, Paulo (org). Controladoria: agregando valor para a empresa. Porto Alegre: Bookman, 2002.

MOREIRA, E. Proposta de uma sistemática para o alinhamento das ações operacionais aos objetivos estratégicos, em uma gestão orientada por indicadores de desempenho. Tese de doutorado em Engenharia, Programa de Pós-Graduação em 
Engenharia de Produção, Universidade Federal de Santa Catarina, Florianópolis, SC, 2002.

MORONI, M. A. Serviços de Manutenção Aeronáutica como Unidade de Negócios: Um Modelode Gestão Baseado num Sistema de Indicadores de Desempenho. Dissertação de Mestrado, Mestrado em Engenharia, Escola de Engenharia , Universidade Federal do Rio Grande do Sul, Porto Alegre, RS, 2003.

MÜLLER, C.J. Modelo de gestão integrando planejamento estratégico, sistemas de avaliação de desempenho e gerenciamento de processos (MEIO - Modelo de Estratégia,Indicadores e Operações). Tese de Doutorado, Programa de PósGraduação em Engenharia de Produção, Universidade Federal do Rio Grande do Sul, Porto Alegre, 2003.

NASCIMENTO, S. et al. Proposição de uma metodologia baseada no Balanced Scorecard para suporte à gestão estratégica de uma transportadora de carga fracionada. Revista Gestão Organnizacional, vol.1, 2008.

NASCIMENTO, L. G.; CAVENAGHI, V. Gestão estratégica e o Balanced Scorecard: proposta de mapa estratégico para empresas de call center. In: CONGRESSO NACIONAL DE EXCELÊNCIA EM GESTÃO, 4., Niterói, RJ. Anais ... Niterói, RJ, 2008.

NEELY, A. Measuring Business Performance. London: The Economist Books Ltd., 1998.

NELLY, A. G., M. P.,K. Performance measurement system design - a literature review and research agenda. International Journal of Operations \& Production, v.15, 1995.

NEELY, A., RICHARDS, H., MILLS, J., PLATTS, K., BOURNE, M. Designing performance measures: a structured approach. International Journal of Operations and Production Management, v.17, 1997.

NETO, O.P. de S. ANDRADE. D.V.P. LIMA, G.F.S. Uma análise da eficiência de entrega em uma transportadora do nordeste. In: Congresso Brasileiro de Educação em Engenharia, 39, Blumenau, SC, 2011. Anais...

NEVES, M. A. et al. Indicadores de Desempenho em Logística. Disponível em: < http://www.guiadotrc.com.br/logistica/indicadores_desempenho_logistica.asp>. Acesso em: 20 mai. 2015.

NOVAES, A.G. Logística e gerenciamento da cadeia de distribuição: estratégia, operação e avaliação. Rio de Janeiro: Campus, 2001.

OLVE, N.; ROY, J. ; WeTteR. M. Condutores da Performance Um Guia Prático para o uso do Balanced Scorecard . Rio de Janeiro: Qualitymark, 2001.

PEREIRA NETO, W. A. Modelo Multicritério de Avaliação de Desempenho Operacional do transporte Coletivo por Ônibus no Município de Fortaleza. Dissertação de Mestrado. Universidade Federal do Ceará, Fortaleza, CE, 2001. 
PETRI, S.M. Construção de um modelo de avaliação de desempenho em uma prestadora de serviços contábeis para identificar oportunidades de melhorias utilizando a metodologia MCDA. Dissertação de Mestrado em Engenharia de Produção, Universidade Federal de Santa Catarina, Florianópolis, SC, 2000.

PIETRO, V. C. Fatores críticos na implementação do Balanced Scorecard. Revista Gestão e Produção, v.13, 2006.

PINHEIRO, P.R.L. Modelo Multicritério de Avaliação do Desempenho Operacional de Empresas de Transporte Rodoviário de Cargas. Dissertação de Mestrado, Programa de Pós-Graduação em Engenharia de Transportes, Universidade Federal do Ceará, Fortaleza, CE, 2013.

PIOTROWICZ, R.C.W. Supply chain best practices - identification and categorisation of measures and benefits. International Journal of Productivity and Performance Management, Vol. 57, 2008.

PORTER, Michael E. Estratégia Competitiva. Rio de Janeiro: Campus, 1986.

PORTER, M. A Nova era da Estratégia. HSM Management. 2000. IN: Júlio, C.A.; Neto, J.S. (org). Estartégia e Planejamento: autores e conceitos imprescindíveis. São Paulo: Publifolha, 2002.

POSSAMAI, O.; HANSEN, P. B. Indicadores de desempenho gerencial. Florianópolis: PPGEP UFRGS/UFSC, 1998.

PRAHALAD, C. K.; HAMEL, G. Competindo pelo futuro: estratégias inovadoras para obter o controle do seu setor e criar os mercados de amanhã. Rio de Janeiro: Elsevier, 2005.

Quesado, P.R. et al. O Balanced Scorecard como ferramenta de gestão estratégica em organizações públicas e sem fins lucrativos. In: Congreso AECA Empresa y Sociedad: respondiendo al cambio, 14, 2007.

RAUPP, F. M.; BEUREN, I. M. Metodologia da Pesquisa Aplicável às Ciências Sociais. In BEUREN, I. M (Org). Como Elaborar Trabalhos Monográficos em Contabilidade. 3 edição. São Paulo: Atlas, 2006.

RECH, A.R. Avaliando a gestão dos correios na Bahia através de indicadores de desempenho. Dissertação de Mestrado, Mestrado em Engenharia, Escola de Engenharia, Universidade Federal do Rio Grande do Sul, Porto Alegre, RS, 2002.

REIS, R.V.M. Utilização do Balanced Scorecard para auxiliar na determinação da participação dos funcionários nos lucros ou resultados das empresas . Dissertação de Mestrado, Programa de Pós Graduação em Engenharia de Produção, Universidade Federal de Santa Catarina, Florianópolis, SC, 2001. 
REZENDE, J.F.C. Balanced Scorecard e a gestão do Capital Intelectual: Alcançado a mensuração equilibrada na economia do conhecimento. Rio de Janeiro: Campus, 2003.

RIBEIRO, P.C.C.; FERREIRA; K.A.. Logística e Transportes: Uma discussão sobre modais de transporte e o panorama brasileiro. In: ENCONTRO NACIONAL DE ENGENHARIA DE PRODUÇÃO, 22., 2002, Curitiba. Anais... Rio de Janeiro: ABEPRO, 2002.

RISCIFINA, V. B. O. Aspectos relevantes para a gestão estratégica de Instituições de Ensino Superior Privadas com Núcleos de educação a Distância: uma proposta baseada no Balanced Scorecard. Tese de Doutorado, Programa de Pós-Graduação em Administração de Organizações, Faculdade de Economia, Administração e Contabilidade de Ribeirão Preto, Universidade de São Paulo, Ribeirão Preto, SP, 2015.

ROBERTO DA SILVA, M. Planejamento estratégico no setor de transporte rodoviário de cargas: A proposta de um quadro referencial. Dissertação de Mestrado, Programa de Pós Graduação em Administração, Universidade do Vale do Rio Sinos, Porto Alegre, RS, 2013.

ROBERTS, F.S. Measurement Theory. In: ROTA, G.C. Encyclopedia of mathematics and its applications, v. 7, Addison-Wesley Publishing Company, 1979.

ROCHA, A.C.B. Um modelo de avaliação da Competitividade Logística Industrial. Tese de Doutorado, Programa de Pós-Graduação em Engenharia de Transportes. Universidade Federal do Rio de Janeiro, Rio de Janeiro, RJ, 2009.

ROCHA, A.C.B. Configuração de um sistema de avaliação de desempenho alicerçado no Balanced Scorecard para uma indústria de confecções de porte médio. Dissertação Mestrado, Programa de Pós Graduação em Engenharia de Produção, Universidade Federal de Santa Catarina, Florianópolis, SC, 2002.

RODRIGUES, E. F, et al. Utilização de Indicadores da qualidade para análise de eficiência dos processos em empresas de transporte rodoviário de cargas . INGEPRO - Inovação, Gestão e Produção, Santa Maria, RS, v. 03, 2011.

RUMMLER, G. A.; BRACHE, A. P. Melhores desempenhos das empresas. São Paulo: Makron Books, 1994.

SABOIA, E. M. O uso de indicadores estratégicos como fator de alinhamento efetivo da estratégia organizacional e os processos de logística interna de uma montadora de veículos. Dissertação de mestrado, Programa de Pós Graduação em Administração, Pontifícia Universidade Católica do Paraná, Curitiba, PR, 2006.

SANDRONI, P. Dicionário de Economia do Século XXI. Rio de Janeiro: Editora Record, 2005.

SCHMIDT, P. SANTOS, J. L. MARTINS, M. A. Avaliação de empresas: foco na análise de desempenho para o usuário interno - teoria e prática. São Paulo: Atlas, 2006. 
SHANK, John K.; GOVINDARAJAN, Vijay. A revolução nos custos: como reinventar e redefinir sua estratégia de custos para vencer em mercados competitivos. 6 . ed. Rio de Janeiro: Campus, 1997

STEWART, Thomas A.. A Riqueza do Conhecimento: o capital intelectual e a organização do século XXI. Rio de Janeiro: Campus, 2002.

Stewart, D. Piecing together service quality: a framework for robust service. Production and Operations Management, Vol. 12, 2003.

SHIFTAN, Y., KAPLAN, S., HAKKERT. S. Scenario building as a tool for planning a sustainable transportation system. Transportation Research Part D.8, 2003.

SILVA, R.R. OLIVEIRA, M.A. LEAL JUNIOR, I.C.Análise de cenários na ferrovia brasileira: um estudo evolutivo dos indicadores de eficiência operacional de uma empresa do setor. In: Encontro de Estudos em Estratégia, 5, 2011. Anais...Rio de Janeiro: Anpad, 2011.

SIQUEIRA, H. S. G. A nova concepção de trabalho. Jornal A Razão, Santa Maria 01/05/2003. Disponível em:

http://www.angelfire.com/sk/holgonsi/novotrabalho.html> Acesso em: 05/11/2015.

SIMONS, R. Performance measurement \& Control Systems for Implementing Strategy. Prentice-Hall, 2000.

SINK D.S.; TUTTLE, T.C. Planejamento e medição para performance . Rio de Janeiro: Qualitymark, 1993.

SOUZA, D. I. MULLER, D.M. FRACASSI, M. A. T. ROMEIRO, S. B. B. Manual de orientações para projetos de pesquisa. Novo Hamburgo: FESLSVC, 2013.

SOUZA, R.P. COSTA, S.A. MACEDO, M.A.S. Análise de eficiência de empresas do setor de transportes no Brasil: um estudo utilizando DEA. In: Simpósio de Administração da Produção, Logística e Operações Internacionais, 13, São Paulo, SP, 2010. Anais...São Paulo, 2010.

TAKASHINA, N.T.; FLORES, M.C.X. Indicadores da Qualidade e do Desempenho. Rio de Janeiro: Qualitymark, 2005.

TAVARES, W. Análise dos indicadores de desempenho do transporte de granéis sólidos a partir da teoria da representação. Dissertação de Mestrado, Programa de Mestrado em Agronegócio, Universidade Federal de Goiás, Goiânia, GO, 2014.

TEDESCO, G. M. I. Transporte Rodoviário de Cargas: contribuição conceitual e metodológica à análise e classificação de mercados. Tese de doutorado em Transportes, Programa de Pós-Graduação em Transportes, Universidade de Brasília, Brasília, DF, 2012. 
TEGMA. Divulgação de Resultados 2015. Disponível em http://ri.tegma.com.br/ShowResultado.aspx?IdResultado=wOldBbxGKYjLAhjc2RT0iw $==$. Acesso em 01 de março de 2016.

TIRONI, L. F.; SILVA, L. C. E.; VIANA, S. M.; MEDICI, A. C Critérios para geração de indicadores de qualidade e produtividade no setor público. Brasília: IPEA/MEFP, 1992.

TOCCHETtO, M. R. L., PEREIRA, L. C.. Seleção de indicadores ambientais para indústria com atividade galvânica. In: ENCONTRO DA ASSOCIAÇÃO NACIONAL DE PÓS-GRADUAÇÃO E PESQUISA EM ADMINISTRAÇÃO, 28., 2004, Curitiba. Anais... Paraná:, 2004.

VACCARI, N. Proposta e aplicação de um modelo de desdobramento da estratégia com base no Balanced Scorecard: o caso de uma empresa de transporte de carga e logística. Dissertação de Mestrado, Mestrado em Administração e Negócios, Pontifícia Universidade Católica do Rio Grande do Sul, Porto Alegre, RS, 2006.

VIANNA, G. Panorama Econômico do T.R.C. Seminário Brasileiro de Transportes de Cargas, XV, 2015, Brasília (DF).

VIARDORT, E. Successful marketing for high-tech firms. Norwood : Ed. Artech House, 2004.

VIEIRA, J. et al. Proposição de uma metodologia a partir do Balanced Scorecard (BSC) para suporte à gestão estratégica de uma empresa de transporte de carga frigorífica. In: Encontro Nacional de Engenharia de Produção, 35, 2015. Anais...Rio de Janeiro, 2015.

WERKEMA, C. Criando a Cultura Seis Sigmas. Série Seis Sigmas, Volume 1, Elsevier, 2012.

WERNKE, R. e BORNIA, A. C. A Contabilidade gerencial e os métodos multicritérios. Revista Contabilidade \& Finanças FIPECAFI - FEA - USP, v.14, 2001.

WOMACK, James P.; JONES, Daniel T. A mentalidade Enxuta nas Empresas: Elimine o desperdício e crie Riqueza.4.ed. Rio de Janeiro: Campus, 1998 


\section{Autor: Hugo Guedes Toledo Florencio}

Tema: Sistema de Medição de Desempenho para Empresas do Transporte Rodoviário de Cargas

\section{Entrevistado:}

1. Para a construção do sistema de medição de desempenho é necessário estabelecer pesos para cada um dos indicadores. Neste sentido pede-se que o entrevistado julgue os indicadores entre si, de forma a definir qual indicador é preferível ao outro. Para isso o usuário deve estabelecer notas de (0-100). Para o indicador de maior importância o entrevistado deve atribuir nota igual a 100. Para os demais indicadores o entrevistado pode arbitrar qualquer nota, de acordo com seu grau de preferência (isto é, conforme a significância de um indicador em relação ao outro). A seguir seguem os exemplos:

Exemplo: Em relação ao risco da carga. Se você considerar o roubo de carga o principal indicador deste item deve-se atribuir nota 100 para o mesmo

\begin{tabular}{|l|c|} 
Em relação ao Risco da Carga & Nota \\
\hline Roubo de cargas & 100 \\
\hline Avarias & \\
\hline
\end{tabular}

Exemplo: Agora resta atribuir uma nota para o indicador de avarias. Se você considerar que o indicador de avarias é muito menos importante que o indicador de roubo de cargas, você deve atribuir uma nota mais baixa. Já se você considerar que o indicador de avarias tem também muita importância, você deve atribuir uma nota mais alta. Assim a nota do indicador de avarias pode variar de 0 a $99 \%$.

\begin{tabular}{|c|c|}
\hline Em relação ao Risco da Carga & Nota \\
\hline Roubo de cargas & 100 \\
\hline Avarias & $0-99$ \\
\hline
\end{tabular}

Exemplo: Há ainda a possibilidade do indicador de avaria ter a mesma importância do indicador de roubo de carga. Nesse caso deve ser atribuído a este indicador a nota 100. Portanto a mesma nota pode ser atribuída para indicadores distintos quando não há uma preferência declarada.

\begin{tabular}{|l|c|}
\hline Em relação ao Risco da Carga & Nota \\
\hline Roubo de cargas & 100 \\
\hline Avarias & 100 \\
\hline
\end{tabular}

Favor Preencher os itens a seguir

\begin{tabular}{|c|c|}
\hline Em relação ao Objetivo de Crescimento da Receita & Nota \\
\hline \% de Inadimplência sobre as vendas & \\
\hline Prazo médio de recebimento & \\
\hline Vendas Incrementais & \\
\hline Margem líquida & \\
\hline
\end{tabular}




\begin{tabular}{|c|c|}
\hline Em relação ao Objetivo Redução de Custos/Aumento da Produtividade & Nota \\
\hline \multicolumn{2}{|l|}{ Índice de produtividade da frota } \\
\hline \multicolumn{2}{|l|}{ Custo com não conformidade } \\
\hline \multicolumn{2}{|l|}{ Custo de transporte como uma \% das vendas } \\
\hline Em relação a Perspectiva Financeira & Nota \\
\hline \multicolumn{2}{|l|}{ Redução de custos/aumento da produtividade } \\
\hline \multicolumn{2}{|l|}{ Crescimento da receita } \\
\hline \multicolumn{2}{|l|}{ Retorno sobre o investimento } \\
\hline Em relação a Perspectiva dos Clientes (Ind. de Resultado do Cliente) & Nota \\
\hline \multicolumn{2}{|l|}{ Taxa de novos clientes } \\
\hline \multicolumn{2}{|l|}{ Taxa de fidelização de clientes } \\
\hline \multicolumn{2}{|l|}{ Nível global de satisfação dos clientes } \\
\hline \multicolumn{2}{|l|}{ Market-share } \\
\hline \multicolumn{2}{|l|}{ Taxa de fidelização de clientes } \\
\hline \multicolumn{2}{|l|}{ Nível global de satisfação dos clientes } \\
\hline Em relação a Perspectiva dos Clientes (Ind. de processos do cliente) & Nota \\
\hline \multicolumn{2}{|l|}{ Número de reclamações dos clientes } \\
\hline \multicolumn{2}{|l|}{ Tempo de resposta as solicitações } \\
\hline \multicolumn{2}{|l|}{ Número de retornos ou devoluções } \\
\hline \multicolumn{2}{|l|}{ Tempo para resolução de problemas } \\
\hline \multicolumn{2}{|l|}{ Tempo de resposta as solicitações } \\
\hline \multicolumn{2}{|l|}{ Número de retornos ou devoluções } \\
\hline Em relação a Perspectiva dos Clientes & Nota \\
\hline \multicolumn{2}{|l|}{ Indicadores de processos dos clientes } \\
\hline \multicolumn{2}{|l|}{ Indicadores de resultados dos clientes } \\
\hline Em relação ao Custo da Frota & Nota \\
\hline \multicolumn{2}{|l|}{ Custo de combustível } \\
\hline \multicolumn{2}{|l|}{ Custo de pneu } \\
\hline \multicolumn{2}{|l|}{ Custo de Manutenção } \\
\hline Em relação a Gestão da Frota & Nota \\
\hline Viagens vazias & \\
\hline Utilização da capacidade de carga & \\
\hline Disponibilidade da frota & \\
\hline Tempo médio de carga e descarga & \\
\hline Em relação a Custo da Frota vs. Gestão da Frota & Nota \\
\hline Gestão da Frota & \\
\hline Custo da frota & \\
\hline Em relação ao Risco da Carga & Nota \\
\hline
\end{tabular}


Roubo de cargas

Avarias

Em relação ao Risco do Veículo

Acidentes de trânsito

Acidentes com fatalidades

Em relação ao Risco do Motorista

Ultrapassagem do tempo de viagem

Multas por motoristas

Em relação ao Risco

Reduzir risco do motorista

Reduzir risco do veículo

Reduzir risco da carga

Em relação a Gestão Ambiental

Consumo de Combustível (Co2)

Contaminações/Derrames Zero

\section{Em relação a Gestão dos clientes}

Índice de coleta e entrega no prazo

Solicitações atendidas para condições especiais de entrega

Taxa de acompanhamento pós-serviço

Acuracidade na emissão do CT-E

Em relação a Perspectiva dos processos internos

Gestão Ambiental

Gestão de risco

Gestão Operacional

Gestão de clientes

Atualidade da Frota

Em relação a Perspectiva do Aprendizado e Crescimento

Satisfação dos empregados

Gratificação por colaboradores

Índice de veículos rastreáveis

Taxa de absenteísmo

Índice de rotatividade dos funcionários

Horas de Treinamento

Em relação a Comparação das perspectivas

Nota

Nota

Nota

Nota

Perspectiva do Aprendizado e Crescimento

Perspectiva dos Processos Internos

Perspectiva dos Clientes

Perspectiva Financeira 